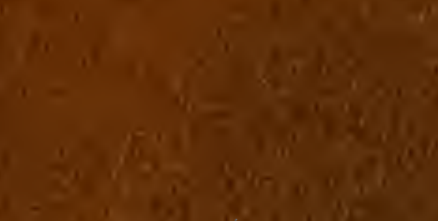

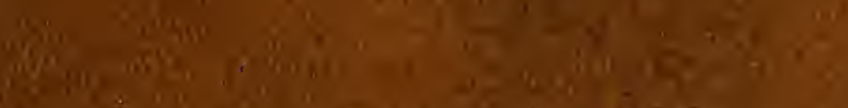

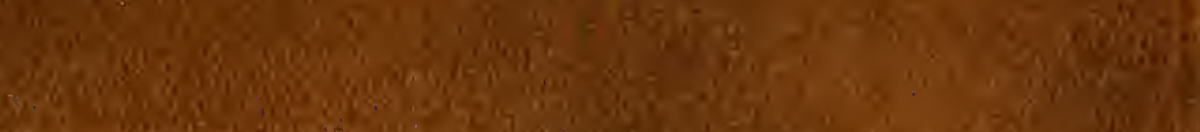

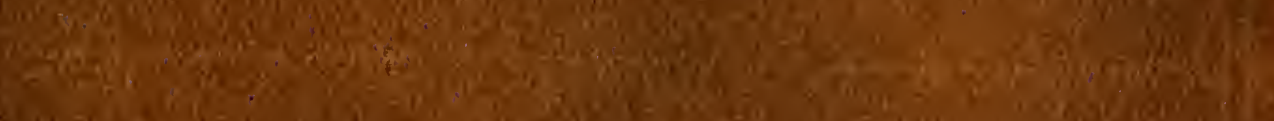

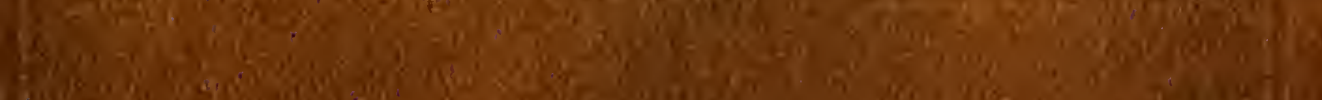

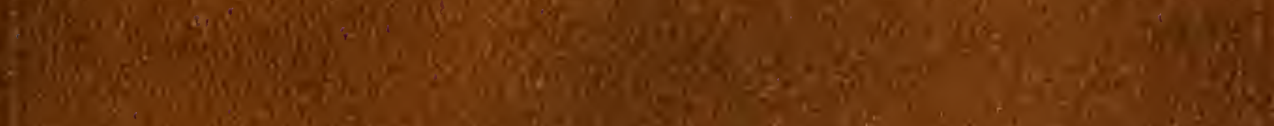





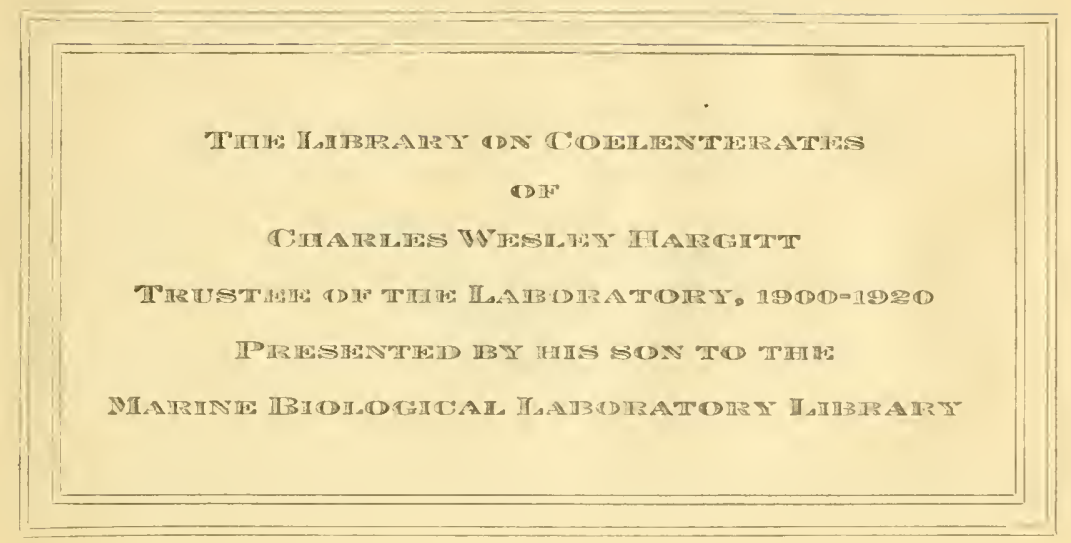





\title{
ZUR LEHRE
}

VOMI

Cbag. W. Heróitt.

stracuse UniyzinuiY, oruange, $Y_{1} Y_{0}$

\section{GENERATIOISWECHSEL}

\author{
UND DER \\ 는 \\ FORTPFLANZUNG \\ BEI

\section{MEDUSEN UND POLYPEN,} \\ roN
}

Dr. CARL GEGENBAUR.

MIT ZWEI TAFELN.

WÜRZBURG 1954.

VERLAG DER STAHEL'SCHEN BUCHIIANDLUNG. 

Wenn ich in den folgenden Bliittern einen der interessantesten Theile aus dem weiten Gebiete der Entwicklungsgeschichte niederer Thicre mir zum speciellen Vorwurf machte, so geschah solches nicht ohne volles Bewusstsein von den zahlreichen, und wie es den Anschein hat, bis jetzt grösstentheils noch unbewältigten Schwierigkeiten, die hier iiberall dem Forscher entgegentreten, und namentlich der Gewinnung allgeneiner Gesichtspuncte, um die es hier vorziiglich zu thun sein muss, hinderlich sind. Als solche IIaupthindernisse einer iiber gewöhnliche Beschreibung sich erhebenden, mehr generalisirenden Darstellung betrachte ich die Stellung jener unserer Betrachtung vorliegenden Geschüpfe, welche sie weit von unseren gewöhnlichen, von höheren Organismen abgeleiteten physiologischen Anschaungsweisen entfernt und durch neue Verhiiltnisse anch neue Begriffe hervorruft, und zwar sehr häufig Begriffe, die eben jener aprioristisch zu nennenden Anschanungsweise widerstrebend sind. Ein anderes, freilich inmer mehr schwindendes Hinderniss für eine allgemeine Auffassung erkenne ich in der verhältnissmässig noch geringen Summe beobachteter Thatsachen, von denen sich allgemeine Schliisse deduciren liessen, ja manche der bekannten Facta sind theils durch die verschiedene subjective Anffassung der einzelnen Beobachter, theils auch durch den jederzeit sich indernden Standpunct der Wissenschaft selbst, und dureh ihre ebendadureh veränderten Anforderungen mehr eine Quelle von Irrthümern, als eine Stiitze der Forschung geworden. Wenn ich daher noch manche den schwebenden Fragen olme Beantwortung lassen muss, so werde ich bei keinem mit dem Materiale Vertrauten desshalb einer Entschuldigung bedïrfen.

Ausser der Mittheilung meines hier einschlägigen, im verflossenen Winter an ker sicilischen Kïste gesammelten Materials, welches sich jedoch nicht iiber eine nur bescheidene Summe von Beobachtungen erhebt, versuchte ich es noch, die wichtigsten und am meisten massgebenden fremden 
Untersuchungen beizufïgen, und soweit mir solches zustand, sie kritisch zu sichten. - Behufs einer bessern Uebersicht der Grenzen theilte ich es ein in einzelne kleinere Abschnitte, von denen jeder so ziemlich je eine der hervorragendsten Fragen in diesem Gebiete behandeln soll.

I. Entwicklung des Eies der höhern Medusen.

Die Brut der Cassiopeia.

Durch die Untersnchnrgen von S a r. ${ }^{*}$ ) und v. Si ebold**) erhielten wir bekanntlich dic erste und bis jetzt einzig vollständige Darstellung der Entwicklıngsreilıe höherer Medusen (Rhizostomiden und Medusiden nach Eschscholz's System) nämlich jene von Medusa aurita und zum grossen Theile auch von Cyanea capillata. Von den übrigen hieher gehörigen Quallengeschlechter"n sind indessen mehrfach einzelne Stadien ihrer Entwicklungsgeschichte bekamnt geworden, so dass wir von diesen aus auch auf weitere mit jenen bei Medusa aurita und Cyanea capillata gleichlanfende Vorgïnge schliessen dürfen. Es gehören hieher die Beobachtungen von Dalyell an Chrysaora, von Ecker an Cephea, und endlich die theils bestiitigenden, theils erweiternden Angaben von B usch. Meine Bcobachtungen betreffen die Eutwicklung des Eies der bislang noch nicht in dieser Hinsicht erforschten Gattung Cassiopeia, und wurden an der im Herbste 1552 im Meere zu Messina nicht seltenen Cassiopeia borbonica Delle Chiaje anfänglich gemeinsam mit Herm Prof. Kölliker angestellt. ${ }^{*}$ ) Die Furchung wurde nicht beobachtet, demn alle Eier der zur Untersuchung gekommenen Thiere hatten sich schon in infusorienförmige Larven umgewandelt, und befanden sich als solche in grosser Anzahl in einer die Arme des Mutterthiers iiberziehenden schleimartigen Substanz. Sie waren in diesem Stadium eiförmig, zeigten deutliche Zellstructır und einen dichten Ueberzug von langen Wimperhaaren (Vgl. Taf. II. Fig. 32). Die peripherische Schichte ihrer Substanz besteht aus durchsichtigen, grösseren Zellelementen, wälırend der centrale Theil der Larve von kleineren, dicht mit Kürnchen angefüllten eingenommen wird. Löste man die

") Sars: Isis 1833. Auszug aus: Bidrag til Sürdyrenes Naturhistorie. Bergen 1829. und: Beskrirelser og Jagttagelser over nogle moerkelige eller nje djr etc. 1835.

*) จ. Siebol d: Beiträge zur Naturgeschichte der wirbellosen Thiere. Danzig 1839.

***) Vergleiche Zeitschrift für Zoologie von v. Siebold und Kölliker. Bd. IV. p. 328. 
Larven aus dem sie umgebenden Schleime ab, was durch Bespülen mit Seewasser leicht zu bewerkstelligen war, so schwammen sie eine Zeit lang (12 Stunden bis 2 Tage) in den ihnen zugetheilten Gefässen umher, um sich dann an irgend einer beliebigen Stelle der Gefïsswand festzusetzen; die langen Cilien schwanden und an ihrer Stelle entstand ein kurzhaariger Flimmerüberzug. Die Larve nahm dann Birnform an, so zwar dass sic mit dem schmälem Körpertheile festsass, während der breitere frei in den Behälter ragte. Im Innern des Thiers sind noch kcine Differenzirungen vor sich gegangen, und es ist weder eine Mundöfnung sichtbar, noch eine saugnapfartige Verbreitung des festsitzenden Theiles, wie diess nach v. Siebold bei Medusa aurita der Fall ist. Am zweiten Tage nach ihrer Anheftung sprossen am freien Vordertheile vier warzenartige Erhebungen hervor, in deren Mitte sich gleichzeitig cine Mundöfnumg bildet. Unterzieht man die Larve nun einer genateren Untersuchung, so sicht man nun auch die Leibeshöhle (Fig. 33 c.) entstanden, welche cincn weiten, etwas undurchsichtigen Sehlauch (Fig. 33 b.) - den Magen ringsum umgibt. Die Larve misst nun $0,3-0,4^{\prime \prime \prime}$ Länge. Die in die nächsten Tage fallenden Veränderungen bestehen in Verlängerung der vier um den Mund sitzenden. Erhobungen (Fig. 33 a.), die sich dadurch zu Tentakeh umgestalten. 'Zwisehen ibuen entstehen noch rier neue, welche bald dic Grösse der ersteren erreicht haben. Die Leibeswandungen sowohl, als auch jene des Magenschlauchs sondern sich bestimmter und letztere erseheinen, namentlich am diuneren Endtheile des Magens, aus einem hellen, grosszelligen Gewebe bestehend (Fig. 34 c.), das sich nach vorne zu allmälig in dunkleres feinzelliges verliert. Der Mundtheil des Magens verlängert sich kegelförmig, und wäehst so in einen selbst über die Tentakelliinge vorragenden Fortsatz aus (Fig. 34 a.), ler grosse Contractilität besitzt, und so sich bald herrorstrecken, bald wieder in gleiches Niveau mit den Ursprungsstellen der Tentakeln zurückzichen kann. Dieser Umstand, der auch bei Medusa aurita, *) Cyanea eapillata, Chrysaora **) und Cephea ${ }^{*}{ }^{*}$ ) beobachtet zu sein scheint, mag vielleicht mit jenem späteren Stadiun, wo die Larve zur Amme wird, in einiger Bezichung stehen. Im Magen gibt sich deutlich Flimmerbewegung kund. Aueh die Entstehung der Nesselzellen fällt in diese Periode. Es sind anfünglich rund-

•) Sars, Beskrivelser etce. p. 17. Pl. 3 Fig. 千 c. und r. Siebold, Beiträge p. 31.

") Busch, Betrachtungen über Anatomie und Entwickelung etc. pag. 28 Taf. VI. Fig. $8-9$.

…) v. Frantzius, Zeitschr. f. Zoolog. Bd, IV. pag. 118. 
liche Zellen mit dunklem Inhalt, die sich zur Stäbchenform verlängern, und dann bei stark angebrachter Compression den charakteristischen Faden hervorschnellen. Ueber die Bildung dieses Fadens konute ich wegen der Kleinheit der Zellen keine näheren Beobachtungen anstellen. In der Leibeswand erscheinen nun vier in die Leibeshöhle vorspringende Längswülste, von denen jeder von einem der erst aufgetretenen vier Tentakeln beginnt, und sich bis an das angeheftete Hinterleibsende hinaberstreckt. Ilire Bedeutung gibt sich gar bald zu erkennen, wenn man bei schwacher Compression sie genaner untersuchen kaun, und dann in jedem der anscheinend soliden. Wuilste einen Längscanal erkemnt, in welchem feine Moleciile sich hin- und herbewegen. Am untersten Ende laufen die Canäle zusammen und vereinigen sich mit demEnde des Magenschlauchs; ob jedoch dessen Lumen mit dem ihrigen in Verbindung steht, ist mir niemals so recht klar geworden, doch dürfte aus sehr nahe liegenden Grïnden diese Annahme ihre Rechtfertigung findell. Wie sich die vier Lüngscanüle (Fig. 34 e.) an ihrem vorderen Ende verhalten, entging mir vollständig, da das dort selı undurchsichtige Gewebe selbst bei stärkerer Compression keine genaue Anschauung der Canäle zulïsst. Bestimmterweise konnte ich sie nur bis zur Basis des betreffenden Tentakels verfolgen. In dieśem Zustande blieben die Larven mehrere Wochen lang, während welcher Zeit ausser der Verlängerung der acht Tentakeln nichts bemerkenswerthes vorfällt; dann spriessen zwischen den schon vorhandenen acht neue 'Tentakeln hervor; der Körper der Larve verlängert sich bis zu 1“", welche Länge auch den ausgestreckten Tentakeln zukommt, ind wurde so in gleichem Volumen noch Wochen lang beobachtet (Fig. 35). Da trat endlich, wahrscheinlich dirch Nangel an zweckmässiger Nahrung hervorgerufen, eine Verkiinmerung, eine Art Rïckbildungsprocess ein, die Thierchen wurden kleiner, hielten stets ihre Tentakeln eingezogen und starben ab, olne mir die-interessantere Fortsetzung ihrer Entwicklung, nämlich ihr Ammenstadium, darzubieten. Diess waren nun die in morphologischer Beziehung gemachten Beobachtungen.

Während der Entwicklung war mir besonders das Ablösen einzelner Larven aufgefallen, welches namentlich in den ersten Stadien gar nicht selten vorkam. Eine bestimmte äussere Ursache konnte ich niemals ausfindig machen; es geschah in ganz ruhig stehendem Gefässe. Die auf diese Art frei gewordenen Larven schwammen dann vermittels ihrer feinen Gilien langsam umher, bis sie sich nach einer Weile an einer anderen Stelle wieder festsetzten, so dass es fast schiell, als ob sie ihren Ort freiwillig verliessen, um ihn mit einem günstigeren zu vertauschen. 
Das von Sars und v. Siebold sowohl, als auch von Busch beobachtete Phänomen der Knospung kam mir bei der Brut unserer Cassiopeia niemals zu Gesicht, ungeachtet des langen Zeitraums, in welchem ich die Brut sorgfältig beobachtete. Nur einigemale boten sich Erscheinungen dar, welche leicht zur Verwechslung mit Sprossung oder Stolonenbildung hätten Veranlassung geben kömen. Ich fand nämlich zuweilen $\operatorname{lm}$ Innern schon ziemlich erwachsener Larven runde weissliche Körper, die im ersten Augenblicke mich an die von Busch*) von Cephea gegebene Darstellung einer Knospenbildung im Innern des Magens lebhaft erinnerten. Eine genau vorgenommene Untersuchung ergab, dass es wirklich infusorienförmige Larven der Cassiopeia waren, die aber mit den Magenwänden in gar keiner Verbindung standen, sic traten unter dem Mikroscope zur Mundöflinung der älteren Larve heraus und schwammen behende daron. Später sah ich auch mehrmals, wie solclie infusorienförmige Larven (und diese finden sich noch lange Zeit, wenn andere sich längst weiter entwickelt haben) von den Aelteren erhascht und verschluckt wurden; ***) in der That gaben diese das beste Futter ab, und so lange noch solche junge Formen vorhanden waren, entwickelten sich die älteren zusehends, während mit der Verzehrung der letzten die Verkïmmerung nicht lange ausblieb. Mit Stolonenbildung war einige Aehnlichkeit vorhanden, wenn eine oder die andere junge Larve sich dicht an einer älteren angesetzt hatte, oder wenu sie gar, wie dies zuweilen geschah, den Leib einer solchen zu ihrem Wohnplatz auserwählte und sich irgendwo auf demselben festheftete. Doch stellte sich durch die mikroskopische Untersuchung immer der Parasitismus hald heraus, und ich darf aussprechen, dass sich bei der Cassiopeia-Brut kein Verhältniss darbot, welches sich nach sorgfältiger Früfung als eine Vermehrung der Larven ergeben könnte.

Wie die Gattung Cassiopeia der Cephea am nächsten steht, so kommen auch die Larven beider Genera mit einander in den meisten Stïcken überein, während sie von denen ans Eiern der Chrysaora, Cyanea oder Medusa entstandenen merkliche Unterschiede darbieten. Hieher gehört namentlich, dass sich bei diesen noch während des Schwärmens einzehe Theile (bei Chrysaora nach Busch sogar die Tentakeln) entwickelı, die bei Cephea und Cassiopeia erst wenn die Larve sich festgesetzt hat, allmählig sich anbilden. In Betreff des inneren Baues der Larven ist aus

") B u s c h, op, citat. p. 31. Taf. 11I. Fig. 4.

*) Auch v. Sie bold hat beobachtet, dass bei Medusa aurita die älteren Larren hre jüngeren infusorienartigen Geschwister rerschlucken. (l. c. p. 31.) 
den früheren Untersuchungen das Vorhandensein der Canüle zwar angedentet, denn Sars und v. Siebold bezeichneten sie als Lüngswülste; ihre Deutung, sowie das Verbundensein mit einem Ringgefässe setzte erst Steenstrup gehörig auseinander. Besonders ist es das Vorhandensein einer gesonderten Leibeshöhle, sowie von vier mit dem Magén zusammenhängenden Läıgscanälen, welche wir erst durch die Mittheilungen von v. Frantzius*) kemen lernten.

Dieser innere Bau ist es, welcher die aus dem Ei der Medusen hervorgegangenen Larven, olngeachtet ihrer grossen äusseren Uebereinstimmung mit den Hydraspolypen, doch himreichend von diesen unterscheidet, und sie als bedeutend höher organisirte Wesen erkennen lässt. Die gesonderte Leibeshöhle nähert sie einigermassen den Anthozoën; die vier vom Grunde der Magenhühle entsplringenden Längscanäle, die wahrscheinlich bei allen in einen vorne an der Tentakelbasis verlanfenden Cirkelcanal sich vereinigen, geben eine mit einer Medusenfamilie (Oceaniden) ganz analoge Organisation kund, und es wiederholt sich hier eine in der Entwicklungsgeschichte oft genng vorkommende Thatsache, dass höher stelende Thiere in ihren Entwicklungszuständen Bau und Formen von nieder stehenden aufweisen. Nur was sich sonst an demselben Individuum äussert, dies zeigt sich hier an der zur Amme sich gestaltenden Larvenform. Wir werden desshalb das polypenäimlich geformte Junge der Medusen, das friher oftmals mit den wirklichen Polypen zusammengestellt, ja sogar als Hydra tuba mit dem Geschlechte unserer Siisswasserpolypen vereinigt wurde, nach dem Vorgange von Joh. Miiller ***) besser als polypenförmig e Larve bezeichnen.

Wie die polypenförmige Larve in das Stadium der Amme trete, scheint nach den bis jetzt vorliegenden Beobochtungen noch nicht gehörig

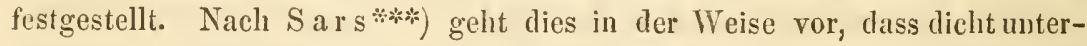
halb rles Tentakelkranzes eine Qnerringelnug entsteht, die bei fortgehendem Wachsthum der Larve immer weiter schreitet und zuletzt den Körper der Larve in zahlreiche wie Tassen anfeinander sitzende Auschnitte theilt. An dem obersten derselben befindet sich der Tentakelkranz der Larve. Vom Rande jedes Abschnittes sprossen nun acht lappenartige Fortsätze

•) v. Siebold und Kölliker's Zeitschrift für Zonlogio. Bd. IV. pag. 118. Taf. VIII. Fig. 1-4.

*) Müller's Archiv 1852. pag. 32.

*.*) Beskrivelser og Jagttagelser etc. p. 16 ff. und besonders Wiegmann's Archiv 1837, pag. 406. 
hervor, während die einzelnen Abschnitte sich immer tiefer von einander einschniren und dann alsbald wirklich von einander trennen. Die schalenförmigen durch Quertheilungen des Ammenkörpers entstandenen Wesen sind Medusen, deren allmälige Weiterbildung zu einer bestimmten Art, und zwar zu derselben, aus deren Eiern man die polypenförmige Larve sich entwickehn sah, gleichfalls von $S$ ars genauer verfolgt wurde.

Sehr abweichend von den S a r s'schen Beobachtungen ist dieser. Vorgang vorn Desor*) an der von ilm nach Dalyell's Vorgang als Hydra tuba bezeichneten polypenförmigen Larve geschildert worden. Nach D e s or bildet sich an der Mundöffnung dieser Larve zuerst eine Knospe, die dureh Abflachung sich in éine Scheibe verwandelt, indess zwischen ihr und der nun zur Amme gewordenen Larve, gleichfalls an der Mundöffnung der letzteren wieder eine Knospe entsteht, welche sich in gleicher Weise scheibenförmig abflacht; indem dieser Prozess sich nun hänfig wiederholt, entsteht eine ganze Reihe aufeinander sitzender Scheibchen, welche alle durch cinen centralen Strang miteinander und mit der polypenförmigen Amme in Verbindung stehen. In die einzelnen Scheiben wachsen vom centralen Verbindungsstrange aus allmählig Gefïsse hinein, ihr Rand dehnt sich in Lapper aus, und so nehmen sie nach und nach die Form von Medusen an, um sich dann als selbstständige Thiere von der Amme abzulösen und unter fernerer Ausbildung einzelner Theile in eine bleibende, bestimmte Form überzugehen.

Wir sehen auf zwei ganz verschiedenen Wegen dasselbe Endziel erreichen, auf der einen Seite nämlich durch Quertheilung, auf der andern durch Sprossenbildung die jungen Medusen hervorgehen. Halten wir beide Entwicklungsmodi gegen einander, so finden wir den durch Knospenbildung eingeleiteten viel einfactier und in Uebereinstimnung mit den Vorgängen bei einer andern Abtheilung der Scheibenquallen, wo gleichfalls die zweite Generation nur durch Sprossenbildung an der Amme entstelit. Ein anderes Bedenken erhebt sich bei näherer Betrachtung des durch Quertheilung veründerten Ammenthieres (Strobila), dessen erstem Absclınitte noclı die Tentakeln des Larvenstadiums aufsitzen. Bildet sich aus diesem ersten Abschnitte gleichfalls eine Meduse, so muss noch eine bedeutende Modification mit jenen Tentakeln vor sich gehen, wenu sie sich in jene der künftigen Meduse umwandeln sollen, und dann müsste man eine grosse Verschiedenheit in der Entwicklungsweise dieser ersten Meduse annehmen

") Ann. des sciences nat. Ser. III. Tome XII. pag. 204. 
im Gegensatze zu den nachfolgenden, bei welcher ja bekamntlich erst nach länger erfolgter Ablösung die Tentakelbildung vor sich geht. Schwieriger als diese wäre dann noch die Erklärung des Uebergangs der Gefässcanäle der Amme in jene der jungen Medusen, und will man diese Vorstellung durch die. Annahme einer theilweisen Neubildung von Gefässen in jedem einzelnen Abschnitte des Ammenkörpers sich erleichtern, so bleibt hiebei immer ein grosser Theil der Erklïirung noch übrig.

Obgleich ich es nicht wage, den sorgfältigen Beobachtungen von Sars Zweifel entgegenzusetzen, so kann ich doch nicht umhin, den von ihm gegebenen Erkliirungsversuchen, andere, mir wahrscheinlichere, gegenïber zu halten. Es sind dies jene, die aus Desor's Beobachtungen hervor gchen, und die auch für die von Sars mitgetheilten Thatsachen bei nur einigermassen modificirter Dentung derselben recht gut ihre Geltung haben können. Jedoch darf nụ fermeren Beobachtungen das Recht des Entscheidens hierüber zugetheilt werden.

Dass alle höheren MeJusen (Rhizostomidae und Medusidae) sich nach dem vorhin angegebenen Modus an polypenförmigen Ammen entwickeln, ist eine bis jetzt durch eine grüssere Reihe von melr oder weniger vollständigen Beobachtungen allerdings gerechtfertigte Annahme; doch möchte ich noch auf einen andern Entwicklungsmodus aufmerksam machen, der wie aus den Beobachtungen von Busch*) hervorgeht, bei Chrysaora der Fall zu sein scheint.

Die aus dem Eie der Chrysaora entstandene polypenförmige Larve vermehrt sich nach $B$ usch vielfach durch seitliche Knospenbildung, wie diess auch von der Larve der Medusa aurita bekannt ist. Ausser dieser seitlichen Sprossung kommt noch eine reichliche Sprossenbildung am Munde der Larve zu Stande, deren Producte sich ablösen und umherschwimmen. Busch glaubt, dass ans diesen Sprossen sich wiederum Larvenformen entwickeln, die dann spüter wie die Larven, an denen sie entstanden, zu Medusenammen sich ausbilden. Es lïsst sich aber hier die Frage aufwerfen: Ist die Sprossung am Munde der Chrysaora-Jungen nicht ein Analogon der Knospenbildung am Munde der polypenförmigen Larve von Medusa, entstchen aus jenen Sprösslingen Medusen, wie solche aus jenen der polypenfürmigen Larve entstehen? Der Unterschied würde nur darin bestehen, dass die Sprösslinge der Medusa-Amme auf einander sitzen bleiben, und sich noch an der Amme zu Medusen entwickeln, indess die

") Beobachtungen über Anatomie und Entwickelung etc. pag. $25 \mathrm{ff}$. 
Sprossen der Chrysaoralarve früher frei werden, als sie die Entwicklung zur Meduse an sich offenbaren. Der Umstand, dass Buseh einzelne Larven (ob diese aus Eiern hervorgegangen waren oder ob es solche ciner zweiten Generation angehörige Sprösslinge waren, geht freilich nicht aus seinen Mittheilungen hervor) sich in freiem Zustande zur Sternform umwandeln sah, wälırend die andern erst wenn sie fest sassen, sich polypenförmig metamorphosirten, spricht einigermassen hiefür. Die Lösung dieser Verhältnisse und der daraus sich ergebenden Fragen muss jedoch auch hier erst weiteren Beobachtungen vorbehalten sein.

\section{Medusensprossung von Polypen.}

Während wir rorhin die Eutwicklung des Eies der höheren Medusen und den dabei statthabenden Generationswechsel betrachteten, liegt uns hier ein ähnlicher eine andere Abtheilung von Medusen (Oceaniden im weiteren Sinne) betreffender Vorgang vor.

Bereits ron einer beträchtlichen Anzahl von Polypen (ich verstehe hierunter natürlich nur die Hydras-Polypen oder Hydroiden) ist das merkwiirdige Factum bekannt, dass zu gewissen Zeiten medusenförmige Wesen an ihnen hervorsprossen; der älteste Beobachter dieser Thatsache ist wohl Cavolini; *) er beschrieb den Vorgang ohne aber ron seiner Bedentung ein reclites Ferständniss zu haben. Erst einer späteren Zeit war es rorbehalten, hierïber neues Licht zu verbreiten, und so folgten sich denn rasch zahlreiche Untersuchungen, denen endlich steenstrup's $* *$ fruchtbare Lehre inneren Zusammenhang verlielı. Steenstrup subsumirte das ganze Verhailtniss der Medusensprossung an Polypen unter die Gesetze des Generationswechsels, er erklärte die Polypencolonien für Ammenstücke, für eine vorbereitende, gescllechtslose, erste Generation, an welcher erst dureh Sprossenbildung die zweite, geschlechtliche, und desshalb hüher organisirte sich erzengen soll.

Die Art und Weise, wie die Medusensprossung am Polypenstocke erfolgt, ist in allen beobachteten Fiillen die nämliche. Sie beginnt immer mit einer Wucherung der äusseren Zellschichte des Pulypenleibs, in deren Inneres der Achscncanal des Polypenstoekes sich fortsetzt. In diesem

-) Ueber Pflanzenthiere des Mittelmeers. Uebersetzung ron Sprengel. 1813.

*) Ceber den Generationswechsel. Uebersetzt ron Lorenzen. 1842. 
Zustande kamn die Medusenknospe von einer jungen Polypensprosse kaum unterschieden werden. Indem die junge Knospe weiter wächst, prägen sich die charakteristischen Unterschiede erst an ihr aus. Es erscheint eine histologische Differenzirung in zwei verschiedene Schichten, nämlich eine äussere, helle, welche die ganze Knospe ïberzieht und sich in die äussere Hülle des Polypenstocks fortsetzt, und eine innere, mehr dunklere, die mit dem Parenchym des Polypenstocks in Verbindung steht. Die Knospe schnïrt sich jetzt etwas von ihrem Ammenstocke ab, so dass sie mit demselben nur durch einen kurzen Stiel in Verbindung steht. Von dem in den Stiel der Knospe cindringenden Achsencanal (gemeinsehaftlicher Nahrungscanal) des Polypenstocks entspringen nun mehrere Fortsätze (meist in der VierzahI), welche die Wandung der Knospe durchziehen und bald bis zum vorderen Ende derselben gelangen. Im Innern der Knospe entsteht jetzt eine IIöhle, welcher rom Stiele der Knospe aus ein Zapfen entgegenwächst, dessen Iöhle mit dem Fortsatze des Achsencanals in der Medusenamme in Verbindung steht, und gleichsam als eine Ausstülpung desselben erscheint. Es ist dieser Zapfen der Magen der künftigen Meduse. In weiteren Stadien entstehen nun vorne an der Knospe, meist da, wo die vorhin erwähnten Lïngscanäle aulhören, und in einen nun inzwischen entstandenen Cirkeleanal iibergehen, kleine Hervcrragungen in verschiedener Anzahl, welche die Anlagen der Randfïden vorstellen. Die Medusenknospe hat n!m eine bis zu $0,15^{\prime \prime \prime}$ gehende Grösse erreicht; die Tentakeln erlangen jetzt ihre Ausbildung und finden sich dann meist als zusammengewundene Füden in die Höhlung der glockenförmigen Medusenknospe eingeschlagen. Die Anzalil der sich in diesem Stadium ausbildenden T'entakel (Randfiiden) ist je nach den Arten eine sehr verschiedene und kam von einem bis zu einer grösseren Summe sich belaufen; ersteres ist an den Medusen der Coryne fritillaria Steenstrup, letzteres bei den Medusen einiger Campanularien, z. B. Camp. gelatinosa, geniculata, nach Van B enedeu, sowie bei den Medusen von Syncorynen (Syncoryna glandulosa Dujardin) der Fall. Gleichzeitig mit der Ausbildung der liandfüden geht die Entwicklung der sogenannten Randkörper vor sieh, sowie anch jetzt der an der Randfadenbasis vorkonmende Pigmentfleck erecheint. Auf diese Weise ist die Medusengemme zum Freiwerden reif, der bisher blind geschlossene Magen erhält seine Mundöffnung, die Randfiden entwirren sich und strecken sich aus, indess die Meduse einige zıckende Bewegungen vollführt und nach mehrmaligen kräftigeren Contractiouen ihrer Glocke sich vom Ammenstocke losreisst, und als freies Wesen davonseliwimmt. 
Als Sitz dieser Medusensprossung erseheint meist der Körper der einzelnen Polypenthiere, seien diese nun zu Colonien vereint oder einzeln lebend. (Coryne? Corymorpha.) Bei Tubularia Dumortieri Van Beneden findet die Knospung am inneren Tentakelrande statt; ebenso bei Corymorpha nutans Sars; bei den meisten Coryneen an der Circumferenz desnackten keulenförmigen Polypenleibes, der dabei dann häufig verkümmert erseheint. In Umfange eines solchen noch bedeutender als bei den Coryneen verkümmerten Polypenleibes erscheint die Medusensprossung auch bei $\mathrm{Cam-}$ panularia; nur bedingt hier der anch die Polypenleiber becherförmig überkleidende Hornüberzug des Stockes eine Kegelform der Brutstätte, und umschliesst somit die knospenden Medusen, die, während sie bei den Coryneen sich frei naeh allen Seiten hin ablösen können, hier durch die Miindung der Kapsel ihren Ausweg zu suchen genötliggt sind. Den Polypenleib durehzieht hier die Achse der Brutkapsel und wurde in dieser Form als eine Art Piacentarium betrachtet und sehliesst sie oben meist ohne Mundöffnung und Tentakelkranz. Ein solches Verhalten kennen wir bei Campanularia gelatinosa und geniculata nach Van Beneden*), wiihrend dic MedusenbrutkapseIn von Campanularia diehotoma oben noch mit Tentakeh ausgerüstet von $\mathrm{Kölliker}$ * **:) beobachtet wurden.

Das Eotstehen von Medusenknospen am Stamme von Polypenstöeken selbst ist bis jetzt nur von Perigonymus muscoides, einem den Syncoryneen angehürigen Polypen bekannt, ein anderes von mir beobachtetes Beispiel soll in Folgendem erwälınt werden.

Von Mitte November vorigen Jahres an erhielt ich bis Ende März ziemlich lä̈ıfig lebende Exemplare von Cleodora tricuspidata, deren Sehalen bis an die änssersten Enden ihrer drei langen Zacken zierlich wie mit weissen Quasten besetzt waren. Die nähere Untersuchung ergab, dass dieses die Körper eines Syncorynenstocks waren, der sich auf der Schale angesiedelt hatte. Der Stamm des Polypenstockes (Taf. I. Fig. 3. a) war kriechend, lag überall dieht der Cleodorensehale an, verïstelte sich vielfach, und an ihm sass von Strecke zu Strecke ein keulenfürmiger Polypenkörper (Fig. 3. b. b) von $\frac{1}{2} "$ Länge, der wit $5-8$ zerstrent entspringenden verschieden langen Tentakeln (Fig. 3. e c...) versehen war

-) Mémoire sur les Campanulaires. 1843.

*) Zeitschrift für wissenschaftliche Zoologie. Bd. IV. pag. 301.

*.) Van Beneden gibt in einer systematischen Uebersicht der Hydraspolypen als Character der Corynen gleichlange Tentakel an, was ich bei mebren untersuchten Arten virgends bestätigt fand. 
Die Dicke des Stammes betrug nur 0,06-0,04"'. Er war mit einer dünnen, gelblich gefürbten Hornhülle iiberzogen, die an jenen Stellen, wo die Folypen von ihm entsprangen, sich merklich verdünnend auf den Anfangstheil des Stieles jẹner Polypenleiber fortsetzte, ohne dass es möglich war, ihr Aufhüren an einer lebenden Colonie zu beobachten.

Ausser mehrfachen Polypenknospen (Fig. 3 a) sassen noch äusserst zahlreiche Medusensprösslinge dem Stamme an, und zeigten mir alle Entwicklungsstadien ganz in der Weise, wie es sonst von den Medusenammen am Körper der Coryneen bekannt ist. In ilrem Anftreten sowohl, sowie in ihren Bezichumgen zu den einzelnen Polypen der Colonie war kein bestimmtes Verhalten bemerkbar, und bald fanden sie sich zwischen einigen Polypen, bald wieder am Ende eines Schösslings. In Fig. 3 sind mehre derselben aus verschiedenen Entwiklıngsstıfen (d, $\left.d^{\prime}, d^{\prime \prime}, d^{\prime \prime \prime}\right)$ dargestellt.

Die reife oder eben freigewordene Meduse (Fig. 4) ist glockenförmig, zuweilen mehr kuglig. Die Länge der Glocke misst $\frac{1}{4} "$, ihre Breite $0,22^{\prime \prime \prime}$, und an ihrem Rande besitzt sie die bekannte Membran, die allen Oceaniden zukommt (Fig. 4 b). An der immeren Fläche der Glocke verlaufen vier Längscanïle (Fig. 4 e) von der ehemaligen jetzt noch etwas hervorragenden Ansatzstelle an bis zu ilırem Rande, und münden dort in einen gemeinsamen Ringeanal. Der Mageu der Meduse (Fig. 4. g) ragt etwa bis zur Hälfte der Glockenhöhe in deren Höhle herein, ist matt bräunlich gefärbt mnd besitzt eine vierlappige, reich mit Nesselzellen besetzte Mundöfinmug. Nesselzellen finden sich anch auf der Oberfläche der Glocke, wo sie in vier deutliche ron der Kuppel entspringende Längereiben, immer je einem Canale entsprechend, bis zum Rande der Glocke herab vorlaufen. Tentakeh sind nur zwei vorhanden, deren bulbusartiger Ursprung je einem Längscanale der Glocke entspricht (Fig. 4. d d). Sie sind äusserst contractil nnd erreichen in ausgedehntem Zustande eine Länge von nahezu zwei Linien. Ihr Gewebe besteht wie bei allen von mir untersuchten Oceaniden, aus querstehenden hellen Zellen, die anfünglich durch Verschmclzung ihrer Wïnde ein maschenartiges Netzwerk zu bilden scheinen; gegen àas Ende des Tentakels zu nimmt inmer nur eine Zelle dessen ganze Dicke ein. Dieses Gewebe bildet durchans die ganze Dieke eines Tentakels, ohne in demselben einen Centralcanal freizulassen. Die Oberfläche ist von der Spitze bis zur Basis mit dichtstchenden feinen Nesselzellen besetzt. Ausser diesen beulen Tentakeln bemerkt man noch am Glockenrande zwei warzenartige Hervorragungen (Fig. 4. d), von welehen jede der Eimmündungsstelle eines der beiden andern Längscanäle in das Ringgefäss entspricht, so dass hiedurch die Anlage fïr zwei weitere Tentakel gegeben scheint. Dass sich 
wirklich hier noch zwei Tentakel ausbilden, beweisen mir einzelne in dem freien Meere eingefangene Medusen derselben Art, die neben den beiden älteren Fangfäden noch zwei jüngere aufwiesen.

Randkörper fehlen, und ebenso scheinen die soust so ausgebildeten Randflecken (ocelli) der Oceaniden zu mangeln, und statt ihrer zeigt sich nur an der Tentakelbasis eine weiter verbreitete diffusbräunliche Färbung. Geschlechtsorgane sind in keiner Weise noch angedentet. - Aus alle dem gelit hervor, dass unserer Meduse noch weitere Veränderungen bevorstehen, ehe sie als vollkommen ausgebildetes Thier zu betrachten sein wird.

Ausser der Oertlichkeit der Medusengemmation, die unserc Syncorynee bis jetzt nur mit Perigonymus muscoides Sars gemein hat, verleiht ihr noch der Parasitismus auf einem pelagischen Thiere ein besonderes Interesse, welches noch dadurch erhöht wird, dass etwa ${ }_{5}^{4}$ der mir zu Gesicht gekommenen Exemplare ron Cleodora tricuspidata (ich schätze ihre Zahl auf 40) Syncoryneenstöcke auf ihrer Schale trugen. Vom November bis März traf ich diese immer in demselben Zustande, mit derselben Medusengemmation. Jedenfalls ergibt sich hier cine auffallende Ausnahme in der Lebensweise unserer Syncorynee von der ihrer iibrigen Verwandten, die sämmtlich stille Buchten und dic Tiefen ruhiger Gewässer einem bewegten Leben auf offener See vorzuziehen scheinen.

Ich bezeichne diese Syncoryne nach dem Thiere, auf dessen Schale sie wohnt als S. Cleodorae.

Bei einer Campanularia (Taf. 1.Fig. 1), deren Art ich auf eine der bis jetzt näher bekannten nicht zurïckzuführen vermag, beobachtete ich gleichfalls Medusengemmation. Der Stamm (Fig. 1. a) dieses Polypen ist kriechend und überzieht mit seinen vieifachen Verzweigungen Zostera und Fucusblätter; von diesem Stocke erheben sich von Strecke zu Strecke eine Linie lange Stengelchcu, welche die Polypen tragen ; der Stamm ist ferner drehrund und glatt, und ebenso sind es anfünglich anch die polypentragenden Stengel, ihre hornige Hülle geht aber allmiillig in die bei den Campanularien bekaunte Querringelung iibcr (Fig. 1. b). Am Ende der Stengel findet sich die kelchförmige, oben etwas ausgeschweifte und am Rande wellig gehuchtete Glocke (Fig. 1. c und Fig. 1. A), in welcher der Körper der Polypen sitzt (Fig. 1. e). Ein einfacher aus etwa $16-24$ Tentakeln (Fig. 1. f) bestehender Kranz umgibt dessen oberen etwas verbreitcrten Kürpertheil, ans dessen Mitte das röhrenförmig ausgedehnte oder kuglig zusammengezogene Mundstiick (g) herrorragt. - Die Brntkapseln dieser Caupanularia sind länglich oval oder kolbenförmig und sitzen mit kurzem Stiele dem Stamme an (Fig. 1. h). Die hornige Hülle derselben zeigt 6-S Quer- 
ringeln etwa in der Weise, wie sie von Van Beneden bei Campanularia volubilis beschrieben wurden; nur sind die Ringe nicht scharfkantig und stellen auf dem verticalen Durchschnitte sanfte Wellenlinien dar. Vom Stocke aus setzt sich der Nahrungscanal des Polypenstockes in die Brutkapsel fort und durclizieht sie bis an ihr vorderes Ende, das er mit mässig dicker Ausbreitung verschliesst. Seitlich voll dieser centralen Achse (dem Placentarium der Autoren) sitzen die Medusengemmen, melı oder weniger noch von einer äussern Schichte derselben eingehiïlt. Je nach dem Entwicklungsstadium der Medusengemmen wird das Achsenstück der Brutkapsel ausgebogen oder nach einer Seite gedrängt. Man trifft in einer Kapsel an 2-8 solcher Medusengemmen und zwar die älteren immer der Mündung nahe, während die jüngeren mehr am Grunde sich finden. Die Entwicklung der Gammen selbst (Fig. I. i) geht im Ganzen nach der schon vorhin allgemein geschilderten Weise vor sich.

Die freigewordenen Medusen (Fig. 2) sind glockenförmig, äusserst durchsichtig, und messen 0,18" im Quer- und Hühedurchmesser ihrer Glocke (Fig. 2. a). Sie besitzen eine breite Randmembran (b), vier im Schirme verlaufende Längscanäle (e), die am Rande angelangt in einen Cirkelcanal einmünden, und ihnen entsprechend vier mit bulbusartiger Anschwellung entspringende Tentakeln (Randfäden), die sich bis zu $1 \frac{1}{2}{ }^{\prime \prime \prime}$ verlängern künnen. Der Magen bildet im Grunde der Glockenhöhle ein kurze cylindrische Hervorragung $(\mathrm{g})$. Die Oberflïche der Glocke ist mit zerstreut stehenden länglichen Nesselzellen besetzt. Am Glockenrande bemerkt man noch acht Randkörper, welche zu zweien in regelmässigem Abstande immer zwischen je zwci Randfïden vertheilt sind. Es sind elliptische, oft gestielte Blïschen, deren jedes eine rundliche Kalkconcretion enthält. Von Goschlechtstheilen ist an den eben froigewordenen Medusen nichts zu bemerken, dagegen gelang es mir, solche an eingefangenen Schirmquallen, die unzweifelhaft dieser Art angeliörten, aufzufinden. An den jüngsten dieser Formen, die sichı direct an die vor Kurzem aus der Brutkapsel getretenen anschliessen, fanden sich alle Venhältnisse wie eben beschrieben, mit Ausnahme der Gefïsscanäle. die etwa in der Mitte ihres Verlaufs eine kleine mit Erweiterung ihres Lumens verbundene Auschwellung zeigten, also gerade an der Stelle, wo bei den Thaumantiasformen die Geschlechtsorgane hervorsprossen. In äIteren Thieren, deren Glocke etwa $1^{\prime \prime \prime}$ Hölıe erreicht hatte, waren dicse Ausbuchtungen grösser geworden, und batten sich zu frei in die Glockenhöhte hineinhängenden Sückchen gestaltet, in deren Wandungen man deutliche, grössere und kleinere Zellgebilde erkemnen konntc. Vermuthlich sind diese Zellen die Anlagen der 
Geschleehtsprodukte - Eier oder Samenzellen. Mit dem Auftreten der Generationsorgane verbindet sich auch eine Vermehrung der Tentakeln. In der Mitte zwisehen zwei Randfäden entsteht nänlich ein neuer, so dass sich nun ihre Zahl auf acht beläuft. Zwischen je żweien derselben kommt daun immer ein Randkörper. Ob hiemit das Wachsthum und die Entwicklung der Neduse begränzt ist, vermag ich nicht anzugeben, da mir keine äteren hierher beziehbaren Formen vorgekommen sind. Es ist aber immerhin annehmbar, dass mit dem Auftreten der Geschlechtsorgane die Entwicklung ihr Ende erreicht hat, und dass weitere Verïnderungen sich nur anf die Grössenverhältniss̊e erstrecken.

Obgleich sehon durch $\mathrm{Van} B$ eneden*;) die Bildungsgeschichte ron Medusen an Eudendrium ramosum genau bekannt ward, so kann ich hier mit Bestätigung des Wichtigsten von $\mathrm{V}$ a n Ben ed en's Untersuchungen doch noch einiges auf die Form der Meduse Bezughabendes beifügen, das ich in den Angaben jenes Forschers vermisse. Die $0,3-0,4^{\prime \prime \prime}$ in der Höhe und $0,3^{\prime \prime \prime}$ in der Quere messende Glocke dieser Meduse besitzt an ihrer Oeffnung eine breite Randmembran. An der Innẹfläche der Glocke verlaufen vier Längseanäle, die am liande, wie gewöhnlich, sich in ein Ringgefäss vereinen. An dieser Stelle sieht man immer eine betrïelttiche von $\mathrm{V}$ an Ben eden beobachtete Anselıwellung von dunkler Färbung, von welcher zwei sehr lang ausdehnbare Randfïden ihren Ursprung nehmen. Es scheinen diese von V $\mathrm{V}$ B $\mathrm{B}$ eneden nur in sehr zusammengezogenem Zustande beobachtet worden zu seyn. Ebenso ist ihm ein dunkelrother Fleek entgangen, der an der Innenseite jeder Tentakelbasis angebrasht ist. Der kurze cylindrische Magen im Glockengrunde zeigt eine in vier Läippchen ausgezogene Mundöffnung, an der vier einfache, an der Spitze mit einem Nesselzellenknopfe versehene Fortsiitze (Mundtentakeln) ihren Ursprung nehmen. Diese Beschaffenheit zeigten schon dic eben vom Ammenstocke losgelösten Medusen. Im freien Meere eingefangene differirten nur unbedeutend in der Grösse, ohne sonst noch weiter ausgebildet zu sein. Der Mangel der Geschleehtsorgane weist darauf hin, dass wir hiel eine noch nicht gehörig entwickelte Form vor uns haben, die vielleicht, che sie röllig ausgebildet ist, noch mehrfache Veränderungen erleiden mag, mögen nun diese in einfacher Vergrüsserung des.Thieres, oder im Hinzukommen neuer Theile, wie z. B. Vermebrung der Randfäden und Mundtentakeln, bestehen. Aus dem bis jetzt von der Meduse des Eudendrium ramosum Bekannten

-) Recherches sur l'embryogénie des Tubulaires. pag. 31 ff. 
wissen wir, dass es eine Lizzia ist, wie auch schon Forbes*) angab. Weitere Beobachtungen, die namentlich auf das Studium der kleinen freien Formen sieh grïiden müssen, werden ihren spätern ausgebildeten Zustand noch erforschen. Um dieses anzubahnen hielt ich die Anfübrung der oben beregten kleinen Unterscheidungsmerkmale für durchans nothwendig, und so künnen spätcre Untersuchungen sich leicht an sie anknüpfen.

Ich habe mich bisher vorzüglich an die Darstellung von Thatsacheu gehalten, als deren Resultat sich die Entwicklung einer zweiten, ungleichen Generation an einer ersten Generation, den Polypen, ergeben hat. Dieser Prozess hat in einer Knospenbilduug seine Grundlage, ohne alle Theilnahme eines geschlechtlichen Momentes. Nur V an Beneden scheint von dieser Anschaungsweise abzuweichen und lïsst die Mednsen theilwcise aus einem sich furchenden Eie, theilwcise aber auch aus Gemmen hervorgehen, bei welch letzterem Modus er noch besondere Umstände als wichtig, ja massgebend erkennt, so dass das an sich sehr einfache Phänomen der Medusenknospung nuter zwei von den fünf von Van Beneden aufgestellten Fortpflanzungsweisen sich eingereiht findet. Analysiren wir diese, soweit sie dic Medusenbildung belangen, etwas genauer, so finden wir unter der zweiten Art der Fortpflanzung (par bourgeon libre) vorzüglich jene Fälle angeführt, wo die Meduse frei am Polypenstocke hervorknospt, und nicht noch von einer besondern Kapsel umschlossen ist: Tubularia calamaris und Dumortieri, Eudendrium ramosum, Syncoryne Sarsii, Sertularia parasitica, und Campanularia. Bei den drei erstgenannten Polypen, deren Medusengemmation von ihm genau beschrieben wird, nimmt er in der der Gemmenbildung vorausgehenden Wucherung des Polypenstockes (pédicule ovifère') die Bildung einer Zelle an, dic man als Ei betrachten könne; auch als Keimbläschen oder Keimstock wird sie angefïhrt. Sie ist der Ausgangspunkt del Entwicklung der Knospe, gleichsam das Modell derselben. Von ciner solchen Zelle konnte ich nie ctwas entdecken, ja es ist alle Wahrscheinlichkeit, dass Van Beneden die sich sehr früh bildende Höhlc**) der Glocke, in welche später der Magen der Medusengemme hineinwächst, hiefuir genommen hat und derselben somit eine Wichtigkeit zutheilt, die ihr nicht gebuihrt. - Dic Entwicklung ans Eiem nimmt Van Beneden hauptsïchlich bei den Medusen der Campanularien an, bei Campanularia gelatinosa scheint iln die sehr frïhe Ablösung der Medusengemme, die noch innerhalb der Brutkapsel stattfindet, hiczu angeleitet zu haben

7) A monograph of the british naked-eyed medusae. 1848. p. 31. ff.

") Vergl.. Recherches sur les Tubulaires. Tl. II. Fig. 7-10. a. Fig. 13. a. 
und bei der gleichfalls medusensprossenden Campanularia geniculata eine in den Brutkapseln sich findende Bilhuıg, welche mit einem durchfurchten lie allerdings einige Aehnlichkeit hat. (Vergl. Mémoire sur les eampanulaires ctc. pag. 30. pl. III. Fig. b.) Da ich diese Campanularia nicht kenne, so muss ich mich jedes näheren Urtheils über diese Bildung enthalten, glaube aber mich soweit äıssern zu duirfen, dass auf keinen Fa!l ein Furchungsprozess in ilı vorliegen kann, da die von $\mathrm{V}$ an Beneden als Dotterkugeln gedenteten Theile in fortschreitendem Waehsthum begriffen sind und sich rergrösscrn, ein Umstand, der geradezu ihrer Deutung als Dotterkugeln zuwider ist. V an Beneden erklärt daher die Brutkapselı der Campanularien, welche ich ọben schon als veränderte zur Medusengemmation bestimmte Polypenthiere bezeichnet habe, für Eierstöcke, sowic er dann auch wicter die cinzehnen an Syncorynen, Tubularien und Eudendrium hervor sprossenden Medusengemmen theils als Eiknospen (bourgeon-oeuf), theils als Eiersiock (ovisac) auffașst und dadurch die Brutstätte einer ganzen Folge von Medusen (Brutkapseln ron Campanularia) den einzeln sprossenden Medusengemmen parallelisirt.

Dasselbe Geschiek wie bei $V$ an B ene de n hatten die Medusengemmen auch bei andern Forscliern, und bald hielt man die Medusen für blosse Eier (wie Ellis und Carolini thaten), oder für Eierkapseln, oder man erklärte sie als höher organisirte za selbstständigem Leben bestimmte Eierstüeke, ein Lmstand, der in Verwechslung mit freigewordenen wirklichen Medusen mit den medusenförmigen Geschlechtsorganen seine Ursache findet*).

Fragen wir nun nach der weiter erfolgenden Lebensentscheidung dieser Medusen, aus denen ihre Bedentung resultirt, so wirl vor Allem eine genaue Wrïrdigung ihrer Organisationsverhältnisse uns den richtigen Weg anzugeben im Stande sein. Bei Beriicksichtigung des Baues der von Polypencolonien erzeugten Medusén finden wir vor Allem einen sehr entwickelten Locomotionsapparat, bestehend in einem an der Unterseite des Schirmes

-) So verwechselte $\mathrm{V}$ a n B en e d en die Medusengemmen von Tubularia und Campanularia mit einer aus Geschlechtsorganen hervorgegangenen Brut, und betrachtet sie ais die Larven wn Polypen, die obgleich mit höheren Organen ansgerüstet, nach kurzer Zeit eines freien Lebens vermittelst des Magenstieles sich festsetzten, ilıre Glocken umstülpten und so zu Polıpen sich umwandelten! (Vergl. Recherches sur l'embryogénie des Tubulaires pag. 36 pl. II. Fig. 25. 26.). Fs ist dies eine Hypothese, die schon durch F'rei und Leuckart (Bëiträge zur Keuntniss wirbelloser Thiere. pag. 2) den gehörigen Widerspruch erfuhr, die aber dennoch in dem neuen Werke ron V. Carus, System der Morphologie, wenigstens als Wahrscheinlichkeit geduldet ward. 
(Subumbrella Forbes) befindlichen Muskellage (Ringfasern), welche am Rande des Schirmes oder der Glocke in eine mehr oder weniger breite contractile Ringmembran iibergeht. Wie dureh Zusammenwirken dieser beiden Theile die Locomotion erfolgt, ist bekannt. Hiezu kommt noch das Gastrorascularsystem, das sich in niclits von dem der schon längst als selbsiständige Thiere bekannten Oceaniden unterscheidet. - Ebenso der Tentakelapparat und die als Simnesorgane gedenteten Theile, die sich theils als Blïschen mit einer Kalkencretion (eigentliche Randkörper), theils als circumseripte Pigmentflecken darstellen. Wir sehen in keinem dieser "Organe eins durchgreifende Versehiedenheit von den grösseren Formen, deren Abstammung uns bis jetzt noch unbekannt ist.

Zur Vervollständigung des Beweises, dass diese an Hydras-Polypen aufgeammten Medusen ansgebildete Thiere seien, fellt noch die Nachweisung ihrer Geschlechtsorgane, Dic meisten dieser bisher als Polypensprösslinge bekannten Formen besitzen bei ilrem Freiwerden rom Ammenstocke keine Andeutung von Generationsorganen, und diess war wohl ebenfalls eine Ursache, dass ihre Bezielung zum Generationswechsel, ihre Bedeutung als zweite geschlechtliche Generation oftmals verkanmt worden ist. Es ist aber hicr vor allem darauf Rüicksicht zu nehmen, dass diese Sprösslinge, wenn sie den Ammenstock verlassen, meistentheils noch nicht in ihrem vollkommenen Zustande sind, und noch in mannigfacher Richtung sich weiterbilden, bevor wir sie als geschlechtsreife Thiere erkennen.

Hicher gehört ausser ihrer Grössenzunahme auch die Vermchrung der Randf:̈̈den und bei einigen Geschlechtern die der Mundtentakeln, wie ich schon oben bei Beschreibung der Sprösslinge einer Campanularia und ron Syneoryne Cleodorae bemerkte. Auch ron einigen andern kleinen Medusen unbekannter Herkunft gelang es mir, dureh melırere durch Vermehrung der Randfïden ansgezeichnete Stadien die Entwicklung und Ausbildung der Geschlechitsorgane zu verfolgen, so dass mit Grund anzunehmen ist, dass bei sorgfältiger Beobachtung der zahlreichen kleìnen Formen sich allmählig eine rollständige Kette darstellen lasse, deren Anfangsglied wir als geschlechtslose Medusengemme kennen, indess das Ende in entwickelten, geschlechtsreifen, zuweilen um vicles grösseren Formen sich finden wird. *)

•) Ein Beispiel, wie sehr sich mit dem zunehmenden Alter sogar auch der IJabitus der Medusen verändern kann, finde ich unter anderem auch bei den Gersonien. Mir waren urter den zahlreichen kleinen Nedusen Formen aufgefallen, die mit mässig genö btem Schirme verseheu, sechs Randfäden und eben so viele Randkörper zählten. Es 
Eine andere Grupne von Medusen zeigt schon bei ihrer Knospung die Aulagen der Geschlechtstheile. Sie ist bedentender von Zahl und sie war es wolıl, die häufig mit Geschlechtsorganen der Polypen verwechselt wurcle. Es jst lier zu nennen die thammantiasförmige zweite Generation der Camp. gelatinosa, wo in Mitte des Verlaufs der vier Canäle des Schirmes sich kleine Erhebnngen zeigen, die Van Beneden*) für Ganglien hiclt, eine Amahme, die später von $\mathrm{Krohn} * * *$ ) berichtigt wurde; indem er bei eincr anderen im Golfe ron Neapel bcobachteten ähnlichen Schirmqualle diese Knötehen dentlich als Zengungsorgane erkannt hat. Ich selbst fand zu Messina oftmals ganz täuschend ähnliche Formen wie sie von $\mathrm{V}$ an $\mathrm{B}$ ened en beschrieben und abgebildet wurden, und konnte an ihnen die Ausbildung der Canalanschwellung am Schirme zu Zengungsorganen gleichfalls beobachten. Auch die von Kölliker ***; an Campanularia dichotoma gesehenen Medusensprösslinge waren schon mit Anlagen der Geschlechtsorgane versehen. Ob das Organ am Glockenrande der Medusen von Coryue fritillaria und Corymorpha nutans wirklich ein Gencrationsorgan ist, wie es Steenstrup deutet, lasse ich bei der bis jetzt noch mangelnden genaueren ,Untersuchung derselben noch unentschieden.

Ferner kennen wir bereits dic Geschiechtsorgane der Medusen von Stauridium durch Dujardin, jene der Sprösslinge von Podocoryna carnea durch Krohn, die einer Sarsia ähnliche Meduse, welche einer Syncoryne entstammt, durch Desor; der letztere sah sogar die Lier in den Magenschlänchen (Ovarien) in allen Stadien der Dotterfurchung. Auch W a gner beobachtete die Eier am Magen einer von Coryne aculeata aufgeammten Meduse. Wir sehen hieraus, dass die Geschlechtsreife der einzelnen von Polypenstöcken sprossenden Medusen in sehr weit auseinander liegenden Zeiträumen erfolgen kanı, dass sie bald schon während des

waren sechs radiäre Gefässcanäle vorhanden, die in einen Randcanal zusammenflossen. Der Magen war klein, sass anf einer kurzen, zapfenartigen llerrorragung in der Tiefe der Schirm-Concavität, und ragte nicht über den Schirmrand hervor. Später beobachtete mannigfache Zwischenformen wiesen mir diese Meduse als eine junge Geryonia proboscidea nach. Der Zapfen, auf dem der Magen sass, verlängert sich, und wächst so z!ım fälschlich sogenannten Rüssel aus, während rom Cirkelcanale aus noch mehrfache Canäle zum Mittelpunct des Schirmes hinwachsen.

-) Mém. sur les Campanulaires. pag. 26. Pl. II. Fig. 15 e.

*) Wiegmann's Archir für Naturgeschichte. 1851. pag. 267.

‥) Zeitschrift für wissenschaftliche Zoologie. Bd. IV. pag. 301. 
Gemmenstadiums sich einleitet, bald erst nach Ablauf einer längeren Frist, in der die Meduse sich anch in anderer Bezielnung verrollkommnet, auftreten kann.

Tie wir wissen, dass die mit Geschlechtsorganen rersehenen Polypen-Colonien immer nur ein und dasselbe Geschlecht produciren, so können wir hierans ein gleiches Verhalten für die nedusenerzengenden Polypenstöcke anmehmen, welclie Annahme in Krohn's Erfalırmg eine Stiitze findet.

Wir kommen somit zu dem Schlusse, dass alle an Polypen erzeugten, frei werdeuden Medusen lüher organisirte, selbständige Wesen sind, nit Geschlechtswerkzengen ausgeriistet, welche Organe gerade bei jenen Polypen vermisst werden, von denen man Medusensprossung kennt. Die Medusen erscheinen also als die 'Trïger der Fortpflanzung, als eine $z$ weite, rollkommene, geschlechtiche Gencration. Ob sie die Function der Fortpllanzung friiher oder später verrichten, ob sie schon nach einmaliger Vollziehmng derselben ihren Lebenszweck erfiillt liaben mi hinsterben, oder ob sie bei längerer Lebensdauer zur öfteren Wiederholung der Fortpflanzung befähight, Generationen auf Generationen crzengen, dies alles kann hier, wo es sich nur um die Erklärung ihrer selbstständigen Individualitiit handelt, nicht von Wichtigkeit sein.

Noch will ich hier auf eine Differenz im Baue der verschiedenen Polypensprösslinge aufmerksam machen, die meines Wissens bisher noch nicht ihre gehörige Würdigung fand. Es bestelıt diese nämlich in dem jeweiligen Vorhandensein oder dem Mangel der Randkörper (Gehörblïschen) und in den rerschiedenen Sitze der Geschlechtsorgane. So sind sïmntliche bis jetzt bekannte Campanulariasprösslinge (Camp. gelatinosa, geniculata nach $\mathrm{T}$ an B eneden, dann Camp. dichotoma nach Kölliker, und endlich die ron mir beschriebene Campanularia) mit Randkörpern versehen, und die Geschlechtsorgaıe bilden sich bei ilnen im Verlaufe der vier Schirmcanäle, während wir bei den Medusen, die von den Coryneen und Tubularinen erzeugt werden, niemals auf Randkörper (Gehörb]äschen, zum Unterschiede von den Pigmentflecken;, die immer an der Tentakelbasis sitzen) stossen und die Geschlechtsurgame an Hagen, meistentheils sogar in dessen Wandungen eingebettet antreffen. Die Meduse deș Stauridium, sôwie jene der Syneuryne von Desor und die der Podocoryna carnea nach Krohn mögen statt zahlreicherer Beweise als Beispiele angeführt werden. 
Die typische Verschiedenheit der Ammenstöcke ätussert sich somit auch gewissermassen an den Medusengemmen, und wir werden in der Folge, wenn diese Verhältnisse gehörig festgestellt sein werden, bei Beobachtung ron Medusen und ihrem Bane auf die Art des Ammenstocks einen Schluss wagen dürfen.

Sind die Medusen eine zweite geschlechtliche Generation, so muss nach dem Gesetze desGenerationswechsels die aus ilnen durch geschlechtliche Fortpflanzung entstandene Brut durch Cmwandlung in Polypen wieder zur ersten (Ammen-) Generation zuriickkehren. Es ist dies ein Terhältniss, welches zuerst Steenstrup als Consequenz des ron ihm aufgestellten Gesetzes urgirte, nnd welches zwar ron Viclen angenommen, aber noch keineswegs erwiesen war, so dass man noch for Kurzem mit Johannes M ï lle r *) fragen konnte, ob nicht die Brut der ron Polypen aufgeammten Medusen wieder direct zu Medusen wïrde, so dass in homogoner Reihenfolge mehrere Generationen entstiinden, ehe eine heterogone Generation die Rückkehr zur ersten (Ammenform) bedinge.

\section{Entwicklung der Medusenbrut.}

Ehe man etwas Entscheidendes über den Generationswechsel der Medusen und Polspen aussprechen durfte, war es nötlig, die Brut der ersteren zu kemnen. Die blosse Kenntniss der Medusensprossung reichte nicht aus zur Schliessung der Kette, demn das Schicksal der ron Medusen erzeugten Jungen war das noch fehlende Glied. Zwar hatte Dujardiu ***; schon friiher die Beobachtung gemacht, dass aus den Eieru der Cladonema, einer Meduse, deren Abstammmg ron einem Syncorynenartigen Polypenstocke (Stauridimm) er entueckt hatte, wiederum Polypen herrorgingen, aber so genan und sicher auch die Knospung der Meduse rom Polypen dargestellt war, so klebte doch der Schilderung der Entwicklung des Eies derselben Meduse zu einem Polypen immer etwas Mangelhaftes, etwas Ungenïgendes an, so dass diese bei der Frage ron der Entwicklung der Medusenbrut nur wenig in's Gewicht fallen konnte. Erst den neueren Forschungen Krohu's *w* ist die Beweisführung rom Schlusse des

i) Müller. Archiv, 1851.

*) 1. c.

*.) Müller. Archiv, 1853. Hft. III. 
Generationswechsels zwischen Medusen und Polypen vollständig gelungen. Als Beobachtungsobject diente Krohn dieselbe Meduse wie D ujardin, es war somit deren Abstammung von Polypen (Stauridium) authentiseh genug gesichert. Krohn beschreibt ausfillrlich dic Furchung, die Bildung einer flimmernden, infusorienartigen Larve, die nach Verlauf einiger Schwärmezeit sich festsetzt, die Cilien verliert, einen hornigen Ueberzug, um sich bildet und in einen Polypenleib auswächst, an welchem vier im: Kirenze stehende Tentakeln hervorsprossen. Unter diesen treten später noch vier neue auf, womit dam der Polyp mit dem von Dujardin beschriebenen Stauridium völlig übereinstimmt. Herr Krohn war so freundlich, nir die cinzelnen Stadien dicser Entwicklung zu zeigen.

Meine eigenen Untersichungen über diesen Gegenstand betreffen die Eier zweier Medusen, die zur Familie der Oceaniden gehörig sind, und somit in Betreff ihrer Abstawmung von Polypen nach den bisherigen Erfahrungen kaum mehr zweifelhaft scin diirften. Eine dieser Medusen, welche ich, da sie mir neu erscheint, hier ans führlicher beschreiben will (in Fig. 1 auf Taf. II. ist sic in natilrlicher Grösse mit ausgestreckten Fangfäden, in welcher Stellung sie oft stundenlange verharrt, abgebildet), gehört zur Gattung Lizzia; ${ }^{*}$ ) sie besitzt einen glasartig durchsichtigen, glockenförmigen Schirm, dessen Oeffinung mit einer breiten Randhaut umgeben ist. An der Imnenfläche des Schirms (Subumbrella Forbes) verlaufen vier ziemlich starke Gefüsscanäle vom Magen zum Glockenrande herab, wo sie in einen Ringcanal einmünden. Die Höhe der Glocke beträgt 5-7"', ihr Querdurchmesser 4-6"'. Im Grunde der Glocke befindet sich auf einem etwas vorragenden Zajfen der kurze fast vierkantige Magen, der an seiner Mundöfnung vier Büschel schön carmoisinrother, dichutomisch verzweigter Tentakeln besitzt, welche, etwa die Färbung ausgenommen, mit jenen, dic von $\mathrm{F}$ or bes ${ }^{* * *}$ ) an Bougainvillea brittanica

") In einer brieflichen Mittheilung an Herrn Prof. Kölliker (Zeitschrift für Zoologie Bd. V. Hft. I. pag. 15) hake ich diese Lizzia als Bougainvillea aufgeführt. Doeh dürften Bougainvillea und Lizzia kaum von einander zu unterseheidende Genera sein, da das für Bougainvillea charakteristische Kennzeicheu, bestehend in nur vier Büscheln von Randtentakeln auch den jungen Lizzien zukommt. So traf ich einigemale junge Individuen obiger Lizzia an, die nur vier Tentakelbüschel besass. Es waren dann diese Thiere noch nicht geschlechtsreif. Bei auderen etwas älteren waren zwiscken -je zwei derselbeu die Anlagen der anderen vier Büschel vorhandeu, indem an deren Stelle nur je zwei Fäden sich fanden, ähnlich wie es von $F$ orbes von einigen erwachsesien Lizzien, z. B. Lizzia blondina angeführt wird.

•) Op. cit. Taf. XII. Fig. 1 e. 
beschrieben werden, ganz übereinstimmen. Am Ende jedes Zweiges dieser Mundtentakeln sitzt ein Kü̈pfchen von Nesselzellen. Am Grunde des Magens führt eine contractile Oeffunng in eine kleine viereckige Höhle, ron deren Ecken je eines der Gefïsse der Subumbrellá seinen Ursprung nimmt. Die Randtiiden (Tentakeln) der Meduse sind auf acht Büschel vertheilt, von denen vier den vier Längscanülen entsprechen, indess die anderen vier Bündıl regelmässig in den Zwischenräumen sitzen. Jedes Bündel zïhlt etwa 10-15 feine, sehr ausdehnbare und dieht neben einander entspringende Fäden, die gegen die Spitze hin matt roth gefürbt sind. An der Basis jedes Biindels ist aussen ein breiter hochrother Fleck. Einen gleichgefürbten Pigmentfleck besizt dann noch jeder einzelue Randfaden auf der imneren Seite, melır oder weniger ron seinem Ursprunge entfernit. Die Gesehlechtstheile sitzen als vier blattartig gerippte, etwas ausgebuchtete Drïsen auf der Oberflïche des Magens und besitzen eine in die Ausbuchtungen der Driise sich eiustiilpende Höhle, welche mit dem oben angegebenen Sinus, aus welchem die vier Canäle der Glocke entspringen, in Zusammenhang steht. Mäunliche und weibliche Organe sind an Form einander gleich, nur sind die letzteren zur Zeit der Reife wegen der durchschimmernden weissen Eier immer etwas heller gefärbt. Männchen wie Weibchen wurden in gleich grosser Zahl beobachtet.

Ich erlaube mir, diese Lizzia nach Hrn. Prof. Kölliker als Lizzia Koellikeri zu bezeichnen.

Die Eier werden durch Platzen der Ovarien nach aussen entleert und fallen dann als weissliche Pünktchen - wenn sie in Masse austreten, wie ein feiner Staubregen - in's umgebende Wasser, wo sie auch befruchtet werden. Ich hatte oft Gelegenheit, dies aus den zahlreichen Samenfäden zu entuehmen, welche die aus dem Gefïsse genommenen Eier umschwärmten, oder anch mit ihren Köpfehen an ihnen festsassen und mit dem freien, fadenförmigen Anhange in zitternder Bewegung begriffen, das Bild eines bewegten, das Ei umgebenden Strahlenkranzes darboten. (Taf. II. Fig. 2.)

Das reife Ei ist vollkommen rund, misst $0,05^{\prime \prime \prime}$ und besitzt einen feinkörnigen 1Dotter, um welchen ich auf keine Weise eine besondere Membran darzustellen vermochte. *) Bei leichter Compression erkennt man

") Ein Umstand, der auch ron C. Vogt beobachtet ward.

Hier kann ich nicht umhin, anf die Bildungsgeschiebte der Eierstocksei er, wie sich solche nach mehrfach wiederholtcn Beobachtungen ergeben hat, aufmerksam zu machen. V. Ca rus sagt in seinem System der Morphologie (pag. 177): „Dio 
im Innern ein helles, seharf umschriebenes Keimblïschen, ohne Kcimfleck. Es erfolgt nun in der Theilung des Eies-der erste Seluritt zum Aufbau des Embryo, nämlich die Dottertheilung, zuerst in zwei, dam vier, dann aeht runde Kugeln, die ebensowenig wie das reife oder das befruchtete Ei eine umhüllende Membran wahmehmen lassen. Die Theilung der Kugeln erfolgt immer auf eimmal, so dass in den verschiedenen Stadien alle Kugeln gleiche Grüsse besitzen. (Taf. II. Fig. 3-4.)

Die einzelnen Theilungsstadien des Dotters stellen Häufehen ron lose mit einander verbundenen Ballen dar. Jeder dieser einzelnen Ballen oder Kugeln enthält im Innern einen Kern, der dureh Theilung des Keimbläschens entstanden, um so deutlieher hervortritt, je weiter die Dottertheilung

Eier der Coelenteraten bilden sich dureh die Umhïllung der die Ovarien füllenden Zellen (Keimbläscheu) mit einer zuweilen zicmlich grobkörnigen Dottermasse, welthe dann von einer zarten Dotterlant umgcben wird etc." Ich fand die Bildung des Eies in verschiedenen Oceaniden in ganz anderer Weise vor sich gehend; besonders wareu es kleine Thaumantiasarten, die wegen der Kleinheit der Ovarien und der verbältnissmässig grossen Eikeime als vorzüglich für diese lieobachtungen geeignct erschienien. Hat sich das Ovarium, wie schon oben angegeben ward, aus einer Ausstülpung eines der vier radiären Schirmeanäle gebildet, so stellt es ein kügliehes, nur mit einem kurzon Stiple dem Scbirme der Meduse rerbundenes Gebilde dar, in dessen Inneres eine blindsackartige Verlängeruug des Schirmcanals hineinragt. * In der Wandung unterscheidet man eine Tunica propria, arf welche dann lielle, fast gleich grosse Zellen folgen (von 0,003-0,004 '“) in denen ein lieru nur durch lieagenticn sichtbar wirl. Auch der liern ist bei allen gleich gross; freie Kerne fehlen durehaus. Man sieht nun weiter, oft schon bei demselben Thiere, wio einzelne der das Oxarium ausfüllenden Zellen sich vergrösseru, indem die Membran sich rom Kerue beträehtlicher erhebt, und nun Moleciile, meist um den Kem sich Jagerud, in dem anfäug]ich homogen sich darstellenden Zellinhalte sich differenziren. Nur inmer 2 oder 3 Zellen des primitiven Ovariumparenchyms durchlaufeu diese Veränderung und werden so zu Likitimen; das Wachsthum derselben schreitet immer weiter vor und der Iulaalt der Eizelle besteht nun aus eincr feingranulirten Substanz, in deren Centrum der helle Kiern (das künftige Kerinbläsehen) eingebettet liegt. Die zarte Membran der Zelle ist, wie vorher, vorhanden, und durch Zusatz von süssem Wasser leicht zum Abheben zu bringen. Erst mit vermehrter Bildung von Dottersubstanz verschwindet scheinbar das lieimbläschen. So nähert sich das Ei seiner Reife, durch:bricht das Ovarium und gelangt so nach ausscll. Wie es kommt, dass die anfänglich leiclit darstellbare Zellhaut, mit der vorschreitenden Umbilanng der primitiven Eizelle zum reifen Eie, jetzt nicht mehr deutlich sich zu erkenuen gibt, vermag ich nicht anzugebell, es ist dies ein Vorgang, der wohl mit dem Leben der Eizelle zunächst zusammenhängt. Doch muss ich darauf bestehrn, dass das Fi der Medusen zu allen Zeiten eine Zelle vorstellt, und von einem präformirteu Kerue, unı welchen sich Dottersubstanz anlagere, die sich schliesslich mit einem Membran überziehe, kann bier keine Rede scin. 
vorgeschritten ist. Eine Membran ist um die einzehen Kugeln ebensowenig nachzuweisen, als dies an dem reifen Eie müglich war, ihre Gleichbedeutung mit Zellen ist daher nur bedingterweise anszusprechen, und erst am zweiten Tage nach eingeleiteter Furchung ist dies in bestinmter Weise möglich, da jetzt ein runder Körper entstanden ist, dessen Elemente augenscheinlich Zellengebilde sind. Die so gebildete I.arre überkleidet sich mit feinen Cilien und sehwimmt frei umber. Am dritten Tage erseheint sie etwas in die Länge gestreckt und geht allnälig in eine cylindrische Form iber, mit abgermudetem Vorder- und Hinterende, wobei sie beim Schwimmen noch schwach schlängelnde Kürperbewegmngen vollführt. (Taf. II. Fig. 5.) Eine histiologische Differenzirung, die bisher noch ausgebliebeu war, wird jetzt erkennbar, und es erscheint so eine helle äussere, und dunkle imnere Körperparthie. Die Larve misst 0,13"' Jä̈nge und 0,01"' Brẹite. Dieses Stadium wiilırt mehrere Tage an, dann tritt die Larre durch Verkürzung in eine ovale Gestalt über (Fig. 6), ihre Cilien sind bedeutend länger, die Bewegungen daher rascher usd lebhafter geworden, und dewen eines Infusoriums (etwa eincr Bursaria oder Opalina) nicht muähnlich. Die friiher dunkelgefärbte Centralsnbstanz hat sich jetzt in eine Höhle ungewandelt, die aber nirgends nach aussen communicirt. Nun kommt etwa am vierten Tage der Bildung des Embryo das Ende des Schwärmestadiums, die Larve senkt sich zu Boden, schwimmt nur noeh träge dort umher, verharrt oft lange an einer und derselben Stelle, sich veständig in langsamen Kreisen herumdrehend, und. setzt sich dam mit dem etwas breiteren Ende ihres Körpers an irgend einer Stelle fest. Es schwinden sum die Cilien auch von den iibrigen Körperparthieen, die Larve rerbreitert die angeheftete Körperfl̈̈che noch mehr, so dass diese zu einer Art Fuss wird (wie diess anch Lovén bei den aus den Eiern der Campanularia entstandenen Larven sah) und hiemit wäre nun der erste Schritt zur Umwandlung in einen Polypen gethan. Aus der schwärmenden Larve ist ein festsitzendes Wesen geworden. Alle weiter anftretendent kischeinungen betreffen nun die Ausbildung des jungen Polypen, demn so kann die festsitzende Larve fiiglich jetzt bezeichnet werden Ueber die ganze Oberfläche entsteht nun, wahrscheinlich durch eine Absonderung der Oberhautzellen, ein hornartiges, diinnes Gehïnse (Fig. 7); die schon fruiher angedeutete centrale Hühle der Larve ist jetzt dentich ausgebildet, und durchzielıt die ganze Länge des $0,12-0,15^{\prime \prime \prime}$ langen Polypenstöckchens, und scheint, wie ans dem Umherwirbeln einer an Moleciilen reichen Flüssigkeit zu schliessen ist, eine zarte Auskleidung von Cilien zu besitzen. An dem vorderen freien Ende scheint sich jetzt mehr Bildungsuaterial 
anzuh:äufen, denn dieser Theil wächst jetzt in eine keulenähnliche Form ans (Fig. 6 c.), und erscheint bei durchfallendem Lichte geschen völlig dunkel. Durch allmählige Verlängerung dieses Theilcs entsteht ein Stiel, an dessen Ende der keulenförmige Polypenleib hervorsprosst; wahrscheinlich geschieht diess auf Kosten des denjungen Polypenstamm darstellenden Theiles, denn man sieht, wie dieser an vielen Stellen oft Strecken weit von dem ilm anfänglich dicht anliegenden hornigen Gehäuse sich ahhebt, und nur die Aclise der Röhre durchzieht. Jetzt sprossen endlich “dic Tentakeln etwa in der Mitte des kenlenfümigen Polypenkörpers hervor, (Fig. 8 d. Fig. 9 A. und B. d.) und mit der nun erfolgenden Bildung einer Munclöffnung ( Fic. 8, 9 c.) ist das Letzte vollendet, um die Polypennatur des aus dem Meduseneie erzengten Wesens hervortreten zu lassen. Die Tentakeln stehen kreuzweise, etwa wie bei Stauridium, sind aber von denen dieses Polypen hinreichend durch die Anordnung der Nesselzellen unterschieden. Bei der Cladonema-Amme stehen nämlich die Nesselzellen auf einem Knöpfchen beisammen am Ende des Tentakels, während sie bei unserem Polypen in einzehen auf der ganzen Lünge des Tentakels in fast in regelmüssigen Zwischenräımen sich folgenden Häufchen stehelı. Die ältesten von mir beobachteten Polypen messen $0,15-0,1$ s' $^{\prime \prime}$ Lüıge, und ihre Fiihler erreichen im ausgestreckten Zustande eine Länge von $0,0 \mathrm{~s}^{\prime \prime \prime}$.

Behufs der Bildung einer ganzen Colonie aus dem einzelnen Polypenthiere zeigen sich an dem festsitzenden Fusse des letzteren (Fig. $7-9$ a.) mehrere, oft $3-4$ Fortsätze, um welche, wie an übrigen Stamme, eine diinne homogene Hornhiille sich bildet. In dicsem Zustande konnte ich die Polypen mehrere Wochen hindurch beobachten, olne dass eine Veränderung bemerkbar ward. Auch die rom Fusse ausgeschickten Fortsätze, die ich als Stolonen hetracliten muss, verlängerten sich nicht weiter, bis zuletzt eine Verkïmmerung der Thiere eintrat, die ganze Ansiedlung abstãrb, und nur noch dic leeren, röhrenförmigen Gehäuse iibrig liess.

Es musste mir nun daran gelegen sein, den aus dem Eie der Lizzia hervorgegangenen Polypen genaner zu bestimmen, aber meine Hoffunng, diese Form unter den iibrigen zu Messina vorkommenden Polypen aufzufinden, blicb eine vergebliche. So viel sich aus seiner im letzten Stadium beobachteten Form erkennen liisst, gehört er offenbar der Abtheilung der Coryneen an; das nur bis zum Anfange des Polypenleibes reichende Gehäuse, die Kenlenform des Leibes selbst, sowie die an seinem Fusse hervorsprossenden Stolonen nähern ihn dem Genus Syncoryne, von dem er sich aber durch seinc in gleicher Höhe sitzenden Tentakeln, die bekanntlich 
bei Syncoryne (wie auch bei Coryne), zerstrent am Polypenleibe sitzen, wird er wieder ron diesem Genus ausgeschlossen. Eine Frage ist noch, ob die letzt beobachtete Form des jungen Polypen wirklich eine ausgebildete ist, oder ob dureh Hinzukommen neuer Tentakeln nicht noch eine charakteristische Veränderung sich einleitet. Das anfïingliche Auftreten einer geringeren Anzahl von Tentakelı, als der vollendeten Thierforn später zukommt, ist bei vielen Coclenteraten eine ausgemachitesaclie, und wurde, was speciell die Hydroiden betrift, bei Stauridium sowohl ron D n j a din als Kroln, dann ron V a n Bened en an dem Embryo der Tubularia coronata, an den Jungen der Tubularia Dumortieri. der Coryne squamata und Hydractinia lactea beobachtet. Auch an den polypenförmigen Ammen der höheren Medusen ist dies der Fall, und häulig ist es auch hier die Vierzahl, in welcher die ersten Tentakeln erscheinen. Ans diesen Griinden ist die Annalme gerechtfertigt, dass unser Polyp eine nocli unausgebildete Form vorstelle, und für diesen Fall kinn noch das Genus Eudendrium in dèn Kreis derjenigen gezogen werden, die hier zur Betrachtung kommen. Der I'olypenleib des Endendrums ist nackt wie jener der Syneorynen; das Gehüuse reicht nur bis zun Anfange des Leibes. Die wirtelförmige Anordnung der Tentakeln des Eudendrium kommt mit jener unseres Polypen iiberein, und bekanntlich besitzen die von Eudendrium ramosum sprossenden Medusen Lizzienform, so dass die Annahme, dass unsere Lizzia, deren Eier zu Polypen werden, der erwachsene Sprössling des Eudendriun ramosum sei, keineswegs zu den unwahrscheinlichen gehört. Der Vergleich des Banes der Medusengemme ron Eudendrium ramosum mit Lizzia Kíollikeri weist mehrfuche Uebereinstimmungen auf, welehen die nur auf Altersdifferenzen zuriickfiilırbaren Verschiedeuheiten das Gegengewicht zu halten nicht im Stande sind. Solche Verseliedenheiten, die auf Altersdifferenz sich begriinden, sind rorzïglich die.Tundtentakeln und die Riundfiiden. Lizzia Koellikeri besitzt verïstelte, rothe Mundtentakeh, die der Endendrien-Sprosse sind einfach und ungefärbt, ferner zeigt die erwaclısene Lizzia acht Tentakelbiindel, jeden aus einer grösseren Anzahl von Randfäden zusammengesetzt; aber jüngere geschlechtsunreife Individuen von Lizzia Koellikeri zeigen nur vier Tentakelbiindel, jeden aus einer kleincren Anzahl von Randfïden zusammengesetzt. Ferner will ich noch auf den rothen Fleck an der Basis der Tentakelbiundel und anf den OcelIus an der Innenseite jedes Tentakels aufmerksam machen, da in diesen Verhältnissen Lizzia Koellikeri mit der Eudendriumgemme völlig übereinkommen. Aber ungeachtet all dieser Uebereinstimmung erkenne ich recht wolıl das behufs einer wirksamen Beweisfühırung Unzureichende der mir 
zu Gebote stehenden Mittel. Es kann eine solche einerseits nur durch ein vergleichendes Studium aller sich etwa findenden Ucbergangsformen rom Polypensprössling bis zur geschlechtsreifen دleduse ermöglicht werden. leh bin desshalb ferne davon, die Lizzia Koellikeri geradezu für einen Abkömmling des Eudendrium ramosum zu proclamiren, sondern ich rersuchte es nur, auf dem Wege der Hypothese das anzudenten, was einer exacten Methode zu beweisen vorbchalten bleiben muss.

Noch bleibt mir die Sichilderung einer zweiten Beobachtung von Entwicklung des Eies ciner Meduse. Ls betriflt eine nicht schr häufig vorkommende Oceanie, die ron $\mathrm{K} \ddot{u} l 1 \mathrm{jker} \mathrm{r}^{*}$ als $\mathrm{O}$ c. arm a t a beschrieben wurde. Die Geschiechtstlıeile dieser Meduse finden sich, wie bei allen ächten Oceaniden (im engeren Sinne), an Magen angebracht, und zeigen lier sich ziemlich in derselben Weise wie es vorhin bei Lizzia Koellikeri erwähnt wurde. Die Eicr werden gleichfalls durch Platzen der äusseren Ovarienwand nach aussen entleert, und dort befruchtet. Sie messen $0,09^{\prime \prime \prime}$, besitzen einen feinkörnigen Dotter, dessen Durchsichtigkcit das runde helle Keimblïschen deutlich zu sehen erlaubt. (Taf. II. Fig. 10.) Der Keimfleck fehlt auch hier, und ebenso eine besondere Dottermembran, obgleich jüngere, nochı mureife Eier, eine solche nachweisen lassen. Die Furchnng selbst geht in derselben Weise, wie bei Lizzia, von Statten, nur stellen ihre Producte keine Kugehn ror, sondern nur Theilstïcke einer Kugel, wesshalb die Obernlïhe des Eies durch alle Furchungsstadien hindurch ziemlich unverïndert die Kungelfọm beibchiilt. (Vergl. Fig. 11-14.) Es theilt sich demach der Dotter anfïnglich durch eine un seinen Aequator laufende Furche in zwei gleiche Inälfen; die Furche ist bis zur Mitte eingedrungen und hat den Dotter vollstiindig gespalten, ohne dass die Ifemisphärenform der beiden Theile sich ändert und in die Kugelform iibergeht. Die zweite Furche, erfolgt dam im rechten Winkel zur Ebene der ersten, wïhrend dann die dritte Furche sich nun über die Mitte der vier ersteren Dotterscgmente zieht. Allen Furchungsacten geht eine Theilung des Kernes rorher (Fig. 11), so anch dem ersten Acte die Theilung des Keimblïschens; die Durchsichtigkeit des Dotters erlaubt Licr alle diese Phaenomene aufs Genaueste-zu beobachten, und die Bildung der Kerne der späterenEmbryonalzellen aus dem urspriinglichen Keimbläseluen (dem Kerne der primitiven Eizelle) zu verfolgen. Um den Kern jeder Dotterkugel sammelt sich immer eine 
dichtere Masse ron Dottersubstanz, die ihn wie ein Hof umgibt, und bei durchfallendem Lichte durch ihre brïunliche Fïrbung sich auszeichnet. Das Endresultat der Dottertheilung ist cin runder Embryo, der bald eifümig wird und lange Wimpern hervorsprossend infusorienartig umlerschwimnt (Fig. 15). Die Larve misst 0,1"' Läinge und $0,08^{\prime \prime \prime}$ in der Breite, ihre mittlere Partie ist dunkler wie bei der Larre. die aus dem Eic der Lizzia hervorging. Nach einem 5-8 Tage andauemden Schwärmestadium (unter Umständen verlängert sich dieses auch auf einige Wochen), während dessen sich weder die Form noch der Bau der Larve verändert hat, sinkt sic endlich zu Boden, verliert ihre Cilien und heftet sich an beliebiger Stelle fest, $u$ bald daranf sich eine homogene Hornbille anzubilden. Sic wächst num in gleicher Weise, wie bei Lizzia angegeben ward, in die Höhe und bildet einen Polypenkürper, dessen nähere Beschafienheit nir wegen der für genauere Beobachtung ungüustig gcwählten Ansatzstellen leider entğangen ist. Lines dieser jungen Polỵarien erhielt ich melırere Wochen hindurch, während weleher Zeit es mehrere zur Teräștlung sich anschickende Stolonen bildete (Figur 16), so dass der festsitzende Theil des Polypenstockes eine Lä1nge von $0,54^{\prime \prime \prime}$ erreichte, während die Dicke der Röhre sich auf $0,04^{\prime \prime \prime}$ belicf.

Beide Untersuchungen, sowohl jene von Lizzia, als die ron Oceania, wurden stets mit der grösstmöglichen Vorsicht rorgenommen, so das irgend cine Verwechslung mit etwa in die Gefïsse gelangten anderweitigen Polypenlarven nicht im geringsten stattfinden konnte, zudem wurde die Entwicklung der Lizziaeier in mehrmaliger Aufeinanderfolge studirt und immer dasselbe Resultat erhalten.

Halten wir num die Entwicklungsgeschichte der Eier der drei bis jetzt hieranf erforschten Medusen vergleichsweise gegen einander, so haben wir in ihr die grösste Uebereinstimmung vorliegen, und bei allen dreien, Cladonema, Lizzia und Oceania, findet die Bildung einer schwärmenden Larve*) statt, die sich zu einem festsitzenden Polypen entwickelt. Es dürfte hicdurch wohl für die ganze Gruppe der Oceaniden der Generationsweehsel

-) Ob diese schwärmenden Larven sich dureh Sprossenbildung oder gar durch Theilung vermehren, wie wenigstens ersteres nach den Beobachtangen ron Busch ron der polypenförmigen Larve höherer Medusun bekannt ist, muss rorderhand noch dahin gestellt bleiben. Krohn und ich baben nichts dergleichen beobachtet, und es dürfte überhaunt unwahrscheinliels sein, da die Vermelırung durch "Sprossenbildung bei der Larve der höheren Medusen jeuer analog ist, die bei den Ammenpolypen durch Stolonenbildung zu Stande kommt. 
-erwiesen sein, wic ihn Steenstrup aufstellte, dass nämlich durch Umwandlung der geschlechtlich entstandenen Brut einer aus Ammenzengung hervorgegangenen Generation in eben diese Ammenstöcke ein Cyclus stattfinde, der sich in folgende Formel zusammenfassen lässt:

Meduse, infusorienfürmige Larve, Polypenstock, Meduse...

Die erste, oder Ammengeneration, wird durch die Polypen dargestellt, die zweite anfgeammte Generation sind die Medusen, welche geschlechtliche, zu selbstständigem Leben sich entwickelnde Wesen sind, und durch geschlechtliche Zeugung wieder die erste Generation hervorrufen; diess ist kurz zusammengefasst dasjenige, wasich hieriiber in Vorstehendem theils durch fremde, theils durch eigene Untersuchung factisch bewiesen zı liaben glaube. Andere, wie Steenstrup und dann Leuckart, sind mir hierin theilweise durch die Hypothese vorausgegangen.

IV. Geschlechtsorgane der Polypen.

Die meiste Verwirung, welche längere Zeit in der Anschaunngsweise der Fortpflanzungsorgane der Polypen geherrscht hat, schuldet wohl zum grössten Theile die leicht erklärliche Verwechshung dieser Theile mit den knospenden Medusen, sowie die häufig vorgekommene Identifzirung der Medusenbrutkapseln (wie bei Campanularia z. B.) mit den oft ganz ähnlich gestalteten Gesehlechtskapseln. Ich habe schon vonvorne herein desshalb die Medusensprö̈sslinge von den in ähnlicher Weise hervorknospenden Geschlechtsorganen der Polypen geschieden und sie einer besonderen Betrachtung unterworfen, was um so leichter thunlich war, als, mit Ausnahme von Podocoryna carnea, von keinem lolypen Geschlechtsorgane bekannt sind, von dem wir Medusengemmen kennen.

Geschlechtsorgane und Medusengemmen sind zwei sich ausschliessende Verhältnisse, die ebendesshalb, wie ich wenigstens dafiirhalte, für die Auffassung der Fortphanzungsweise der Polypen von der grössten Wichtigkeit sind. Als eine fernere Ausnahme hievon kömste man vielleicht die Campanularia geniculata auflühren, von welcher V an Beneden *) Medusensprossen beobachtete, wälirend Lovén ${ }^{*}$ ) die weiblichen und damn später

*) Sur les Campanulaires. Pl. III. Fig. 1.

**) Wiegmann's Archiv, 1837. S. 322. Taf. VI. 
M. Schaltze*) die männlichen Generationsorgane auffand. Offenbar liegt aber hier eine Artverwechslnng vor, wie sich nach einer genauen Vergleichung der von den betreffenden Autoren gelicferten Beschreibumg und Abbildungen herausstellt. Die Campanularia geniculata Van Benede n's ist durch reichlichere Verästelnng, sowie durch das Vorkommen der Medusenbrutkapseln an verschiedenen Stellen des Polyjenstockes ansgezeichnet und ron der Campanularia geniculata ron Lovén und M. Sehultze verschieden. Diese besitzt nämlich einen einfachen mit zwei Reilien von Aesten besetzten Stamm, und ilure Geschleclutskapseln sitzen genan und eonstant in den Astwinkehn. Auch bei iilteren Autoren scheint dieselbe Verwechslung statt gefunden zu haben, und Ellis *) beschreibt und zeiclınet genau die Campanularia, die später Lovén und M. S e hul tze untersuchten, indess Tan Beneden in Carolini ****) scinen Torgänger fand; die Identitït der Cavolini'schen und Van Beneden'schen Campanularia geniculata wird noch durch die Medusen liergestellt, welche die beiden letzteren bei diesen Polypen beobachteten. In der Abbildung des Cavolini auf Taf. VIIL. Fig. 4 ist dieselbe Meduse erkenibar, die $\mathrm{V}$ an $\mathrm{B}$ en e den in seinem Mémoire sur les campanulaires auf Pl. III. Fig. 4, 5 gezeichnet hat. Das hicher gehörige Verhilitniss von Pod oc o r y u c a rn e a wird weiter unten in Bezug auf Erklärungsversuche besprochen werden.

Ausser diesem Falle ist mir keiner bekannt, wo Geschlechtsorgane und Medusengemmen an derselben Polypenart getrofien worden wären. †)

Die Geschlechtsorgane sind beiden Polypen constant auf verschiedene Stöcke vertheilt, so dass die cinen immer nur männliche, die andern nur weibliche Organe herrorbringen. Darin stimmen alle' neueren Beobaehter miteinander iberein; und anchschon Ca volini gibtan, dass er die versehiedenen Arten der Geschlechtsorgane (des Eudendrium ramosum, wo er

-) Miiller's Archiv, 1850. pag. 53.

*) Naturgeschichte der Corall-Arten; übersetzt ron krünitz. 1767. Taf. XII. Fig. 19.

*.*) Ueber die Pflanzenthicre des Mittelweeres; übersetzt ron Spreugel, 1813. Taf, VIII. Fig. $1-4$.

+) Eine genane und gewisscnhafte Artmnterscheidung ist hier eiu dringendes Bedürfniss, und es macht sich immer mehr füllbar, wie sehr dicser Theil der systematischen Zoologie noch im Argen liegt. Die älteren Werke, wie jenes des trefflichen Cavolini, sind nur zur Bestimmung jener Polypengesehleehter, die nur wenige Arten enthalten, von Nutzen, für die arteureichen Gattungen der Corynen, Campanularien, Sertularien und Tubularien ist uur eine zerstreute, ans den rerschiedensten Zeiten stammende Specialliteratur vorhanden, in der nur selten einer differentiellen Diagnostik Rechuung getragen wird. 
mämliche und weibliche Organe fuir verschiedene $\Delta$ rten von Eiern hielt) nie auf einem Polypenstócke beisammen fand. *)

Beginnen wir die nähere Untersuchung der Generationsorgane mit den einfachsten Formen derselben, so finden wir diese vorziiglich bei den Hydractinien und Corynen, wo sie ms R. Wagner **) bei Coryne vulgaris,

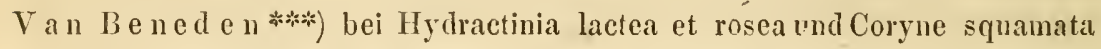
beschrieb. Das Organ tritt hier immer am Umfange des keulenförmigen Polypenleibes (Capitulum der Autoren) auf, meist nahe an den untersten Tentakeln, und stellt sich anfünglich als eine warzenartige Wucherung des Körperparenchyms dar, gegen welche die Leibeshöhle (Nahrungscanal) des Polypen hier auswïchst, ohne sich gerade weiter in das Parenchym der entstandenen Warze zu erstrecken. Durch listiologische Differenzirung: des Gewebes entstchen nun Zellengebilde, die sich rom übrigen Gewebe bald abgränzen und entweder in Eier oder in Samenelemente rerwandeln. Die Anzahl der in einer solchen Kapsel sich bildenden Eier ist selır verschieden, und scheint ron der Gattung und der Art abhängig zu sein, so dass während Coryne squanata in 'jedem Saickchen nur ein einziges Ei bildet, bei Hydractinia rosea eine grössere, bis zu 9 sich erhebende Anzahl entsteht.

Eine andere, etwas weiter entwickelte Form finden wir bei Tubularia coronata und Eudendrium racemosum repräsentirt. Bei Tubularia entstehen nach Van Beneden auf verästelten, zwischen dem änssern und innern Tentakelkranze hervorgesprossten Stielen kolbige oder ovale Körper der vorigen Art. Durch die Stiele zieht eine mit dem allgemeinen Leibescanale zusammenhäıgende Höhlung. Zwischen den Wandungen dieses in Mitte der Kapsel blind endenden Canals und dem äusseren Ueberzuge der Kapseln entstehen num die Geschlechtsproducte. Van Beneden sah nur Eier, und zwar in jeder Krapsel stets ein eimziges. An der Spitze der Kapsel bemerkt man melirere $(2-4)$ papillenartige Erhabenheiten, die mit unentwickelten Tentakeln sich vergleichen lassen.

*) Line Ausnahme hievon maeht unser Sulsswasserpolyp, indem bei diesem Hoden und Eierstöcke an Einem Individuum entstelıen, wie uns E h renberg's (A ohandluugen der Rerliner Akademie, 1836) und besonders v. Si ebold's (Handbuch dervergleichenden Anatomic) Untersuchungen kenuen lehrten. Es ist aber ïberhaupt noch eine Frage, ob Hydra seinen meerbewohnenden Ferwandten so nahe steht, als diesbisher fast allgemeis $\theta$ Aunahme ist.

") Prodromus historiae generationis. pag. 5.

*.*) Mémoire sur l'embryologie des Tubulaires. 
Was Eudendrium racemosum betrift, so zeigen sich männliche und weibliche Organe mit geringen Modificationen nach demselben Modus eniwickelt. Die weiblichen Organe sitzen als lilïschen an deu Enden von Stielen und stellen kleine Träubchen dar, wie sie Ca rolini schon kanne. Die mïnnlichen Organe schliessen sich einigermasscn an die vorhin bei Tubularia angefïhrten an, nur durehsetzt der ans dem Sticl kommende Achsencanal die Kapsel vollstündig. und die samenbildenden Elementartheile entwickelten sich rings um diese Achse. Tnterhalb der erstentstandenen Kapsel entsteht am Stiele eine zweite, hinter dieser eine dritte u. s. W. bis sich 4-5 soleher Kapsehn finden, die alle ron einem gremeinsamen Stiele getragen mu ron dessen hohler Achse dureliselzt werden. Mehre dieser perlschurartig aneinander gereihtc Kapschn trugenden Stiele stehen in Dolden beisammen. Immer die Tordersten, also die Erstentsłandenen, reifen zuerst, entlecren ihren Samen mid schwinden. So sah es auch Krohn*), der zuerst diese Organe genaner beschricben hat.

Ein Fall, wo namentlich das Terhältniss der Achse zur Kansel besonders klar erscheint, ist bei Tubularia beobachtet, es ist wohl diesellue, die anch Van beneden mutersncht, und das Betreffende darüber bereits mitgetheilt hat***: Ich halte sie der Tubularia indicisa nahestchend. Mïnliche nud weibliche Organe sitzen auf rersehiedene Stijcke vertheit auf verïstelten zwischen dem :̈usseren ind inneren Tentalielkranze der cinzelnen Polypenköpfehen hervorsprossenden Sticlen. Die nü̈nlichen Orone sind weniger entwickelt, und stellen rüthliche runde Bläschen dar (Taf. II. Fig. 10), deren Durchmesser etwa $0,8^{\prime \prime \prime}$ betrïgt. In ihrem Imern zẹgen diese Kapseln den etwas batichig erweiterten, röthlich gofeärbten Fortsaiz (Fig. 10 c.) des Achsencanals des Sticles (b), der vorne nach der Oberfläche der Kapsel zu blind geschlossen endet. Zu änsserst wird die Kaysel ron einer in die Corticalsubstanz des Stieles iibergehenden Kibile (s.Fig. iv) überkleidet, worauf dam die ron ihr histologisch differenzinte Saamen bereitende Parenchymschichte folgt (Fig. 10 d), welche direct den hollen Centralkolben iunlagert.

Die weiblichen Organe sind den männlichen ganz anslog gebildęt (Fig. 11) und bestehen aus eben so grossen Kapschn, dic im unentwickelten Zustande mit den jungen Samenkapsehn rüllig übereinstimmen. Spätcr hebt sich die äussere Sehichte (lig. 11 d.) von der sic durchsetzenden

") Müller's Archiv, 1S43. pag. 180.

") Zeitschrift für Zoologie. Bd. IY. pag. 300. 
Achse etwas ab, und vorne an der Kapsel erscheinen $4-5$ meist im Kreise stehende Knüpfchen, welche den Anlagen von Medusen-Randfïden nicht unähnlich sind. Die im Centrum hohle Achse (c.) der Kapsel ist von cinem keimbereitenden Parenchyme nmlagert. Einzelne der Zellen entwickeln sich und werden zu Fiem, welehe dann verschieden grosse ins Lumen der Kapsel ragende Vorsprünge bilden; die reifen Eier lüsen sich später aus ihrer Umbüllung und gerathen frei in lie Kapschöhle, wo sie befrnchtet werden und damn ihre Weiterentwicklung durchmachen. Der Unterschied dieser weiblichen Organe ron den m:ännlichen liegt daher rorziglich in dem sich Abheben der Kapselhülle vom keimbereitenden Parenchyme, so dass dadurch rings nm das letztere ein ffohlraum entsteht, in welchen die abgelösten Eier befruchtet werden und sich fortentwickeln; die Befruchtung selhst, oder viehmehr der Zutritt der Samenfiiden wird durch eine gleichzeitig zwischen den tentakelartigen Vï̈rchen entstardene Oeffuung möglich gemacht. Während die mit dem Kapselstiele in Verbindung stehende Achse der Trapseln schon bei den mänulichen Organen durch ihre banchige Erweiterung, sowie durch illr weiteres Vordringen in die Kapsel selbst eine höhere Entwicklungsstufe cinnimmt, als wir es rorhin bei Hydractinia und Coryna sahen, so ist sie bei den weiblichen Organen noch weiter entrickelt, sie ist frei, nur rom kembereitenden Parenchyme umgeben, und sogar beweglich geworden. Namentlich gibt sich letzteres am vorderen Theile derselben zu erkemen. Bis zu ihrem vorderen blindgeschlossenen Ende ist sie hohl, communicirt mit dem Centralkanale des Kapselstieles, und dureh diesen auch mit dem Nahrungskanale des Polypen selbst, sowie auch in ihr wie in jenen Kanïlen eine an Molecülen reiche Flüssigkeit bestuindig umhergewirbelt wird.

Bisher haben wir mur Kapseln gesehen, die von einer hohlen Aclise durchzogen, entweder einfache, geschlossene Blasen vorstellten, oder vorne nuch mit einer von Tentakelrudimenten nmstellten Oeffnung versehen waren; immer bildete die lohle Achse eine directe Fortsetzung des Leibeskanals des Polypen. Eine andere, wie mir scheint bis jetzt noch unbeLamnte Form von Geschlechtsorganen ist jene, wo der hohle Fortsatz des Leibescanals des Polypenstockes sich nach seinem Eintritte in die Geschiechtskapsel in mehrere Aeste theilt. :)

") Einer mündlichen Mittheilung von Herrn Prof. Kölliker zufolge wurde diese Organisation auch von ihm nenerdiugs bei einer Syncoryne an der Küste ron Ostende beobachtet. 
In dem einen Falle bei einer der Campanularia geniêulata V an Benedenss nahe stehenden Art*) (Tuf. I. Fig. 5) finden sich in den Astwinkeh $\frac{1}{2}$ "' lange, fast spindelfurmig gebildete Kapseln, dic wie die Nedusenbrutkapseln der übrigen Campanularien ron der homigen Hülle des Polypenstocks iberzogen werden. Die Oberfäche der Kapseln ist glatt, wiebeider Campanularia geniculata V a n B en ed en's, und ihre Achse ist wierier ron eimem rerkimmerten Polypenleibe gebildet, der bei jüngeren Geschlechtskapseln in seiner vollkommenen Integritü erscheint. Erst mit dem Treiterwachsen der Kapsel renkitimmert der in ihr befindliche Polypenleib, rerschliesst die Kapselmiindung, und bildet an sich die Generationsorgane, deren Weiterentwicklung den ursprïnglichen Folypenleib ganz absorbirt, bis sie endlich die Tapsel melı orler weniger ausfiillen (Vergl. Fig. 5 c. und Fig. 6). Gehen wir anf lie Bildung der Geschlechtsorgane ein, so sehen wir dise an dem spüter der Terkimmerung anhein fallenden Polypenleibe in glcicher Treise anftreten, wie an Iem Capitulum gewisser Corynen, Syncorynen und Ifdractinen (siehe dariber weitsp oben). Es bildet sich zuerst eine Herrorstiilpung des Leibes, in welche der Achseneanal, (der der Nagenhöhle des verkimmerten Polypen entspricht) hineinwïchst. So entstehen nun Bläschen, wie sie in Fig. T A. B. dargestcllt sind. Der Centralkanal jedes dieser Blikecluen (Fig. T A. B. a.) wächst num in zwei oder vier l"ortsuitze aus (Fig. 7 C. a.), die das Parenchym des Bliischens durchzichen und nach kntzem Verlaufe blind enden; um sic herum entstehen die Samenzellen. Dic cinzelnen Blaischen werden zu samenbereitenden Organen; vitlig ausgebildet messen sie 0,0S-0,10\% ind mulagern dann dicht gedrängt den verkimmerten Tolypenleib. Thre Anzaln beträgt $8-15$. Dic entwickelten, reifes Sperma einschliessenden, finden sich im Tordertheile der gemeinsamen Kapsel, während die weniger entwickelten hinter diesen, melı im Grunde der

*) Diese Campanularia besitzt einen liriechenden, vielfach sich rerziweigenden Stamm, der häufig zwischen Eudendriumstëcken und Sertularien auf verschiedenen Fucus-Arten an Molo des Lazareths zu Messina sich, findet. Tnm Stamne erheben sich einzelue freie Aeste (Fig. 5) welche in regelnässiger Aufeinanderfolge seitliche kurze Zweige abgeben, die dann die Polypenleiber (Capitula) tragen. Diese selbst unterseheiden siels in nichts Besondereu von den Köpfehen der übrigen Campanularia-Arten. Die Becherchen, in denen sie stecken, sind ganzrandig (Fig. $5 \mathrm{~A}$ : ist eiues derselben ohne Polypen abgebildet), trichterförmig, ohne Ausbuchtuug. Sowohl an den Aesten, da wo Zweige abgehen, als am Anfange der letzteren und am Anfange der Pulypenbecherchen ist das Polypengehäuse queergeriugelt. 
Kapsel sich finden. In den vorderen Bläschen ist damn imner eine Theilung der in sie cintretenden Achse in zwei bis vier Zweige wahrzunehmen, welche besonder's bei ihrer röthlichen Färbung ein ähnliches Bild darboten, wie die, unentwickelten Medusengemmen in den Brutkapseln anderer Canıpanularia-Arten.

Alle vorgefundenen dieser Art zugehörigen Campanularienstöcke waren entweder steril oder sie trugen nur die vorbeschriebencn männlichen Geschlechtskapseln. Bei Betrachtung dieser 'Theile kann ich uicht unlin, auf die aufiallende Achnlichkeit aufmerksam zu machen, welche sie mit den analogen Kapseln der Campanularia geniculata Van Bene de n's besitzen. Es scheint, dass Van Beneden ähnliche Samenkapsehn vor sich hatte, die er aber wegen des in die einzeluen Bläschen derselben cintretenden Achsencanals für Eibehïiter erklïrte. *) Allerdings hat der in vier Zweige sich theilende undurchsichtige Canal ron der Fläche betrachtot einige Achnlichheit mit einem sich gerade furchenden Lie, da ich aber Tan Beneden's Campanularia geniculata nicht aus eigener Anschauung kenne, so bleibt das eben Bemerkte nur cine Vermuthung.

Eine zweite Art ron solchen mit Canälen durchzosene: Ceschlechtsorganen beobachtete ich bei ciner bis jetzt gleichfalis r oc'r unbeschriebenen Campanularia, die sich häuffg mit jener Medusengeneration, welche weiter oben beschrieben wurde, zusammenfand. Der Stamm dieser Art ist kriechend, ron Stelle zu Stelle erhebt sich ein einfacher polypentragender Zweig (Taf. I. Fig. 8 b.) der schwach geringelt mit einer becherförmigen Polypenkapsel (Fig. 8 c.) endet. Das Becherchen ist schwach gewöibt und am Rande mit 12-14 tief gehenden Zähnelungen versehen (Fig. 8 A. a.). Der Polypenleib selbst kommt mit denen anderer Campamlarien uiberein. Zwischen diesen Folypenstengehn sitzen nun länglich ovale, cirea $\frac{1}{2} " \prime \prime$ lange Kapseln mit kurzem Sticle dem Stamme auf. Die Oberfäche der Kapsel ist mit $6-7$ flachen Quecrringeln versehen. In Grösse und ïusserer Gestalt entsprechen sic somit jenen, die oben als Brutkapseln von Medusen beschrieben wurden. Eine genanere Untersnchung des Inhaltes ergibt aber ein anderes Resultat. Es zeigt sich nïmliclı in der Kapsel cin länglich-ovaler Körper, der ziemlich genau ihre iussere Form nachahmt, durch den Stiel in den Polypenstamm iibergeht, und sich an dem abgestumpften Vorderenle der Kapsel mit dunkelkörniger Zellmasse verbreitet. Die äussere Parthic dieses ron der Hornkapsel

") Mém. sur les campan. Pl. III. Fig. 3. 
eingeschlossenen Körpers steht von letzterer durch einen verschieden starken Zwischeuraum ab, der ron zahIreichen kürzeren ocier längeren Verbindungsstrïngen durchsetzt wird. Vorne in der Kapsel geht diese Corticalsubstanz in die Zellenmasse uiber, welche den Verschluss der Kapsel bildet, nach hinten lässt sie sich in den Sticl rerfolgen, und setzt sich durch diesen in die iaissere Schichte des Polypenstammes fort. Innerhalb des Sticles verläuft eine Fortsetzung des Nahrungscanals rom Polypenstamme; diese tritt in die Geschlechtskapsel ein und theilt sich in fünf Zweige, von denen der eine, stärkere, in der Achse der Kapsel fortverlauft, und vorne blind endigt, wïhrend die übrigen vier sich zu der vorhin heregten Corticalschichte begeben und in regelmäissigen Abstïnden von einander gerade nach vorne verlaufen, um etwa in gleicher Höhe mit dem Centralcanale der Kapsel gleichfalls geschlossen zu enden (Fig. 8 li).

Innerhalb dieser rou vier Längscanälen durchzogenen Corticalschichte und in, seiner Längsachse von der directen Fortsctzung des Stieleanales durchzogen findet sich der samenbereitende Theil des Organs, der je nach seiner melı oler minder vorgeschrittenen Entwicklung bald nur Saamenzellen enthält, bald dichte Massen entwickelter Saamenfäden einschliesst. Die Saamenfüden selbst schliessen sich in Form und Grösse an die schon bekannten anderer Polypenthiere an; sie bestehen aus rundlichen Köpfehen mit cinem feinen, laaäälmlichen Anhange, dessen Ende nur schwer zu erkennen ist.

Noch ist in Betrefi der vier gefässartigen C'ankile anzuführen, dass sie nicht immer gerade nach vorn rerlaufen; lüufig sieht man an ihmen scitliche Ausbuchtungen, und nicht selten auch Verïstlungen derselben, die sich dann - immer in der Corticalsubstanz verlaufend - bis zum nächstliegenden Längseanal erstrecken künnen, und dann mít demselben oder einem Zweige von ilım anastomosiren. Auf diese Art entsteht dam um den saamenbereitenden Kern der Kapseì cin oỉt reich entwickeltes Canahnetz (Fig. 9), welches bei der rïthlichen Fïrbung sciner Wandungen sogleich in die Augen fällt, und für die Ernährung des Generationsorgan wohl sicher rou grosser Bedentung ist. Wie in allen Ausstiilpungen und Fortsïtzen des Nahrungscanals des Polypenstocks, fehlt anch hier die Flimmerung nicht, und wenn es mir auch nicht glïcken wollte, die Cilien selbst dentlich zu erkenneu, so wird mir doch solches durch das rasche Umherwirbeln einer mit Molecülen und grösseren Kïrnchen reichlich geschwïngerten Flüssigkeit (wie diese auch im Nahrungseanale des Polypenstockes rorhanden ist fast zur Gewissheit. 
Treibliche Organe wurden an inserer Campanularia niemals ron mir beobachtet, obgleich ich riele Stöcke derselben, und zwar' zu sehr rersehiedenen Zeicen zur Untersuchung rornahm.

Es unterscheidet sich also dieses Organ wesentlich ron dem weiter oben beschriebenen, und zmar vorzüglich dadureh, dass hier die ganze Kapsel (ioh meine hier die änssere ron hornartiger Substanz gebildete) ron einem cinzigen Saamenorgane alsgefiiltt wird, während wir im rorigen Falle deren riele $(S-1 \tilde{y})$ in einer einzigen Kapsel eingeschlossen fanden. Die Wichtigkeit dieser Cnterschiede, die ich später genauer auseinandersetzen rerde, reranlasst mich, für die rerschiedenen Verhältnisse auch rerschiedene Bezeichnung zu wählen. Ich werde desshalb, um Verwechslungen rorzubeugen, die eine Art ron Geschlechts- oder Medusenbrutkapselu, wo sich die Producte in mehrfacher Zahl bilden, als polymere, jene, wo nur eines sich bildet, als monomere Kiapseln bezeichnen.

Ich liabe frïher erwïhnt, dass diese Kạpelin, mögen in ihnen Medusen sich bilden oder einfache Geschlechtsknospen entstehen, als die Analoga ron Polypenkürpern zu betrachien sind, dass sie nämlich in gleicher Weise wie letztcre sich entrickeln und anch anfüinglich einen polypenförmigen Fürper einschlicsen, der erst mit dem Auftreten ron Medusensprossen oler Gezchlechtsgemmen zu rerkïmmern beginnt. Küllikem) hat, wie ebenfalls schon crwähnt wurde, dies füi letztern Fall nachgerriesen. Eine Kapsel mit Hiedusensprossen oder mit mehreren secundüren Geschlechtsgemmen, wie wij dies im ersten, Campanularia Jetreffenden Falle sahen, ist somit morphologisch gleich mit den medusensprossenden, suwie mit den geschlechtlichen Individuen ron Coryna, Syncoryna, Hyảractinia u. s. m. In beiden Fiillen lıaben wir einen wit den iibrigen (sterilen) Indiriduen gleichartigen Polypenleib (Capitulum), an dessen Oberfläche die Splossung ihren Sitz diat, und der in beiden einander gegenïberstehenden Fällen eine mehr oder weniger augenfillige Rïickbildung $* * *$, deren (irad hier wohl nichts zu be-

,) 1. cit. på. $30 \mathrm{i}$.

*) Eine sulche morphologische und phrsiologische Alteration der Polypenleiber findet auch bei rein pathologischen Vorgängen statt; =o fand ich die Capitula des Eudendrium ramoscm sehr bäufig durch einen Parasiten in älnnlicher Weise rerändert, wie wir es bei proliferirenden Coryneen sehen. Der Parasit war Pyonogou $\mathrm{mm}$, das seine Lier in ten Polypenleib gelegt hatte, die dann darin die Furchung durchmachten, und sich weiter entwickelten. So liesseri sich oft in eirigen Yulypen alle Entwicklungszustände dieses Thieres überschaneu. Der l'olypenleib war dabei iberwässig rergróssert, seine T'entakeln eingeschrumpit und aur als kurze, onregelnuäsig stehende Stummel vorhanden, die rera autnde Hohle eutweder geschmunden, oder mit Pycnogonum-Brut angefüllt. 
deuten haben kann, erklïrt, mag er nun nur Medusen aufammen oder Geschlechtsorgane herrorbringen. Weniger anfäillig ist diese Riickbildung des proliferireuden Polypenkörpers bei den Coryneen, wo sich häufig noch die ganzen Tentakeln, oder pelottenartige Tentakelrudimente, fast immer aber noch die Mundüffnnng erliält, so dass das betreffende Indiriduum nicht einseitig zur Fortplanzung dient, sondern auch noch für die Ernährung der Colonie, wenn auch im minderen Grade mitzuwirken fähig ist. Bedeutender ist die läükbildung oder Verkiimmerung bei den proliferirenden Individuen der Campanularien, wo schon sehr frühe die Bestimmung der Amme, oder des geschlechtlichen Individuums sich durch den Ausschluss ron der Theiluahme an der Ernähüung der Colonie zu erkennen gibt. Diese Indiriduen besitzen dann weder Tentakeln noch Mundöflnung, und ihr Leib reducirt sich oft zu einen dünneu, die Hornkapsel durchziehenden Strang. Zuwcilen sondert die die Kapselöffinang rerschliessende Zellmasse noch eine Hornschichte nach aussen ab, und bewirkt so einen rollkommenen Ver:chlus:

Foch sind hier die Grösscnunterschiede herrorzuheben, die zwischeu den proliferirenden (seien die Producte dieser KKnospung Geschlechtsorgane oder Medusen) und den sterilen Individuen vorkommen, und die darin bestehen, dass erstere bei aller organologischen Beschränkung in Bezug auf Umfang sich oft ror den übrigen auszeichnen: dies ist besonders bei Syncorsneen der Fall. Weniger kömnen die Brut- und Geschlechtskapseln der Campanularien hier angezogen werden, da es nicht ein einzelner Polypenleib ist, der sie ausfüllt, sondern vorziiglich die an dem rerkümmerten Polypenleibe entstandenen Geschlechtskapselu oder Medusengemmen.

Was vielleicht die Analogie der Form zwischen den polymeren Geschlechtskapseln der Campanularieu und den seschlechtlichen Corrneenpolrpen stören möehte, ist die hornige Hülle. welche erstere überzieht und oft noch durch besondere Querringelung ausgezeichnet ist. Es erklïrt sich das Vorkummen dieser Hornkapsel einfach aus dem typischen Character les Campanularien-Geschlechts, rermöge dessen sich um Alles, was au diesen Polypenstöcken sprosset und knospet, seien es sterile Polypenleiver, oder ammende, oder geschlechtliche. sich mit einer Hornschichte überzieht, die da, wo den Sprossen eine andere Bedeutung inneliegt, auch eine besondere von den Becherchen der sterilen Individuen rerschiedene Furm amnehmen kann.

Diese Analogie kann nur für jene Fälle Geltung heben, wo polymere Kapseln rorliegen, das ist. Wo die Sprossung von Medusen nder Geschlechtsorganen an riichgebildeten Polypen entsteht; bei den monomeren Gesclilechtskapscln, wie im letzterwälnte1s Fall eine Forn daron betrachtet wurde, 
stéllt die ganze Kapsel ein einziges Geschlechtsorgan vor, das sich somit nicht erst an einem Polypenleibe bildet, sondern direct vom Stamme des Folypenstockes seine Entstehnng nimmt. Es fragt sich also nur, sind die Kapsehn urspringlich Polypenthiere, die sich behufs der Fortpflanzung umgewandelt haben, sind sie Analoga von Polypen, oder sind sie Analoga der einfachen Geschlechtsorgane, wie wir sie zu mehreren in den desshalb polymer genannten Geschlechtshapseln entstehen sahen? Eine dritte Möglichkeit scheint mir nnter den gegebenen Verhältnissen nicht wohl annehmbar. Die erste Frage glaube ich vemeinen zu muissen, und zwar desshalb, weil wir cinestheils nirgends ein Beispiel nachweisen kümen, dass sich irgend ein l'olypenthier direct in cin Generationsorgan umwandle, vielmehr sind es eben die P'olypenleiber, dic wir zwar in etwas alterirtem Zustande als dic Stätte der geschlechtlichen Knospenbilelung beobachten (Syncoryna, Coryna, Podocoryna, Hydractiniti, Tubularia, Campanularia ex parte). Anderntheils liegt weder beim Begine der Bilung des Organs, noch auch später ein Theil vor, der sich auf einen Polypenkörper zurickführen liesse, wir sehen dic Entstelung vielmehr ganz in der Weise cines Geschlechtsorgans, und zwar eines höher organisirten, vor sich gehen, und auch im ausgebildeten Zustinde stimmt der Bau mit den der höher organisirten Geschlechtsorgane rollkommen iiberein. Sowolil auf dem Wege der Exclusion als auch durch Vergleichnng kommen wir zu dem Schlusse, dass dic monomeren Geschlechtsorgane jedem einzehen in einer polymeren Kapsel enthaltenen Organe anolog seien. Der Sitz dieses monomeren Organ am Polypenstocke selbst mil nicht ndch Art der iibrigen Geschlechtsorgane, an cinem Polyjenleibe, beweist nichts weiter gegen die von mir angestellte Verglcichung, als dass eben diese letztere Localität nicht die allein normale tiir lie Entsehung der Geschlechtsorgane ist, dass vielmehr Geschlechtsorgane ebensogut an irgend einen Theile des Stammes, entfernt ron cinem Polypenleibe sich bilden kömen, als sie an den Polypenleibern selbst entstehen. Dasselbe Verhalten haben wir bereits auch von Medusensprossen kemen gelernt, die nicht an der sonst gewöhnlichen Loealitï (dem Polypenleibe) sich bilden, sondem direct dem Stamme des Polypenstockes entspringen (Perigonymus muscoides, Syncoryna Cleodorae).

Es bleibt mir noch die Pretrachtung Giner andern'Form von GeschlechtsOrganen, die sich an die bisher exwhnten eng anschliesst, aber doch durch ihre hibhere Organisationsstuf? wieder graduell unterscheidet. Ich meine jese Organe der Campanularia geniculata, die schon Ellis *) kannte, 
und deren genauere Beschreibung wir Lovén*) für die weiblichen, M. Schultze $\left.{ }^{* *}\right)$ fïr die männlichen zu danken liaber. Auch ihrer Entstehung liegt die Rückbildung oder Verkïmmerung eines Polypenleibes zu Grunde, wie aus Lovén's Beobachtungen hervorzugehen scheint. An diescm die gemeinschafliche Kapscl durchziehenden und dieselbe vorne verschliessenden Polypeukörper sprossen nun der Reihe nach von unten nach oben einzelne secundäre Kapseln hervor, die sich völlig wieMedusengemmen verhalten, wenn man davon absieht, dass in ihnen die Bildung eines centralen Zapfens, der bei den wirklichen Medusengemmen zum Magen wird, nicht zu Stande kömmt, dagegen entwickeln sich, wenigstens bei den weiblichen Theilen vier rom hohlen Stiele des Organs entspringende Gefässcanäle, die sich vome an den mit Tentakeln versehenen Rande in einen Ringeanal zu vereinen scheinen. Je weiter diese secundären Kapseln in der Entwicklung vorschreiten, um so mehr rïcken sie nach oben gegen den Eingang der sie umschliessenden gemeinsamen Hornkapsel, durehbrechen endlich die Decke derselben, um, mit einem kurzen hohlen Sticle mit dem Polypenrudimente noch immer in Verbindung stehend, sonst völlig frei nach aussen zu ragen. Schon mit dem ersten Auftreten dieser Organe an der Seite der verkiimmerten Polypen bilden sich in ihrem Inneren Eies oder Samenfäden aus; die Eier entstehen zu zweien in einer Kapsel und scheinen erst dann ihre Entwicklung einzugehen, wenn die betreffende Kapsel nach aussen getreten ist, weil crst damn eine Einwirkung des männlichen Zeugungsstoffes ermöglicht zu sein scheint. Je mehr die Bildung der Embryonen vor sich geht, um so anfallender wird die Riickbildung des sie umschliessenden medasenförmigen Organes, so dass die Tentakeln derselben beim Austritte des Embryo dureh eine zwischen ihnen entstandene Oefinnung nur noch als kurze Stummeln sich darstellen. Bald darauf schrumpft auch die Kapsel und geht, ohne dass sie sich lostrennt, zu Grunde. Der Bildungsgang der mämulichen Organe geht ziemlich in derselben Weise vor sich, wie es nach Lorén's Beobachtungen von den weiblichen angegeben ward. Statt der Eier im Innern der medusentürmigen Kapseh entstehen Samenzellen, aus denen sich eigenthümlich geformte Samenelemente entwickeln.

Wichtig füi die Bedentung der als Geschlechtsorgane betrachteten, scheinbar selır mannigfaltig gestalteten Theile ist die Entwicklung der in 
ihnen entstandenen Eigebilde. Schon ältere Forscher sahen aus ihnen Polypen hervorgehen, so z. B. Cavolin i*) bei Eudendrium racemosum. Am genauesten aber wurde die Entwicklung des Eies, oder viclmchr die Umwandlung des infusorienfürmigen Embryos bei Campanularia geniculata von Lovén erforseht, und die Anheftung desselven nach einem vorausgegangen Schwärmestadiım, die Tmkleidung mit einer starren, hornälınlichen Ilülle und das Hervorprossen eines Polypen ausfübrlich beschrieben. Die Entwickinng cines in den medusenfïrmigen Geschlechtsorganen der Polypen gebildeten Eies gelit also genan nach denselben Normen vor sich, wie Krohn es bei den Niern der Neduse des Stauridium (Cladonema) und ich es bei Lizzia Koellikeri und Oceania armata fand, ein Umstand, der weiter unten noch naiher gewürdigt werden soll. Auch bei Tubularia geht die Entwicklung des Eies in ïhnlicher Weise vor sich, wie wir theils durch die von $V$ an Beneden und.M um ery ${ }^{*}$ ) beschriebenen Thatsachen, theils durch Kölliker's neucste Untersuehungen hieriiber wissen. Das Ei eines Polypen wandelt sich wieder in eimen Polypen um; nur fehlt bei Tubularia die Zuvischenstufe der infusorienförmigen Larvenform, denn das Ei entwickelt sich innerhalb der meitusenförmigen Geschlechtskapsel zu einem Polypen, de: bei seiner Gebrirt schon ziemlich die Form des erwachsenen Thieres angelegt hat; doch gibt es anch hier noch ein freies Larvenstadium, das uur in eine spätere Entwicklungsperiode fällt. Der Entwicklungsgang des Eies der Tubularien ist nach meinen Beobachtungen folgender: Nachdem die Eier von dem zapfenartig in die Höhle der Geschlechtskapsel ragenden Stiele sich abgelïst haben, formen sie sich nach vollendeter Furchung in einen rundlichen Embryo um (Taf. I. Fig. 12 A.), der sich hald linsenlürmig abflacht und an seiner Aequatorialzone 6-8 Fortsätze hervortreibt, was dern von der Fliiehe gesehenen Embryo die Gestalt eines Sechs-oder Achtecks verleint (Fig. 12 B.). Es wachsen jetzt diese Fortsitze noch weiter ans, und zeigen dentlich den Ban der späteren Tentakeln (e.) Nun entsteht auf beiden Fläichen des Embryo eine Hervorragung, von welcher die cine zu cinem rundlichen Knopfe anschwillt, während die andere bnckelartig hervorwäclsst. In Mitte der ersteren entsteht eine trichterfümige Definung, der Mund, der in eine innere, ziemlich gerïumige Höhle, den Magen, fülnt. In diesem Zustande werden die

") 1. cit. pag. 80. Taf. VI. Fig. 7.

") Quarterly Journal of microscopical Science. 1852. pag. 28. Die Beobacbiuugen sind an Tubularia indirisa angestellt. 
Embryonen aus dem Orarium entleert, und schwimmen mittels eines zweiten sie iiberkleidenden Wimperiberzuges umher. Die Tentakeln sind nun viel schlanker geworden und an ihrem Ende mit einem runden, dicht mit Nesselzellen besetzten Kn̈öpfehen versehen (Fig. 13). In den Wandungen der Magenhöhle wird nun anch eine röthliche Fä̈bung sichtbar, welche in kleinen, rundlichen, fein granulirten Zellen ihren Sitz hat; diese Zellen iiberkleiden die ganze rortretende Höhle und stehen wohl sicherlich zur Absonderung irgend eines Secretes in spezieller Bezichung. Wic lange dieses freie Larvenstadium anwährt, scheint von rerseliedenen Lmständen ablü̈ngig zu sein, denn an in Gläsern aufgezogenen Larven schwarkte die Daner zwischen 3 bis 10 Tagen. In der letzterenZeit senkten sie sich zu Boden und krochen dann mit ihren langen Tentakehn an den Clvenblätíern umher, bis sie sich endlich mit dem der Mundöfinung gerale entgegengesetzten Hinterleibsende irgendwo festsetzten. Der Körper des Thieres wurde dann urnenförmig, mit ziemlich roluminösem Bauche, und einem davon etwas abgeschnïrten Fusse. Ton der grössten P'eripherie des Leibes entsprangen die Tentakeln, welche jetzt eine grössere Beweglichleit erlangten, als dies bei der freien Larve der Fall war (Fig. 14). In einigen Tagen streckt sich der Körper mehr, und scheint so allmälig in lie Form des erwachsenen Thieres iiberzugehen. Die Bildung eines imern Tentakelkranzes um die Mundöflnung, sowie die Anlage einer Rölıre konnte ich bei den jungen'Tubularien niemals beobachten. Es scheint, dass ungüustige Nahrungsverhältnisse sie ron der Weiterentwicklunig abhielten.

Werfen wir nun einen Rïickblick auf die Darstellnng; der GenerationsOrgane, so sehen wir bei allen eine schwïeher oder stärker herortretende A ehnlichkeit mit den wirklichen Medusengemmen. Wir finden bei innen immer irgend eine Entwicklungsphase der Medusengemme reprïsentirt und sehen dam das Generationsorgan einseitig nach dieser Richtung hin sich fortentwickehn, ohne fernerhin eine grössere Aehnlichleit mit einer Meduse sich anzubilden, als eine ihm urspriinglich schon innewohnende, die je nach den verschiedenen Orten einen gewissen Höhepunct erreicht. Der Umsiand, dass nicht alle Charactere der Medusen sich gleichmässig in den Geschlechtsgemmen ansprïgen, sondern dass bald die Gefiisseanïle mangehn, bald die 'Tentakehı, bald wieder die Schirmhöhle fehıt, oder der Magen, dass in keinem Falle aber sich Randkörper bilden, dies Alles macht die Anschaung etwas schwierig; nichtsdestoweniger wird diese Schwierigkeit durch zahlieiche Uebergangsformen vülig wieder paralysirt und durch eben diese Uebergangsformen erlalten die Theile ilne Deutung; die wir ohne sie nicht wohl'wagen dürften. So fehlt den weiblichen 
Organen der Campanularia geniculata nu ein Magenrohr und das Lostrennen vom Polypen, um in ihuen vollstiindige Medusen zu erkennen oder den weiblicheı Urganen der von Källiker zuerst beschriebenen Tubularia ron Messina die Ausbildung đer Tentakeln, das Auftreten von Gefässcanälen, die Mundïfinung des wie ein Medusenmagen gestalteten Zapfens, sowie endlich wiederum das Abtrennen, un auch in ihnen wirkliche Medusen zu finden!

Bei all' dieser Aehnlichkeit in Fntwicklung und Form, in Sitz und Bedentung, wie wir sic zwischen Geschlechtsorganen uud Medusengemmon bestehen sehen, diurfen wir jedoch nicht vergessen, dass eine Gränze existirt, die scharf genug hier gezogen ist, um die Uebergänge der Formen nur bis zu cinem gewissen Grade zu verwerthen, ma eine völlige Vereinigung der Medusengemmen und Geschlechtsorgane als identische Theile zu verhindern. Als solche Gränzmarke besteht der Begrifin der selbständigen Individualität.

Wir können desshalb Geschlechtsorgane, sei ihre Medusenform noch so bestimmt ausgeprägt, wie bei manchen Campanularien und mehreren Tubularien, ebensowenig als wirkliche Medusen anffassen, als wir die freiwerdenden, sich fort entwickelnden, und selbstiindig fortpflanzenden Medusen zu blossen Geschlechtsorganen herabwiirdigen diirfen, wie diess z. B. $\mathrm{Huxley}$ *) that, der alle freien Medusen, die an Polypen aufgeammt wurden, nur für abgelüste Creschlecirtsorgane erklärte.

Wir umgehen diese Śchwierigkeiten, wemn wir die Geschlechtsorgane der Polypen von ihrer einfachsten Form an bis dahin, wo sie die vollcndetste Medusenähnlichkeit besitzen, für Analoga der Medusen erklären, für functionell gleichartig gestellte Gebilde, welchen beiden die Fortpflanzung auf geschlechtlichem Wege iibertragen ist. Eine nochmalige Darstellung der Gründe hiefür halte ich für unnöthig, da ich bereits bei Beschreibung der Geschlechtsorgane den einen oder morphologischen Theil der Beweisfïlirung nachzuweisen rersuchte, wïhrend dem physiologischen Theil derselben ebenfalls bereits in der Entwicklungsgeschichte des PolypenLies lechnung getragen ward.

Sind aber die Cieschlechtsorgane der Polypen analog mit den Medusengemmen, die wir bereitsals geschlechtliche und höher entwickelte zweite Generation der ammenten Polypenstöcke kennen lernten, so sind auch die bisher als Geschlechtsorgane bezeichmeten Theile die Analoga einer

") Philosophical Transactions. Part. II. for 1849. pag. 430. 
zweiten Generation; sie stellen eine zweite Creneration ver, die aber auf einer morphologisch niederen Entwicklnugsstufe rerharrt, indess sie functionell, in Beziehung auf die Polypen, dieselbe Bedeutung beanspruchen wie die freie Medusengeneration. Hienach wiire bei allen Hydraspolyn m ein Generationswechsel zu statniren, der bald in ansecebildetem Grade, bald nur in der Anlage - gleichsam rersuchsweise - zu Stande kommt. Dieses letzte Verhältniss müchte ich als ., unvollkommenen Generationsweehsel" bezeichnen, bekeme dabẹi aber wohl, dass auch hiemit noch nicht der ganze Umfang dieses Zustandes ausgedruickt ist.

Es hat den Anschein, als ob hier ein Uebergang zwischen Organ und Individum, zwischen einer oft sehr einfach organisirten Geschlechtskapsel und einem relativ hoch entwickelten geschlechtlichen Einzelwesen einer Meduse - stattfände, als ob somit hier Verhältnisse vorlïgen, dic unseren bis jetzt festgehaltenen Begrifien ron Organ und selbständigem, Individuum widersprächen. Es ist abcr hiebei wohl zll beriicksichtigen, dass dieser scheinbare Uebergang nicht an einem einzelnen Thiere stattfindet, dass nicht eine beliebige Sprosse jetzt blosses Creschlechtsorgan ist, um sich später zum Individum, zur Meduse zu entwickeln; es ist riehmehr das in Betracht zu nehmen, dass dieser Uebergang an einer ganzen Reihe ron Wesen in allmäliger Steigerung stattfindet, und somit als ein vicl weniger schrofies Verhältniss sich heransstellt. - Vielleicht ist dieser Gesichtspunct im Stande, iiber die plysiologische Bedeutung des Generationswechsels neue Ansgangsıuncte zu eröffnen.

Es wurde schon oben für die Gleichwerthigkeit der medusiformen Geschlechtsorgane und der wirklichen Medusen die Thatsache in Erwïhmung gebracht, dass bis jetzt bei keinem Polypen beiderlei Zustinde zu gleicher Zeit beobachtet wurden. Ja, wenn wir ron dem rereinzelten Falle bei Podocoryna carnea*) absehen, so ist, wenigstens nach meinem Wissen, kein Fall bekannt, in den wir iiberhaupt Medusensprossung und Geschlechtsorgane, selist nicht eimmal zu verschiedenen Zeiten bei Einem Polypen finden, so dass die Ammahme, dass eine Polypeneolonie bald Medusen aufamme, bald nur in der I'roduction von Geschlechtsorganen thätig sei, nur einzig und allein in der Sarsschen Bcobachtung bei Pollocoryna carnea ihre Stiitze fundet, während alle iibrigen, und zwar nicht wenig zahlreichen Beobachtungen sich durchweg dagegen aussprechen.

") Fauna littoralis Nerregiae von M. Sars, p. 6, 7. 
Meine eigenen Beobachtungen, die sich in den Zeitraum eines halben Jahres rertheilen, lehren mich, dass dieselben Polypenarten sich immer in demselben Zustande befanden, indem die einen nur mit Medusengemmen, die anderen nur mit den sogenannten Geschleclitsorganen anzutreffen waren. Was den speciejlen Fall rer Podocoryna carnea betrift, so liisst sich das Vorkommen von Medusengemmen als das normale, von Sars auch mehrmals lieobachtete Verhalten ansehen, während die Entwicklung von Eierkapseln vielleicht nur in mehr abnormen Verhältnissen ihren Grund hat. Sehen wir doch auch bei anderen Thieren, niederen und höheren, wie veründerte Lebensverhailtnisse, unginstige Wohnpliitze, Mangel an Licht, Nabrung etc. mehr oder minder ein Hinderniss der Weiterentwicklung alogeben. Alle diese ['mstïnde, zu welchen noch verschiedene Temperatur- und Tiefenverlü̈ltnisse kommen, mägen anch im Stande sein, einen Polypenammenstock an der Bildung von Medusengemmen zu hindern, und jhn nur zur Production nieder gebildeter Analoga in der Form ron einfachen Geselılechtsorganen zu veranlassen.

Ich will nun zat zeigen versuchen, dass auch solche verschiedenartige Einflisse nicht wohl als die Ursachen einer verschieden productiven Thätigkeit der Polypenstïcke aufgefasst werden können, und führe deshalb einige Thatsachen an, die sich aus meinen und fremden Beobachtungen ergeben.

For Allem ist zu beachten, dass dieselben Polypenarten an den verschiedensten Orten immer nur dieselben Formen (seien es Geschlechtsorgane oder Medusenj hervorbringen. Eudendrinm ramosum des Canals sprosst die nämlichen Medusen wie jenes von Messina, und auch in der Bncht ron Palermo fand ich es wieder in ganz gleichem Zustande, obgleich die änsseren Verhältnisse, in denen dort die Ammenstöcke leben, ziemlieh von jenen zu Messina verschieden sind. Die Tubularia, welehe Kölli ker im September an Pfählen im Hafen zu Messina entdeckte, fand ich im Januar in grossen Colonien an dem Kicle nordiseher Kauflahrer, die erst seit wenigen Wochen die Gewässer des Mittehmeeres durchzogen. Diese Tubularien trugen dieselben Geschlechtsorgane, wie jene, die den ruhigen Hafen von Messina bewohnen. Die Geschlechtsorgane des Endendrium racemosum sind dieselben im Golfe ron Neapel, wo sie Cavolini schon vor langer Zeit erkannte, mul Krohn vor Jahren näher beschrieben hat, wie jene die ich im Winter zu Messina untersuchte. Es können demnach dieselben Entwicklungsvorgänge unter ganz verschiedenen äusseren Verhäittuissen elfolgen, und die Annahme, dass die Polypen bald Me- 
dnsen, bald Geschlechtsorgane herrorbringen, entbehrt weaigstens jedes positiven Beweises.

Wie verhilit sich aber diesen Angaben gegenüber die Sa r'sche Beobachtumg an Podocoryna carnea? Im ersten Angenblicke scỉeint sie allerdings ein mächtiger Beweis für die rorhin bestrittene Theorie zu sein: und ans ihr scheint klar hervorzugehen, dass die Polypen sich auf zweifache Weise fortzupflanzen in Stande sind, einmal mit Dazwischenkommen. cines Generationswechsels, indem sic Mednsen herrorsprossen, und das andercmal in directer Weise auf geschlechtlichem Wege, intem sie Generationsorgane produciren. Hier liisst sich aber Folgendes entgegenstellen : Wir kennen noch nicht die Geschlechtsorgane der ron Podocoryna carnea anfgeammen Medusengemmen, sondern wir wissen nur, dass dic sogenannten Creschlechtsorgane dieses Polypen Eier hervorungen, also als Orarien sich rerhalten. Ist es num nicht möglich, dass die Medusen der Podocoryna die Männchen sind, dass diese somit eine hühere Entricklungsstufe, eine vollkommene Individualität erreichen, indess die TTeibchen auf einer weit nicderen Stufe stehen bleiben, und niemals es zur Selbständigkeit bringen: So viel Unwahrscheinliches diese Hypothese auch habeu mag; so schwindet doch ein grosser Theil hieron, sobald wir beriieksichtigen, dass anch bei den sogenannten Geschlechtsorgamen eler anderen Polypen ähnliche Zustände, wenn nicht constant, doch wenigstens nicht selten sind. Wir finden häufig, dass mämuliche und weibliche Organe cine ganz rerschiedene Entwicklungsstufe erreichen, dass bei den einen die Medusenähnlichkeit dentlichansgeprägt ist, während wir sie bei anderen nur angedeutet finden, man rergleiche so die mämlichen und weiblichen Organe der Tubularia, der Campanularia geniculata nach Lo rén mud M.S ch h It ze, und man wird diese Angabe bestätigt finden. Bei meiner Betrachtung der Geschlechtsorgane hate ich ebenfalls auf diesen Untersehied in der Entwicklung, oder vielmehr der Anshildung der betreflenden Organe aufmerksam gemacht. Sollte sich num wirklich herausstellen, dass dic Medusen der Podocoryna carnea nur männlichen Geschlechtes sind, so wäre für die vorhin vertretene, zucrst ron $\mathrm{Le} \mathrm{u} \mathrm{kar}$ *) anfestellte Theorie ron den sogenannten Geschlechtsorganen der Polypen ciue breite Basis gewonnen, und das, was 'ich bisher nur durch Grïnde der Analogie zu stiitzen vermochte, fünde in einer Thatsache eine Bestätigung.

") Handwörterbuch der Physiologie ron R. Waguer. Bd. T. Artikel: "Zeugung". 
Nichtsdestoweniger glaube ich aber, dass vorläufig diese der Analogie entnommenen Grïnde hinreichend sind, und dasz bei dem gegenwärtigen Stande unserer Kemntnisse von diesen Geschöpfen es nicht wohl begriindet werden kann, hier eine andere Annahme zu substituiren, ohne bekannte Thatsachen geradezu absprechen zu wollen.

Die Polypencolonicn, dercn zweite Generation (die sogenannten Generationsorgane) es zu keiner holen Entwicklung bringt, sondern nur als ein mit den Medusen in Beziehung auf ihre Genese und ihre Bestimmung gleichwerthiges Product besteht, treten in cine ganz cigenthümliche Lage zum Generationswechsel. Wïhrend dic Polypencolonien, wclche Medusengemmen produciren, als A mmenstöcke der Medusen aufgefasst werden miïssen, kömnen wir unnöglich jene, welche nur Analoga von Medusen erzengen, gleichfalls als Ammenstücke bezeichnen, eben weil ihnen das den Pegriff Amme bedingende Moment (eine rollkommene zweite Gencration) abgeht. Sie stchen also dadurcb zu den wirklichen Ammenstöcken in demselben Verhältnisse, wie ihre Producte zu den Producten jener, und sind alse unvollkommene crste Generation zu deuten, wie wir ihre geschlechtlichen Sprossen (die Gesehlechtsorganc) als unrollkommene zweite Generation kemen gelernt haben. In dieser Beziehung verhiclte sich zum Beispiele Tubularia Dumortieri zur Tubularia coronata, wie dic Medusengemmen der ersteren zu den Geschlechtsorganen der zweiten. Je weniger intensiv aber die Erscheinung des Generationswechsels sich an diesen Geschöpfen ausprïgt, desto mehr tritt auch ihre selbständige Individualitït hervor, und wenn wir nur jene Formen kännten, die wie unsere Hydra, oder die Hydractinien und gewisse Arten aus der Familie der Coryneen und Campanularien mit uur wenig entwickelter zweiter Generation versehen wären, wenu uns also die zahlreichen und mannigfachen Uebergänge dieser Geschlechtssprossen zu einer selbständigen, vollkommenen, zweiten Gencration fehlen wïrden, so miissten wir jene Theile einfach als Geschlechtsorgane auflassen, olme irgend eine Nebenbedeutung zum Wechsel der Generation.

Bei eincr nnr einseitigen Anffassung der Extreme der betrachteten Erscheinungen mag es viclleicht den Anschein haben, dass ich in manchen Stïcken zu weit gegangen, dass ich distinkt Geschiedenes vercinigt habe, und gar den scheinbar feststehenden Begriffen von Individnum und Organ zu nahe getreten sei, wogegen ich einfach erwiedere, dass in der Naturforschung die einzelnen Begriffsbestimmungen nicht a priori construirt, sondern als Resultate der Forschung sclbst, mit jeder Feststellung einer neuen Thatsache, und jedem dadurch neu gewonnenen Gesichtspuncte 
sich modificiren, und eben diesen neuen Anschaunngsweisen sich adaptiren miissen.

Ein ähnliches, vielleicht noch in bestimmterer Weise für meine Theorie sprechendes Verhalten zeigen die Geschlechtsorgane der SchwimmPolypen, so dass ich es für wichtig genug halte, um auch hier noch einmal auf jene Thiere einzugehen. Die ron C. Vogt, Leuckart und Huxley ausgesprochene Ansicht, dass die schwimmenden Colonien oder Siphonophoren Polypenstöcke seien, die sich mit den festsitzenden Stöcken der Hydraspolypen in eine zoologische Systemgruppe vereinigen lassen, hat durch die umfassenden Untersuchungen Kölliker's*) eine neue Bestätigung erfahren, und auch meine an diesen Thieren angestellten Beobachtungen haben mich ein Gleiches gelehrt. Den Siphonophoren sowie den Hydraspolypen liegt ein gemeinsehaftlicher Stamm zu Grunde, der bei den crsteren frei und beweglich ist, und hïufig noch mit einem hydrostatischen Apparate (Luftblase der Physophoriden lind Luftcanäle der Telelliden) versehen erscheint, während er bei den letztern sich festheftet, und sich häufig mit starrer, hornartiger Hülle umgibt. Vom Stamme entspringen die Einzelthiere der Colonie, mit dem für den Haushalt dieser Geschöpfe nothwendigen Fangapparate, der bald mit den Thieren selbst verbunden in Form von Tentakeln erscheint, wie bei den Hydraspolypen, oder getrennt ron den Einzelthieren dem Stamme direct entspringt, wie bei den Siphonophoren und dann häufig als ein nit mannigfachen Nesselfäden ausgeriisteter und höchst complicirter Apparat sich darstellt. Ausserdem treffen sich bei den Siphonophoren noch andere der freien Lebensweise dieser Thiere angepasste Organe, die sich theils als Deck-und Schutzorgane, theils als Locomotionswerkzeuge präsentiren, und die neucrlich durch Le uckart durch das ron ihm aufgestellte Gesetz der Polymorphismus eine sehr sinnreiche, wenn auch nicht in derAusdehnung, wie es Leuckart wollte, haltbare Deutung erfuhren.**;

-) Die Schwimmpolỵpen ron Messina. 1852.

•) Wenn sich auch das Gesetz der Polymorphismus auf die medusenförmigeu Schwimmstücke der Siphonophoren, sowie auch auf die sogenannten Deckstücke übertragen lässt, so ist es doch wohl zn weit gegangen es auch auf andere appendiculäre Organe überzutragen; wir müssten dann consequenterweise jeden Fangfaden und jeden an demselben sprossenden Secnndär-Fangfaden für ein Individuum halten, und kämen zuletzt zu dem Paradoxon auch die Tentakeln der Hydraspolypen für Individuen zu erklären: Denn halten wir einmal die rom Stamm der Colonie entspringenden Fangfäden für Indiriduen, fürTentakelthiere, so müssen wir dies auck für jene annehmen, welche ron den einzelnen 
Was die sogenannten Geschlechtsorgane betrifft, so betrachte ich die der Siphonophoren mit Leuckart als eine zweite Generation, wie jene der Hydraspolypen, denn wie bei letzteren laben wir wieder die zahlreiclisten Uebergänge von der einfachsten Form bis zm entwickelten Meduse. Als einfachere Formen treffen wir die traubenartig gruppirten Eikapselı von Agalmopsis, oder jene ron Forskalia(Köll.); höher entwickelt erscheinen die Geschlechtsorgane der Hippopodiiden, und am hïchsten dann jene der Diphyiden. Die Medtusenform ist bei allen diesen mehr oder weniger ausgeprägt, nnd crinnert an Formen, die wir bei den Hydraspolypen trafen. Alle diese Theile erseheinen auch hier als zweite Gencration, und zwar als unvollkommene, da keiner dieser Theile, und selbst diejenigen nicht, die sich ablösen (Diphyiden) und längere Zeit fortzuleben im Stande sind, als wirkliche Neduse sich legitinirt. Randkörper, Fangfiden und ein Ernährungsapparat, der fähig wäre, Nahrung vou aussen einzunehmen, gehen diesen freien Geschlechtsgemmen gänzlich ab. Tollkommen dagegen ist der Generationswechsel bei den Velclliden (Velella, Porpita?), wo die zweite Generation zur wirklichen Meduse wird.

V. Wimpernde Medusenlarven.

Es ist eine wichtige, bis jetzt in ihrer Tragweite noch gar nicht zu iiberschanende Thatsache, dass es auch Medusen gibt, die olne Dazwischenkommen eines Generationswechsels auf gesehlechtlichem Wege entstanden sind. Die erste Kenntniss dieser Thatsache verdanken wir J. M iiller, *) in der Entdeckung der wimpernden Larve von Aeginopsis meditcranea. Dass das wimpernde Medusenjunge aus einem Ei hervorgegangen sein muss, und nicht als das Prodnet einer Knospung, die wir bisher mehrfach betrachteten, angesehen werien darf, unterlicgt wohl keinem Zweifel.

Ansser mannigfachen Entwicklungsstadien der Aeginopsis mediterranea die mit der von J. M̈̈ller beschriebenen bis ins Detail übereinstimmen,

Polypenleibern der Siphonophoren entspringen, und ron diesen ist dann kein weiter Weg mehr zu den gleichfalls häufig nahe an der Basis des Polypenleibes entspringenden Tentakeln der Coryneen. Oder sind vielleicht nur die rom Stamme der SiphonophorenColonie entstehenden Tentakeln Einzelthiere? was sind dann die an den Polypen der Siphonophoren-Stämme sich bildenden, die nach demselben Modus eutwickelt sind?

") Müller's Arch. 1851. p. 252. Taf. XI. 
gelang es mir, noch eineandere wimpernde Larve aufufinden, und dieselbe durch alle Entwicklungsstadien zu verfolgen.

Die juîngste von mir angetroffene Stufe war jene, wo die frei im Meer lebende Larre ziemlich die Form einer umgekehrten, weithalsigen Flasche hatte, 0,05"' Grösse besass, und dicht mit feinen Cilien iiberkleidet war. An dem etwas eingeschnïrten, den Hals der Flasehe vorstellenden Theile befindet sich unten eine Vertiofung, die sich jedoch nicht in den rundlichen Körper erstreckt. An dem letzten, und zwar dem Halse etwas genähert, bemerkt man 3 oder 4 konische, oft stabartig verlängerte Hervorragungen, die mit längeru Cilien überileckt in spitzem Winkel gegen die Lüngsachse des Körpers gerichtet sind. Es sind diess die Anfänge der Tentakeln. Zwischen ilınen sitzen 4 kleine, orale Bläschen, in denen man einen dunkel contourirten rundichen Körper bemerkt; offenbar sind diess die Anlagen der Randkörper. Das Parenchym des bis jetzt noch soliden Larvenkörpers wird aus hellen, ziemlich gleich grossen Zollen gebildet, deren jede, wie dureh cinen schwachen Säurezusatz leicht nachzuweisen ist, einen centralen Kern enthält. In einem weiter vorgerïckten Stadium (Fig. 1S) sind die Tentakeh (e.) schon fast von doppelter Körperlänge, während der Körper selbst, und der von ilım entspringende Magensehlauch (b.) noch auf der früheren Stufe steht. $\mathrm{Zu}$ den vier ursprünglichen Tentakeln sind noch vier neue hinzugekommen. Auffallend ist dabei, dass die Entwicklumg derselben eine selır ungleiche ist, so dass sich immer ziemliclie Verschiedenheiten in ihrer Länge herausstellen. Das Ende der Tentakeln ist immer etwas kolbig angesehwollen und mit rothem Pigmente geziert. Die Oberfïche trägt durchaus lange Cilien und zeigt einzelne, oft in Querreihen geordnete, dunkle Kömer oder Pünktehen, welche wahrscheinlich den Anlagen der Nesselkapselı entsprechen. Actire Bewegungen der Larve sind nur spärlich, und werden ausschliesslich von den Tentakeln ausgefuihrt, die sieh langsam iıeben oder senken köunen, ohne von den lebhaften Bewegungen der Randfäden anderer Medusen irgend eine Spur kund zu geben. Wenn die Larve so in ruhigem Kreisen mit ansgespreizten, starren Tentakeln umherselwwimmt, hat sie bei oberfächlicher Beschauung einige Achnliehkeit mit gewissen Echinodermen-Larven (Asteriden, Ophiuren), welche Aehnlichkeit durch die rothgefärbten Tentakelenden und jhren reichen Wimperbesatz selbst unter dem Mikroskope noch im ersten Augenblicke der Untersuchung bestärkt wird (Fig. 18, 19). Die nächste Veränderung besteht in der Bildung einer centralen Höhle im Innern des Körpers, die jedoch fïr sich selbständig zn bestehen scheint, and mit der nun auch etwas tiefer gewordenen Magenhöhle in durchans 
keinem Zusammenhange steht (Fig. 20 e.). Weiterhin wächst num auch der ursprünglich runde Kürper der Larve melr in die Breite, und zwar nach der Richtung der Tentakelurspriinge hin, so dass er sieh mehr der Scheibenform nïhert nud dann bald eine conrexe und eine concave Oberflïche besitzt. Ton Mitte der letzteren entspringt der nun gleichfalls grösser und länger gewordene Magenschlanch (Fig. $20 \mathrm{~b}$.), der von seiner urspriinglich drchrunden Form in die Breite iibergeht, md dabei an seinem freien Rande in zwei deutliche Lippen sich anszieht (vergl. Fig. 20). Von nun an wird der Magen beweglicher und Schlingversuche desselben sind nicht selten zu beobachten. Ob er schon zur Aufnahme von Nahrung geeignet ist, ist mir unbekannt, wenigstens liessen alle Larven dicses Stadiums niemals Speisetheile im Magen erkennen. Doch lïsst die nicht unbetrïchtliche Volumsvermehrung des Kïrpers eine schon friher eintretende Nahrungsaufnahme als nothwendig erscheinen. In der Folge schreitet das Wachsthum des Korpers in der Weise vor, dass vorzüglich der Rand der Schribe sich verlängert und so allmälig in die Schirmform iibergeht; die schon friher bemerkliche Concavität des Schirmes wird dadurch immer tiefer mo er erscheint endlich in Gestalt einer Glocke, an deren Rand die Tentakeln und Randkürper sitzen. Auflallende Veränderungen sind unterdessen im Innern vor sich gegangen, indem die ursprïnglich isolirte Centrallü̈lle des Körpers (Fig. 20 e.) sowohl mit dem Magen sich in Verbindung gesetzt liat, als auch acht gegen den Glockenrand verlanfende Fortsätze ausschickte (Fig. 21 e.). Die Centralhöhle erlangte dadurch eine Steruform. Betrachtet man die Glocke ron ihrer gewölbten Seite (Fig. 23), so bemerkt man, dass die Fortsätze (e`) der Centralhöhle (e) nicht in gleicher Ebene von dieser ausgehen, sondern dass vier derselben in Kreuze stelıend höher abgehen, während die andern vier, gerade in die Kreuzwinkel der vorigen treffend, von einer tieferen Stelle des ursprünglichen Centrallohlraumes ihre Entstelıng nehmen. Wahrscheinlich entstehen die einen vier von ihnen in einer früheren Periode und die andern vier folgen später nach. Diese acht hohlen Fortsätze wachsen nun biø nahe an den Glockenrand und vereinigen sich dort mit einem neu aufgetretenen Randcanal (Fig. $23 \mathrm{e}^{\prime \prime \prime}$ ). Die Einmündungsstelle eines jeden dieser acht Glockencanỉle in den Randcanal entspricht einer der acht Tentakeh, doch ist die Tentakelbildung hiemit noch nicht begränzt, sondern man sicht an älteren Larven mehrfach neue hervorsprossen (Fig. $22 \mathrm{c}^{\prime \prime \prime}$ ) so dass sich die Gesammtzahl derselben bei älteren Formen auf $10-15$ belïnft. Eine Regelmässigkeit in dieser Tentakelbildung ist durchaus nicht zu erkemmen, sondern es scheint bald hier bald dort eine Sprosse 
sich zu bilden, bis so ziemlich der ganze Rand mit Tentakeln besetzt ist. Die Randkörper (Gehörbläschen) bleiben bei ihrer schon friiher begrenzten Anzahl, und zeigen auch in anderen Beziehungen keine Veränderungen.

Ist num hiemit die rollständige Mednsenform ausgebildet, so schwindet das die Oberfliche der Glocke iiberziehende Wimperkleid, dic Glocke maclit jene eigenthïmlichen zuckenden Dewegungen und wird mit der nunmehr hinzukommenden Bildung eizer Randhaut das hauptsiichlichste Locomotionsorgan des Thieres, das nun einen Querdurchmesser von $\frac{7}{4}{ }^{\prime \prime}$ erreicht hat. Die Cilien an den Tentakeln sind dabei noch immer vorhanden, und sind noch in Stande, durch ihre Schwingungen ein Fortriicken des Thieres zu bewerkstelligen. Aeltere Thiere, die durch ihre Gefïsscanäle und den Bau ihrer Raudfäden sowie durch die zweilappige Magenöffnung sich als aus diesen Larven entstanden erkennen liessen, zeigten ausser beträchtlichen Grössenunterschieden - denu der Durchmesser ihrer Glocke betrug bis $1^{\prime \prime \prime}$ - keine andere aufï̈llige Veränderung; Geschlechtsorgane waren anch an diesen nicht vorhanden, ja nicht einmal angedeutet, und es scheint somit, dass diese Form noch lïngere Zeit nöthig hat, elıe sie geschlechtsreif wird.

Die Stelhmg, welche dieser Meduse im System zukommt, lässt sich wohl erst sicher begründen, wenn einmal die Geschlechtsorgane vorhanden sind, doch ist vorläufig so viel aus ihrem Paue und Ilabitus ersichtlich, dass sie den Gymmopthalmata (Forbes) beizurechnen mnd ihrer ïbrigen Organisation zufolge dem Thaumantiasgesehlechte nahe stehen wird. Am auffallendsten sind die Tentakeh gebildet, die ansser ihres persistirenden Wimperiberzuges noch durch ihre Rigidität ausgezeichnet sind und sich in dieser Hinsicht an jene der Aequoriden (Cunina, Aegina, Aeginopsis etc.) anschliessen. Da ich glanbe, dass wenigstens die Form dieses Thieres in der oben beschriebenen Weise ausgebildet und vollendet sein wird, wenn auch sein Wachsthum in der varhiu angegebenen Grösse noch nicht beendet ist, so erlaube ich mir, weil es mir numöglich ist, diese Meduse unter eine der bekinnten Gattungen unterznbringen, ein neues Genus anfzustellen, und dies als Trachynema zu bezeichnen; die Art nenne ich Trachynema ciliatum.

Durch die Kenutniss von der Entwicklung dieser scheinbar dem Genus Thammantias nahe stehenden in gewisser Hinsicht sich an die Aequoriden anschliessenden Meduse aus einer wimpernden Larve, werden die Entwicklungsverhältnisse der Medusen mm ein Beträchtliches complicirter, als sie selbst durch fo h. Müller's Beobachtung von der wimpërnden Aeginopsis-Larve sich herausstellten. Aeginopsis gehört einer 
von den Oceaniden (im weiteren Sinne) wohl gesonderten Familie an, man hätte desshalb wohl annchmen können, dass nur bei diescrMedusenfamilie (den Aequoriden) die Entwicklung von Medusen aus Meduseneiern ohne Einschaltung eines Generationswechsels vor sich gehe, während bei der Entwicklung der Oceaniden noch dic Bildung einer Ammengeneration hinzukomme. Meine Beobachtung an Trachynema, einer Meduse, dic wohl zwischen den Oceaniden und Aequoriden steht, scheint auch ausserhalb der letzteren Familie eine Entwickling ohne Generationswechsel (homogone Fortsetzung nach Mïller) zu bestätigen, wobei nur die Frage noch ist, wie weit dieses Verhaiten auf dic iibrigen dieser Familie angchörigen Gattungen sich ausdehne, ob es bei einer oder einigen Gattungen dieser Familic bestche, wo es dann dic einzige Art der Fortpflanzung ausmacht, oder ob es weiter greife und sich noch mit einem Generationswechsel (heterogone Fortsetzung Miill er’s) combinire. Der erstgesetzte Fall diurfte der wahrscheinlichere sein, da unsere Gattung Trachynema denn doch in Einigem von den einem Generationswechsel muterworfenen Oceaniden differirt; es ist dies das Verhalten der Tentakeln, dic durch ihre Rigidität einige Verwandtschaft mit den Aequoriden crkennen lassen, so dass wir diesc Meduse wohl als ein Verbindungsglied zwischen beiden Familien ansehen können, indem sie mit der einen theilweise die äussere Form, mit der anderen dic Fortpflanzung gemein hat. Soll die Eutwickhmgsgeschichte den alleinigen Ausschlag geben, so mïsste sic dann entschieden im Anschlusse an Aeginopsis den Aequoriden zugetheilt werden, zu welchen sie sich dem Baue ihres Gastro-rascularsystems zufolge in gleicher Weise verhalten wiirde, wie die erste Gruppe der Es ch s cholt z'schen Medusiden (die mit Radiärgefässen und einem Randeanal versehenen Gencra Medusa und Sthenonia umfassend) zur zweiten Gruppe derselben (welche dic mit sackartigen Magenanlıängen versehenen Genera Cyanea, Pelagia und Clıry•• saora in sich begreift).

Fernere Beobachtungen, welche besonders die aus den Eiern dieser im Larvenzustande wimpernden Medusen (Acginopsis, Trachynema) in Bezug auf ihre Entwicklung in's Auge fassen miisscn, mögen dann zeigen, in wic weit meine anf morphologische Verlültnisse basirten Folgerungen gerechtfertigt sind oder nicht. Durch Köllikers *) Beobachtung über die Geschlechtsverhältnisse der Aeginopsis ist jedenfalls ein vorbereitender Schritt hiezu geschehen, indem wir dadurch erfahren haben,

") Zeitschr. f. wissensch. Zool. Bd. IV. p. 327. 
dass diese Wesen keine nur vorübergehenden, oder rielleicht immer geschlechtslos bleibende Formen sind, sondem vollkommen entwickelte Medusen.

VI. Fortplanzung der Medusen dureh Knospung.

Dass bei einer Abtheilung von Medusen, die wir als Abkömmlinge der Hydraspolypen kennen, ausser der geschlechtlichen Fortpflanzung mit Einschiebung einer Ammengeneration noch eine andere Fortpfianzungsweise existirt, nänlicł jene durch Knospenbildung (mit homogoner Fortsetzung) dies wurde bekanntlich zuerst von Sar:) an Cytaeis octopunctata gezeigt und von demselben später noch für andere Polypenabkömmlinge bestätigt. Seitdem wurden unsere Kenntnisse von diesem merkwürdigen Factum durch Forbes**; Untersnchungen an Sarsia gemmifera, S. prolifera und Lizzia

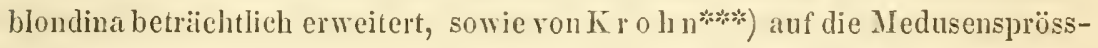
linge eines der Podocoryna carnea nahe stehenden Polypen, und ron Busch †) anf Bougainvillea mediterranea ausgedehnt. Der Letztere hat zugleich dargethan, lass dies die Productivität dieser Thiere in grossem Massstabe kindgebende Phänomen unablı̈̈ngig von der geschlechtlichen Zeugung vor sich gehe, dass es eben so gut an geschlechtsreifen Individuen stattfinde, als an noch unentwickelten; iiberdiess hat $\mathrm{Busch}$ noch die Beziehung der Kinospenbildung zum verdauenden Apparate und seinen Fortsätzen (dem Gastro-vascularsysteme) in weiterer Auseinandersetzung gezeigt. Die Knospenbildung selbst erfolgt sonach theils am Magen, theils an den Ovarien, theils wieder an der Tentakelbasis, rom Randcanale der Glocke aus, ohne dass sich jedoch fuir die Sprossung an den einzelnen Localitäten eine Gesetzmässigkeit auflinden liesse. Wen Modus der Sprossenbildung selbst haben $\mathrm{Sars}$, Forbes und Busch ausführlich beschrieben, und er ergibt sich rollkommen mit jenem iibereinstimmend, den wir bei der Medusensprossung an Polypen kennen. Alle diese, die homogone Fortsetzung der Medusen mittels Sprossenbildnng betreflenden Thatsachen, gehen nur an solchen Medusen vor sich, die sich bereitsals Abkömmlinge

-) Fauna littoralis Norregiae.

“) Op. cit.

**) Wiegman n's Arch. 1852. p. 267.

†) Op. cit. 
von Polypen beurkunden. Sie gehören sämmtlich der Gruppe der Oceaniden an. Es dürfte desshalb das Factum von Sprossenbildung bei einer anderen Abtheilung von Medusen, deren Entwicklungsverhältnisse uns bis jetzt noch ziemlich unbekannt sind, von cinigem Interesse scin. Es betrifft dies eine zu den Aequoriden gehürige Form, welche sich an die Gattung Cunina anschliesst, olıne jedoch in allesi Stiicken mit ilır übercinzustimmen.

Die in Frage stehende Meduse (Taf. II. Fig. 30) misst 5"'im Quecrdurchmesser, besitzt einen äusserst pelluciden, obcrflächlich stark gewölbten, unten flachen Körper, an dessen Rande sich gegen 16 kurze Tentakeln finden, und eine inconstante, oft gegen 20 sich belaufende Anzahl von bläschenförmigen Randkörpern, deren jeder 2-10 rundliche Concretionen einschliesst. Die Randhaut ist sehr breit, und hïngt im Ruhezustande wie eine schlafie faltige Mcmbran gerade herab, wie dies sehr hïufig auch bei anderen Aequoriden der Fall ist. Auf der Unterläche der Scheibe befindet sich die Magenhöhle, welche, die ganze Fläche eimehmend, sich am Rande in 16 zwischen je zwei 'Tentakelursprünge hinabragende Ausbuchtungen (Magensäcke) furtsetzt (Figur 30 a). Die Mundöffnung liegt im Mittelpuncte der Scheibc, und stellt ein rundes, in der Unterfäche der Scheibe befindliches Loch vor, das sich bis zu einem so betrïchtlichen Umfange erweitern kaun, dass es einen grossen Theil der Magenhöhle nach aussen blos legt. Geschlechtsorgane wurden noch nicht an ihr beobachtet. Vorläufig schlage ich für diese Meduse den Namen Cunina prolifera vor, indem ich mir vorbehalte, diese und andere zu dieser Gruppe gehörigen beobachteten Mcdusen an einem andern Orte noch näher zu charakterisiren.

Innerhalb des Magens dieser Meduse fanden sich nun dicht gedrängt liegend verschieden grosse Scheibchen, welche sich schon mit dem blossen Auge durch ihre weissliche Färbung zu crkennen geben. Ihre Zahl mochte sich auf etwa 40 belaufen. Eine genane Untersuchung ergab, dass es junge, auf verschiedencn Entwicklungsstadien befindliche Meduscu waren, deren entwickeltste Formen ganz den Charakter des Mutterthiercs trugen. Es lag also hier cine Brut vor, deren mannigfache Stadien bei dem Mangel von jenen einen Furchungsprocess darstcllenden Formen, gleich von vornehcrein eine Entstchung auf nicht geschlechtlichem Wege vermuthen liessen, bis ich mich bald überzengen sollte, dass in der That ein solcher Vorgang, und zwar cine Vermehrung durch Knospenbildung stattfinde. 
Im Unkreise der seichten, nur in der Fliiche sich ausdehnenden Magenlọ̈hle fander sich nämlich kleine, nur $0,01^{\prime \prime \prime}$ messende Wärzchen, mehr oder weniger in die Magenhölıle vorspringend, und scheinbar ganz aus dem dicMagenwände bildenden kleinzelligen Gewebe zusammengesetzt. Diese Gewebselemente wurden jedoch erst sichtbar, als das Mutterthier im Absterben begriffen war, vorher sehienen die Wärzchen vollkommen homegell, rur mit dunklen zerstreuten Körnchen besetzt. Ausser diesen, und unregelmässig zwischen ihnen sassen etwas grössere, welche kuglige, mit einer etwas eingeschnïrten Basis ron der Magenwand entspringende Knöpfthen vorstellten (Fig. 24 a. b.). Andere erschienen etwas abgeflacht, und zeigten auf der frei in die Magenhöhle sehenden Flïche vier im Quadrate stelıende dunkle Pünktehen(Fig. 25 b.). Der Stiel, mittels dessen sie mit der Magenwand verbmden waren, hatte sich noch mehr eingeschnïrt, und dieselben Formen, die noch an ihm festsitzend beobachtet wurden, sah man auch frei herumliegen. Der Scheibenrand wüchst jetzt etwas vorund stellt sich als ein kreisrunder Wulst dar, auf dem man nun die vorerwähnten vier dunklen Puncte sitzen sieht. Diese geben sich jetzt als kleine Herrorragungen zu erkennen und stellen dieAnlagen der ersten vier Tentakel vor.

In der Mitte der Scheibenfläche erscheint eine runde Oeffnung (Fig. 27 a.), die nach innen sich ausdehnt und die Magenhöhle bildct. Zwischen den zu kurzen Zäpfehen herangewachsenen Tentakeln (Fig. 28 b.) liegen je 4-5 lïnglich orale Randbläschen mit ursprünglich einem Otolithen, spätere Stadien enthalten deren mehrere, doch ist dann ilıre Anzahl gleichfalls inconstant (Fig. 31 a. b. c.) wie diess auch schon beim Mutterthiere bemerkt ward. Individuen von $0,3^{\prime \prime \prime}$ Querdurchmesser waren schon mit der vollzähligen Summe von Randkörpern versehen, durch Verlängerung des Schirmrandes entsteht nun die Randhaut, mit deren Auftreten die Jungen die ersten zuckenden Bewegungen iussern. Es haben sich nun die vier Tentakel weiter ausgebildet, und zwischen ihnen zeigen sich von neuem kleine Hervorragungen, die als die Anlage der iibrigen Tentakeln gedeutet werden können; so haben die grössten einen Schcibendurchmesser von 1,2" ; melırere von ihnen traten, eine Erweiterung der Mundöffnung ihres Mutterthieres beniitzend, nach aussen, und schwammen als muntere Medusen umher. Der Schirm oder die Scheibe dieser Thierchen ist um Vieles flacher (Fig. 29 zeigt ein solches Thier von der Seite) als bei der Mutter, auch mangeln noch die sackartigen Ausstülpungen des Magens, deren Bildung erst während ihres freien Lebens zu Stande zu kommen scheint. 
Es erimnert dieses Verhältniss mich an ein ïhnliches von Kölliker*) bei Eurystoma rubiginosum Köll. beobachtetes, wo sich gleichf̣alls viele junge Qualienformen in dem Magen der Meduse vorfanden, freilich sind diese verschiedenen Jugendzustände nicht als die Sprösslinge der sie einschliessenden Meduse zu betrachten, wenigstens liegt keine directe Beobachtung hiefiir vor, und andere mit ihnen vorkommende Quallen scheinen vielmelır einer ganz andern $\Lambda \mathrm{rt}$ anzugehören (Stenogaster complanatus Köll.), so dass naclı K $\mathrm{K} l l i k e r$ "leicht gedenkbar ist, dass das fraglicle Individum von Eurystoma von einem ganzen Schwarm junger Stenogaster einige in sich aufgenemmen hatte." Lis ist dies Verbältniss um so auffallender, als Eurystoma rubiginosum eine meiner Cunina prolifera sehr nahe stehende Form ist, und anderseits wieder Stenogaster complanatus den von mir bei letzterer Qualle beobachteten Sprösslingen iahnlich ist. Weiter lieriiber zu entscheiden steht mir nicht zu, ich wiederhole dalıer schliesslich nur, dass meine an Cunina prolifera angestellte Beobachtung mit einer geschlechtlichen Vermelırung durchaus nichts gemein hatte, sowie dass die Entstehung der jungen, im Magen befindlich gewesenen Quallenbrut auf eine im Umkreise der Magenlı̈̈lle stattfindende Knospung durch alle Uebergangsstadien sich zurïckfuiliren liess. - Ausser der Lokalität diescr Sprossung - denn die Mageuliöhle wurde meines Wissens bis jetzt noch nicht als Knospenstiitte beobachtet - ist die Art und Weise der Sprossung selbst sclieinbar im ersten Augenblicke von jener wie sie bei den Oceaniden bekannt ist, sehr differirend, doch ist hier zu berücksichtigen, dass der von den Oceaniden ziemlich abweichende Bau der Aequoriden, namentlich die Verhältnisse des Verdanungsapparats und iiberhaupt des ganzen Gastrovascularsystems auch wieder Modificationen in der Knospenanlage und in der Weiterentwicklung derselben vedingen muss. Eine andere Abweichung ist das relativ selır frühzeitıge Ablösen der Sprösslinge vom Mutterthiere, wällırend dies bei den Occaniden erst bei vollkommen ausgebildeten Medusenformen der Fall ist. Nur das auch nach geschehener Abtrennung noch längere Zeit hindurch andanernde Verbleiben in dem zur Bruthöhle umgewandelten Magen bietet hiefür einigen Ersatz, und ermöglicht zugleich die weitere Ausbildung der Jungen selbst bei aufgehobenem organischen Zusammenhange mit dem Mutterthiere. --

") Zeitschr. f. wissensch. Zool. Bd. IV. p. 327. 
VII. Ueber systematische Stellung der Polypen zu den Medusen.

Ungeachtet der innigen Bezichungen, in welchen vicle Polypenstöcke za den Quallen stehen, diirfte doch eine Vereinigung der ersteren mit den letzteren auf viele Hindernisse stossen, von denen jedenfalls dieses das bedeutendste ist, dass wir von viclen dieser Polypencolonien gar keine vollkommene zweite Generation kemmen, sondern nur eine unvollkommene, die bisher als Geschlechtsorgane gedeutet ward. Ausserdem ist noch die Zahl der in ihrem vollkommenen entwickelten Zustande gekannten Polypensprösslinge zu klein, um sie für eine Systematik ihrer Ammen zu verwerthen. Es wird hiezu cine viel grössere Zahl von genauen Untersuchungen erforderlich sein, ehe eine vollstïndige Auflösung der Hydraspolypen und eine Vertheilung derselben unter die von ihmen aufgeammiten Medusen in's Werk gesetzt werden kann. Die mur sogenannte "Gesehlechtsorgane" producirenden Polypen werden dann je nach den verschiedenen Geschlechtern der von iluren Verwandten aufgeanmten Quallen, diesen roransgestellt, und gleichsam als nieder organisirte Formen von Ammenstücken betrachtet werden muissen. Wir wissen bereits von den Echinodermen, dass den cinzelnen Abtheilungen derselben immer ein bestimmter Larventypus vorausgeht, der ein besonderer für die Ophiıren, ein besonderer für die Asteriden oder die Echiniden ist etc.; und das relativ Wenige, was wir von der Medusenentwicklung kennen, lehrt uns ebenfalls, dass die Ammen einer Abtheilung immer demselben Typus angehören, woraus zı erschliessen ist, dass dic bisher bestandenen P'olypengenera nicht weit von einander getrennt werden, wenn man sie immer nur dem betreffenden Quallengeschlechte zutheilt. 
Das Wichtigste der von mir besprochenen Punkte stelle ich in folgende kurzgefasste Siitze zusammen:

1) Höhere und niedere Medusen (Rhizostomida und Medusida nach Eschscholtz; Steganophthalmata Forbes - Oceanida, Geryonida, Aequorida etc. nach Eschscholtz; Gymnophthalmata Forbes) unterschicden sich wesentlich durch die Art ilırer Entwicklung.

2) Bei den hïlieren Medusen und den Oceaniden findet ein Generationswechsel statt, der aber durch die Organisation und Bedeutung der ersten (Ammen-) Generation verschieden ist; denu

3) die Ammen der löberen Medusen sind nur polypeuförmig, sie sind höher organisirt als die llydraspolypen, aber ibre Dauer ist kïrzer, denn ihre Selbstiindigkeit geht auf in der Erzengung der zweiten Generation;

4) Ammen eines Theiles der zweiten vorerwähnten Medusengruppe (der Oceaniden) sind die Hydraspolypen.

5) Thre Medusengemmen werden zu selbständigen, geschlechtlich sich fortpflanzenden Wesen.

6) Die gezchlechtliche Brut dieser Polypensprösslinge kehrtwieder zurersten Generationzuriick.

7) Die sogenamnten Geschlechtsorgane der Polypen sind die Analoga der Medusen, die plysiologischen Aequivalente einer zweiten Generation; desshalb

8) sind auch die sie erzengenden Polypen keine wirklichen Ammen, sondern nur Analoga von Ammen.

9) Consequent wird auch die geschlechtliche Brut dieser sogenannten Geschlechtsorgane wieder zu Polypen.

10) Weder die Bilang ron Medusengemmen (vollkommene zweite Generation), noch jene der sogenamten Geschlechtsorgane (unvollkommene zweite Generation) ist an gewisse Localitäten gebunden, sondern kann uiberall äusserlich am Ammenstocke entstelren.

11) Wie von Seite der ersten Generation durch homogone Sprossenbildung eine Vergrösserung der Ammencolonien bewirkt wird, so entsteht durch homogone Sprossenbildung bei der zweiten Generation gleichfalls eine Vermelırung.

12) Die wimpernuen Medusenlarven beweisen, dass eine Abtheilung der Medusen direct auf geschlechtlichem Wege entsteht, gleichzeitig geht aber auch aus dem Baue dieser Medusen hervor, dass sie nicht zu jenen gehören, die einem Generationswechsel unterworfen sind. 
13) Dic Siphonophoren sind schwimmende Polypencolonien, und ihre sogenannten Geschlechtsorgane die Analoga einer zw eiten Generation, so dass sie sich in dieser Beziehung wie die Hydraspolypen verhalten.

14) Die Fortpflanzung der Medusen lässt sich nach den bis jetzt bekannten Thatsachen in folgendem Schema darstellen:

Fortpflanzung mit Generationswechsel.

Pulypenförmige Ammer.

(Höhere Medusen.)

Vermehrung der Ammen durch

Sprossen-Bildung; die Sprossen werden frei. Die zweite Generation planzt sich nur heterogon auf geschlechtlichem Wege fort.
Polypen.

(Oceaniden.)

Vermehrung der Ammen durch Sprossen-Bildung; dic Sprossen bleiben mit dem Ammenstocke verbunden und bilden Colonien. Die zweite Generation pflanzt sich a) heterogon auf geschlechtlichem Wege, und b) homogon durch Kinospen fort.

Fortpflanzung ohne Generationswechsel.

(Aequoriden.)

Nur homogone Fortpflanzung:

a. geschlechtlich (wimpernde Larven);

b. durch Knospung (Cunina prolifera);

c. durch Theilung (Stomobrachium mirabile. Köll.). 


\section{ANHANG.}

Ich versuche hier schliesslich eine tabellarische Darstellung aller bis jetzt über den Generationswechsel der Polypen und Medusen bekannten Thatsachen (so weit die mir zugängliche Literatur es möglich machte) zu liefern, theils um dadurch eine Uebersicht über das vorhandene Material zu geben, theils auch un das sich gegenseitig fast durchweg ausschliessende Vorkommen von Geschleel tsorganeu (unvollkommene zweite Generation) oder Medusengemmen (vollkommene zweite Generation) anschaulicher zu machen. Ich beniitzte dabei nur jene Beobachtungen, die ich für sorgfältig genug angestellt hielt, und habe desshalb von den ailteren Beobachtungen eines Carolini nur jenes anfgenommen, was sich aus den betreffenden Darstellungen als hinreichend sicher und auch den jetzigen Anforderungen entsprechend ergibt.

Von den vier Rubriken entlält die erste die Namen der Polypen, an denen Beobachtungen angestellt wurden, die zweite umfasst die beobachtete zweite Generation, die entweder in Form von Medusen, oder als sogenannte Geschlechtsorgane sich darstellt. Die dritte Rubrik begreift die Entwicklung der geschlechtlichen Producte dieser zweiten Generation, und in der vierten endlich habe ich die Literaturnachweise beigefügt. Der Name jedes Beobachters ist immer eingeklammert in jene Rubrik gesetzt, in welche die Beobachtung fällt. 


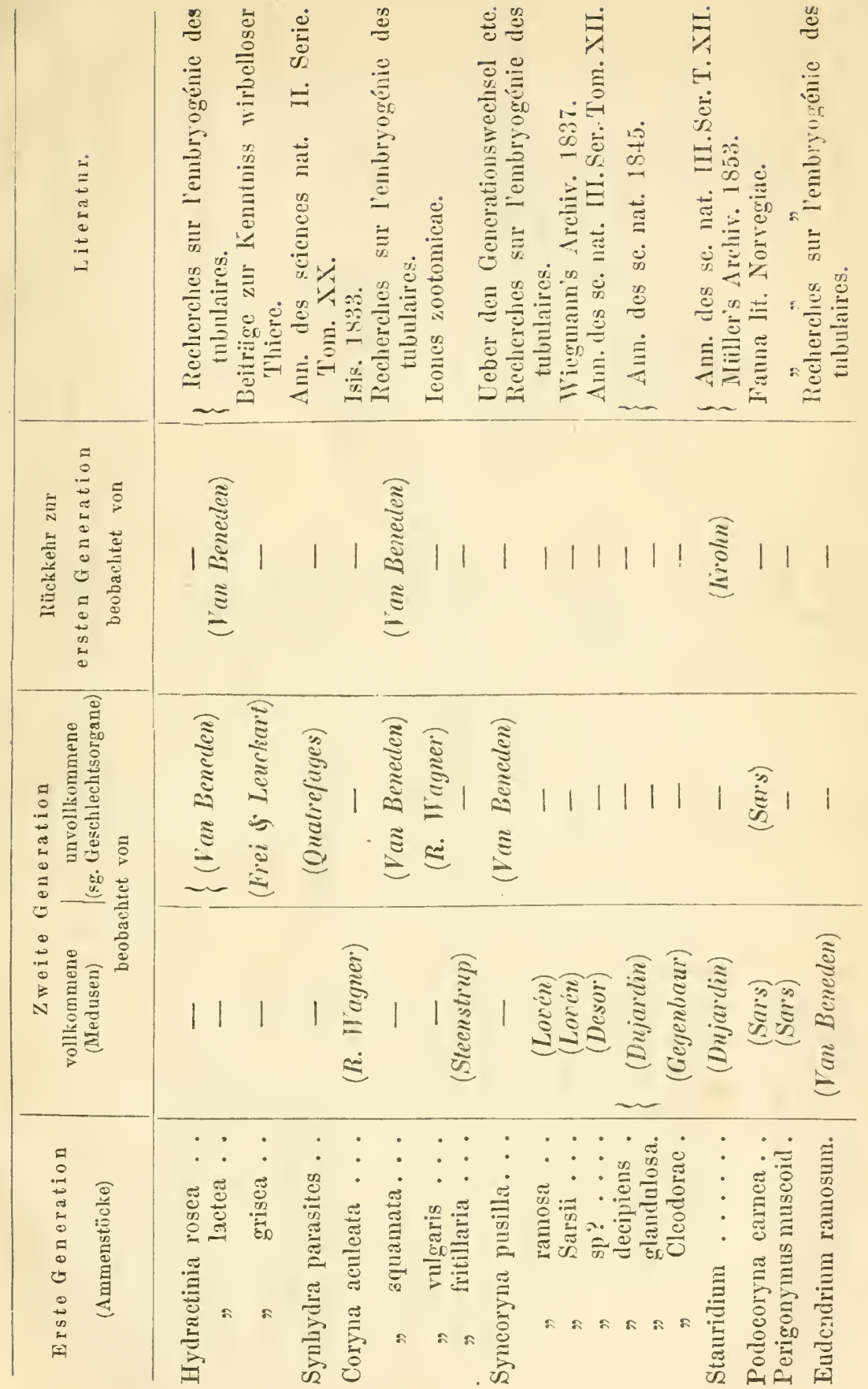


里

3

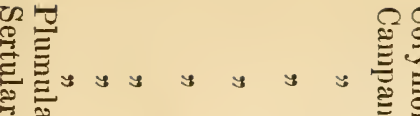
‥

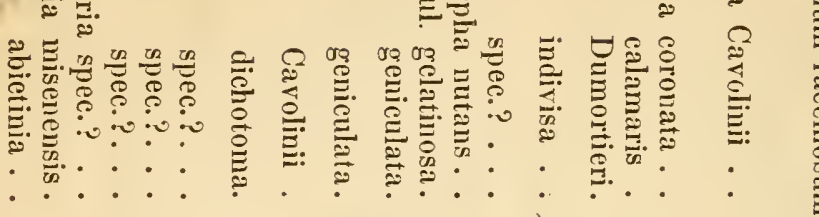
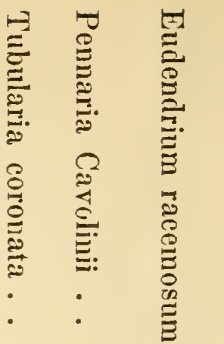

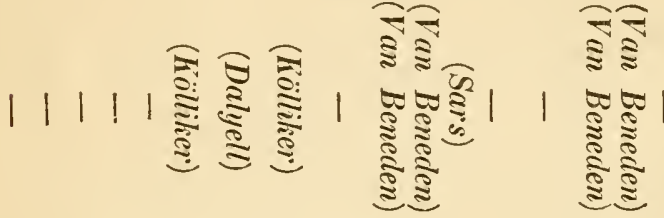

ลิ

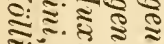

क्त.

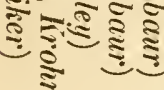

촐

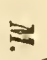

पूर्ड

离胥 111

(艹)

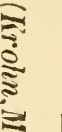

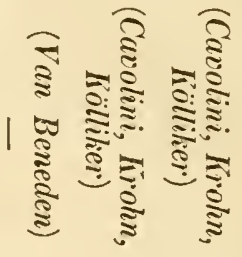

刍

ह $\mathrm{N}$

:

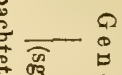

ธ

तै

可苛

क्

बึ

है

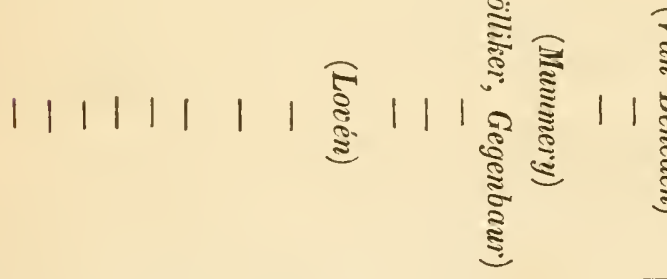

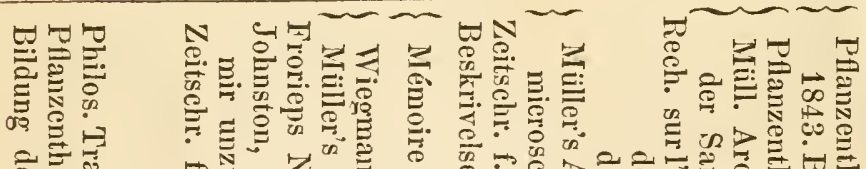

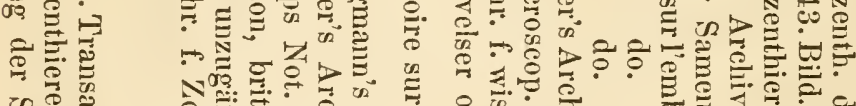

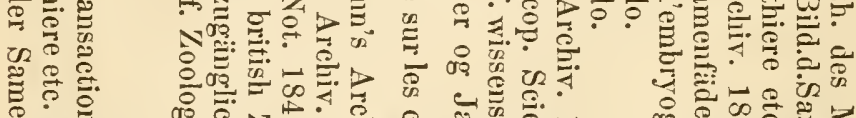

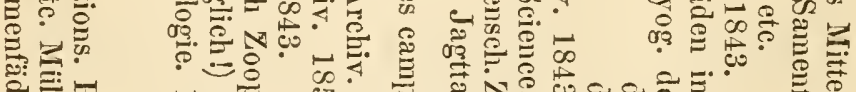

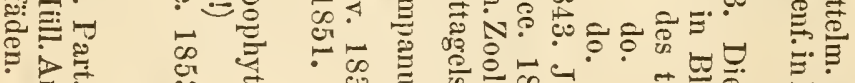
包

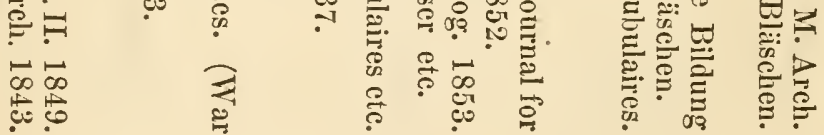




\section{Erkläiung der Ablihlungen.}

\section{Tafel I.}

Figur 1. Campannla ria n. sp. vergrïssert.

a. Ein Theil des kriechenden Stockes.

b. Aufgerichteter Stiel eines Polypen. b' Sprosse eines Polypen.

c. Gluckenförmige Erweiterung des hornigen Ueberzugs zur Aufrahme eines PolypenKiirpers.

d. Achse des Stnckes. die nach unten in den Starnm, nach wben in

e. den Leib eines Polypen übergeht.

f. Tentakeln, am ansgebreiteten Rand des Poḷpen sitzend, vollständig ausgestreckt.

g. Vorstreekbarer Mundtheil des Polypen.

h. Eine (polymerc) Bruthapsel, ïberall wn der Hornliille des Polypenstocks überzogen, die auf ihr $4-5$ Querringel bildet.

i. i. Zwei Medusengemmen, die obere mehr, die untere weniger entwickelt.

k. Magen der künftigen Meduse, dessen llülıle sich in den Achsenkanal des PolypenStoeks fortsetzt.

I. Anlage der Teutakeln der Medusen.

Figur 1. A. Ein isolirtes Becherchen derselben Campanularia.

a. Endtheil des Stieles. a' Iornige Wandung des Becherchens. a" Wellig ausgebuchteter Raud.

b. Achse des Polypenleibes.

c. Andeutung des Polypenleibes. af, Figur 1. e.

Figur 2. Freigewordener Meduseusprössling derselben Campanularia.
a. Glocke.
b. Randmembran.
c. Ocffnung in die Höhle der Glorke.
d. Ausgestrekkto Tentakeln.
e. Canäle der Glocke (der Randcanal ist nur angedeutet).
f. Randkörper.
g. Magen der Meduse. 
Figur 3. Syncoryna Cleodoraen. sp.

a. Kriechender Stamm.

b. b. Zwei Polypenkörper.

c. Tentakeln derselben.

d. $d^{\prime}, d^{\prime \prime}, d^{\prime \prime \prime}$ Medusensprossen auf verseliedenen Entwicklungsstadien. d"' ist im Begriffe sich von Ammenstocke loszutremen.

Figur 4. Freigewordene Mednse von Syncoryna Cleodorae.
a. Glocke.
b. Iiandmembran.
c. Oeffunng in die Glocke.

d. d. Die beiden Tentakeln ausgestreckt. d' Aslagen zweier anderer Tentakeln.

e. Gefässcanäle des Gilocke.

f. Magen der Meduse.

g. Reihen von Nesselzellen auf der Aussenfläche der Glocke.

Figur 5. Campan ularia n. sp. (?) vergrössert.
a. Kriechender Theil des Stockes. $c^{\prime}$ Ein sich frei erhebender Stengel.
b. Polypentragende Zweige desselben.
c. Geschlechtskapseln (polymere).

Figur 5. A. Ein Polypenbecherchen stärker vergrössert. Bezeichnung wie in Figur 1. A. Figur 6. Geschlechtskapsel derselben Campanularia.
a. Aeussere hornige Hülle.
b. Eintretende Achse der Geschlechtskapsel, an welcher
c. die einzelnen bläschentürmigen Geschlechtsorgane sitzen.
d. Furtsätze des Achsencanales in die Geschlechtsblïschen.

Figır 7. A. B, C. Entwicklung der einzelnen Gesch'echtsbläschen.
a. Ausstïlpung des Achsencanals in
b. das samenbereitende Parenchym.

Figur 8. Campanularia n. sp. (?) vergrössert.
a. Kriechender Stamm der Colonie.
b. Polspentragender Stengel.
c. Polypenbecherchen.
d. Achse des Polypenstengels, die sich in
e. den Polypenleib fortsetzt.
f. Teutakeln, halb ansgestreckt.
g. Monomere Geschlechtsorgane.
h. Gefässcanäle, die in der Corticalschichte des Samcubereitenden Parenchyms ver- laufen.

Figur S. A. Ein isolirtes Becherchen derselben Campanularia.

a. Stengel. a' Hornige Wand des Becherchens. a" Tiefgezähnelter Rand desselben.

Figur 9. Gefässramificationen aus einer andern Geschlechtskapsel desselben Polypen (isolirt dargestellt).

Figur 10. Männliche Gescllechtsorgane einer T $\mathrm{T}$ u b $\mathrm{l}$ a $\mathrm{r}$ i a sp. ? rergrössert.

a. Stiel an dem die einzeluen hapseln sitzen.

b. Achsencanal dẹsselben, der sich in dic Kapseln fortsetzt und 

c. dort bauchig erweitert.
d. Samenbereitendes Parenchym.

Fignr 10. * Samenfäden derselbeu Tubularia.

Figur 11. Weibliche Organe dieser T'ubularia.

a. b. c. wie in Figur 10.

d. Kapselhaut.

e. tentakelähnliche Wärzchen am Vordertheil der Kapseln.

f. Verschiedene Entwiklungszustäude der Embryonen.

Figur 12. A. B. C. D. Entwicklungszustände der Tubularia-Embryonen innerhalb der Geschlechts-Kapsel.

Figur 13. Ein zum Austritte reifer Embryo.

a. Mundtheil desselben.

b. Hinterleib.

c. Tentakeln.

Figur 11. Eine seit Kurzem festsitzende junge Tubularia.

a. Körper derselben.

b Fussartige Ausbreitung.

c. Mundöffung.

d. Teutakeln.

\section{Tafel II.}

Figur 1. Lizzia Koellikeri, natürliche Grösse. Mit ausgestreckten Randfädeu.

Figur 2 - 9. Entwicklung der Eier dieser Lizzia.

Figur 2. Ein aus dem Ovarium getretenes Ei, von Spermatozö̈n umgebeu.

Figur 3. u. 4. Zwei verschiedene Furchungsstadien. Im Inneru der Furchungskugeln ist ein deutlicher Kern sichtbar.

Figur 5. Wimpernde Larve.

Figur 6. Späteres Stadium derselben.

Figur 7. Junger Polyp, bei

a. festsitzend.

b. Hornige Hülle desselben.

c. Sprosse, die in einen Polypenleib auswächst.

Figur 8. u. 9. A. B. Drei junge Polypeu auf verschiedenen Entwicklungsstadien.

a. Festsitzender Theil der in Figur 9 in Stolonen sich fortsetzt.

b. Polypenleib.

c. Mundöffuung desselben.

d. Vier Tentakeln; in Fig. 9. B. eben hervorsprossend, bei Fig. 9. A. röllig entwickelt, aber etwas contrahirt, und in Fig. 8. ausgestreckt.

e. Nahrungscanal des Polypen.

f. Horngehäuse.

Figur 10-16. Entwicklung des Eies der Oceania armata.

Figur 10, Ei vor der Furchung.

Figur 11. Erstes Furchnngestadium. Theilung der Kerne vor der Theilung der Furchungskugel.

Figur 12. Nächstes Stadium der Dottertheilung. 
Figur 13. u. 14. Zwei spătere Stadien.

Figur 15. Iufusorienfümige Larve, mit langen Cilien bedeckt.

Figur 16. Ein Po'rpenstock, der sich aus der festsitzenden Larve bildete.

Figur 1i-23. Eutwicklong der wimpernden Larve ron Trachynema ciliatum Die Bezeichuung ist bei alleu Figurcn dieselbe.

a. Kürper der Larve und Glocke der künftigen Meduse.

b. Magen.

c. Tentakeln. c' Tentakelsprossen.

d. Randkürper.

e. Centralhöhle des Kïrperø und Ausgangsstelle der Gefässcanäle der Glocke. ed Gefässcanäle der Glocke, die bei $e^{\prime \prime}$ sich in einen Ringcanal einigen.

Figur 23. stellt das Veruältniss der 8 Gefässcanäle zu ilırer Ceutralhöhle und dem Ringcanale dar. Die Zeichnung ist nach einer Ansicht der Meduse von oben.

Fignr 24-31. Cunina prolifera u. Ep. und ihre Brat.

Figur 24. Kinospen aus der Magenhöhle,

a. ron der Seite,

b. ron obengesehen.

Figur 2.j. Weiter vorgerückte Knospen, b. Anlagen der Tentakeln.

Fignur 26. Späteres Stadium. Die Meduse hat sich obgelöst. In der Mitte der Scheibe wird der Mund sichtbar. $\left(a_{,}\right)$

Figur 2i. Die Tentakeln b. sind roilständiger angelegt.

Figur 25. Zwischen je 2 Teutakeln erscheint eiue Reshe von Randkürpern.

Figur 29. Ansicht derselben jungen Cuuina von der Seite.

Figur 30. Cunina prolifera, seitliche Ansicht.

a. Magensäcke. b. Tentakeln

Figur 31. Verschiedene Randkörper dieser Meduse.

Figur 32-35. Entwicklung des Eies der Cassiopeia borbouica.

Figar 32. Wimpernde I arre.

Figur 33. Festsitzende Larve, die rorne 4 Tentakel (a) herrortreibt.

b. Terdauende Hihle der Larve.

c, Leibeshöhle.

Figur 34. Eine weiter entwickelte Larve.
a. Mundstiick.
b. Teutakeln.
c. Verdauende Höhle.
d. Leibeshöhle.
๑. Gefässcanäle.

Figur 35. Späteres Stadium. Larre mit 16 langen Tentakeln. 





5.

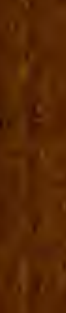

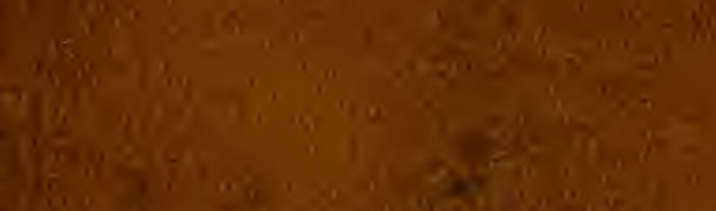

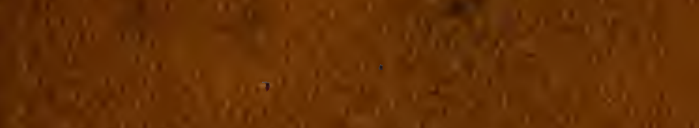

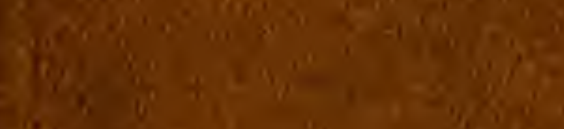

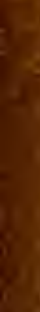

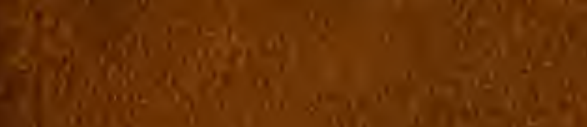

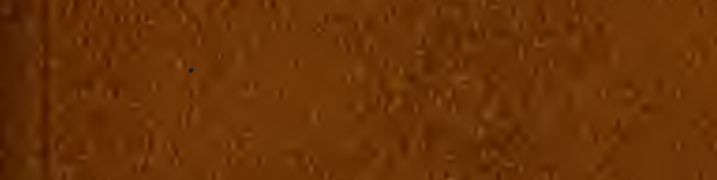

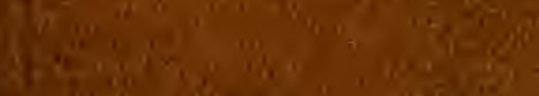

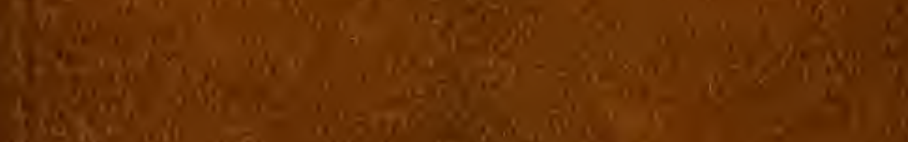

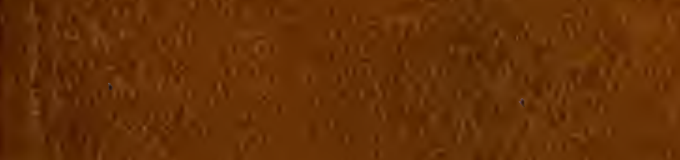

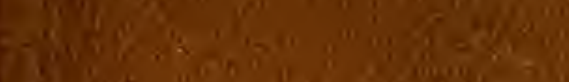

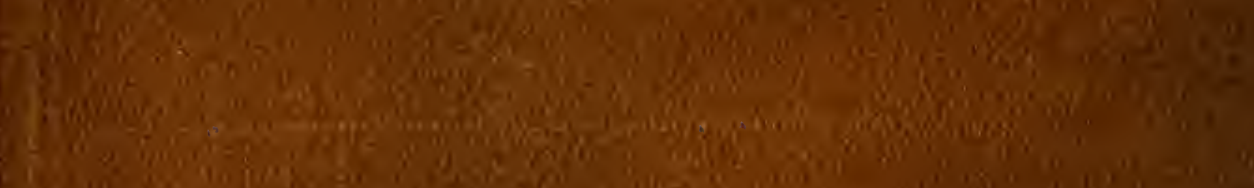

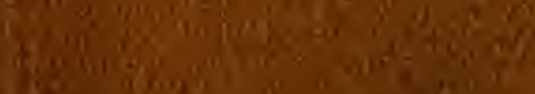

a

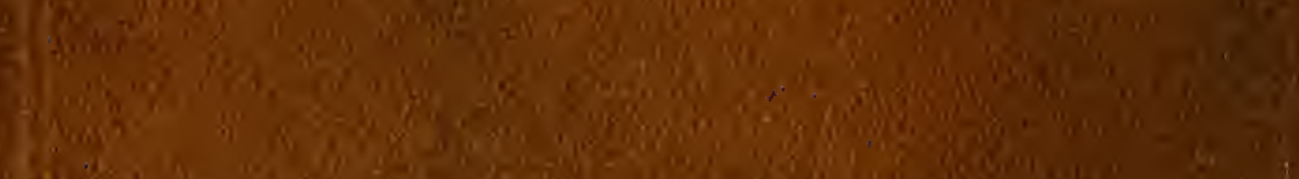

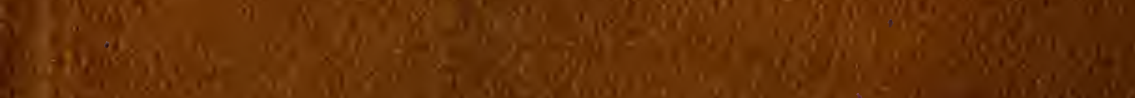

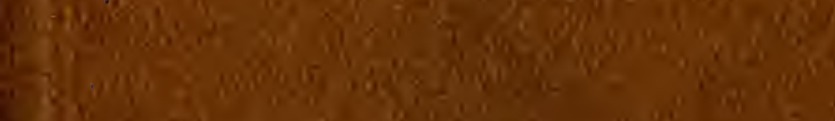

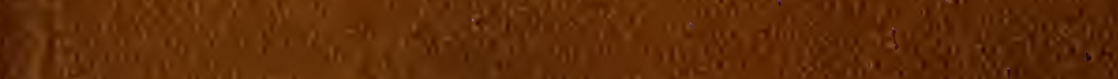

